\title{
Electrochemical HI-Mediated Intermolecular C-N Bond Formation to Synthesize Imidazoles from Aryl Ketones and Benzylamines
}

Zan Yang, Jiaqi Zhang, Liping Hu, An Li, Lijun Li, Kun Liu, Tao Yang* and Congshan Zhou*

College of Chemistry and Chemical Engineering, Hunan Institute of Science and Technology, Yueyang 414006, P. R. China

*E-mail: zhoucongsh@126.com; yangtaozcs@126.com

\section{Contents}

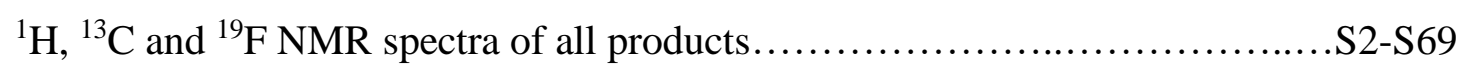


${ }^{1} \mathrm{H} /{ }^{13} \mathrm{C}$ NMR spectra of typical substrates and all products
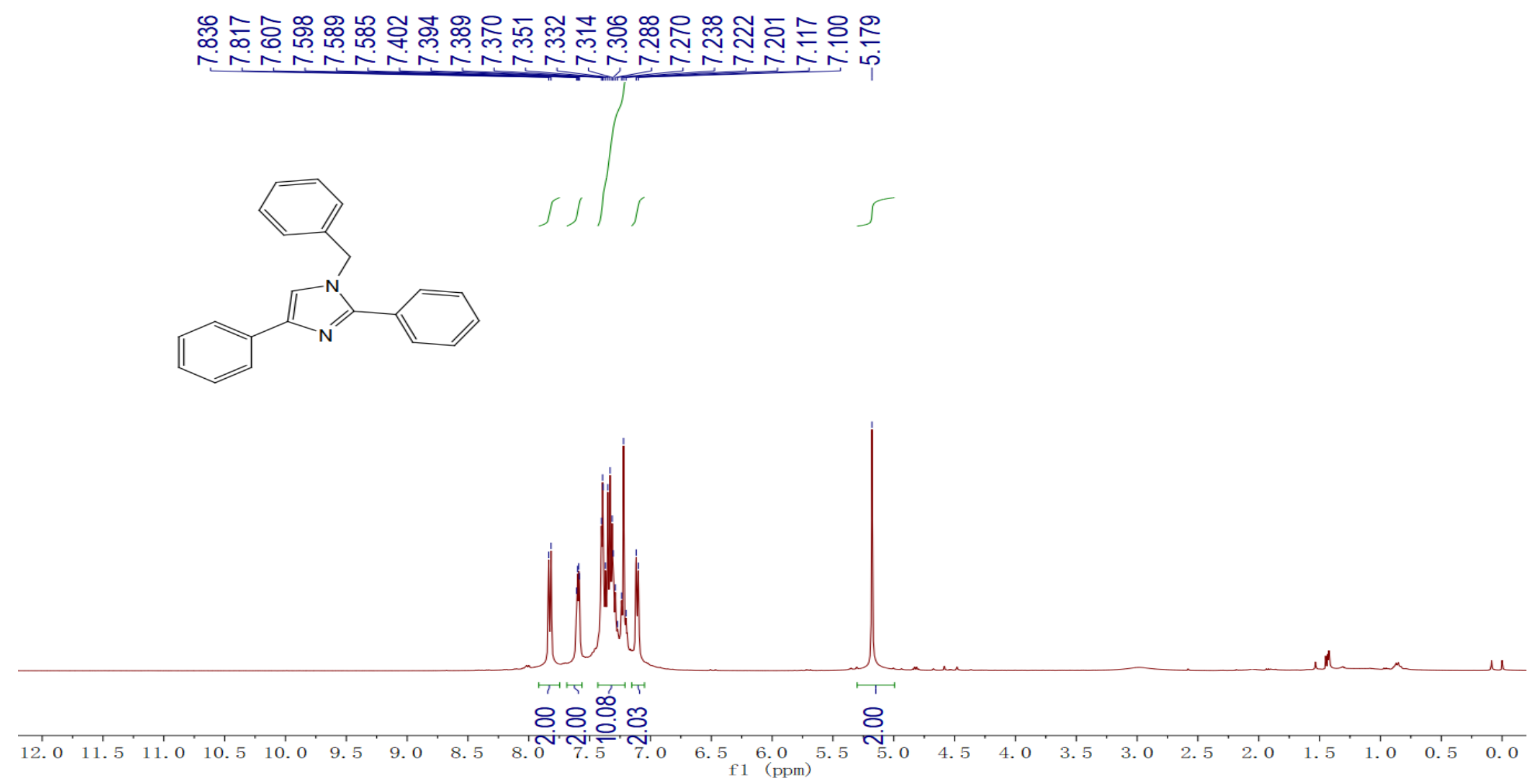

Figure $\mathrm{S} 1{ }^{1} \mathrm{H}$ NMR $\left(400 \mathrm{MHz}, \mathrm{CDCl}_{3}\right)$ spectra of 3aa 


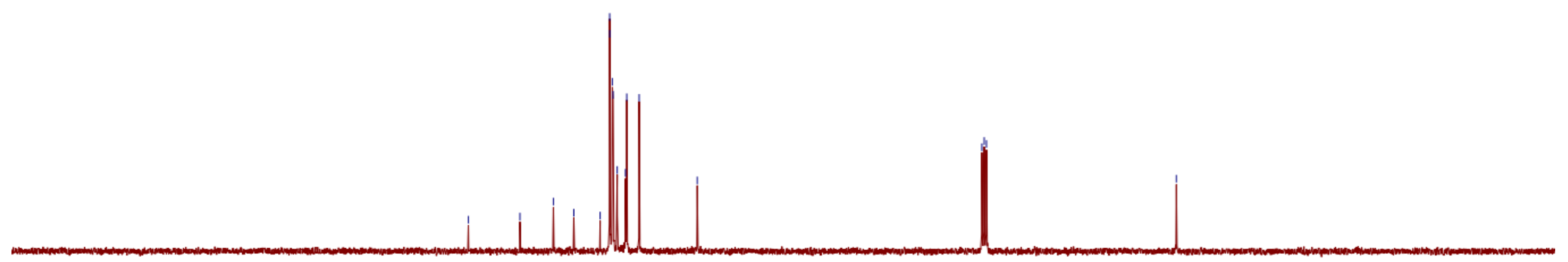

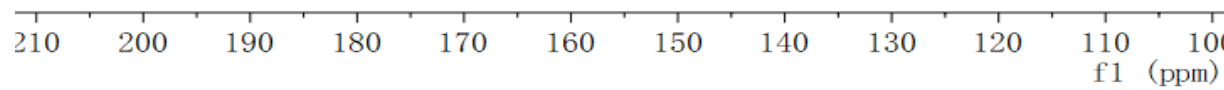

Figure S2 ${ }^{13} \mathrm{C}$ NMR (101 MHz, $\mathrm{CDCl}_{3}$ ) spectra of 3aa 

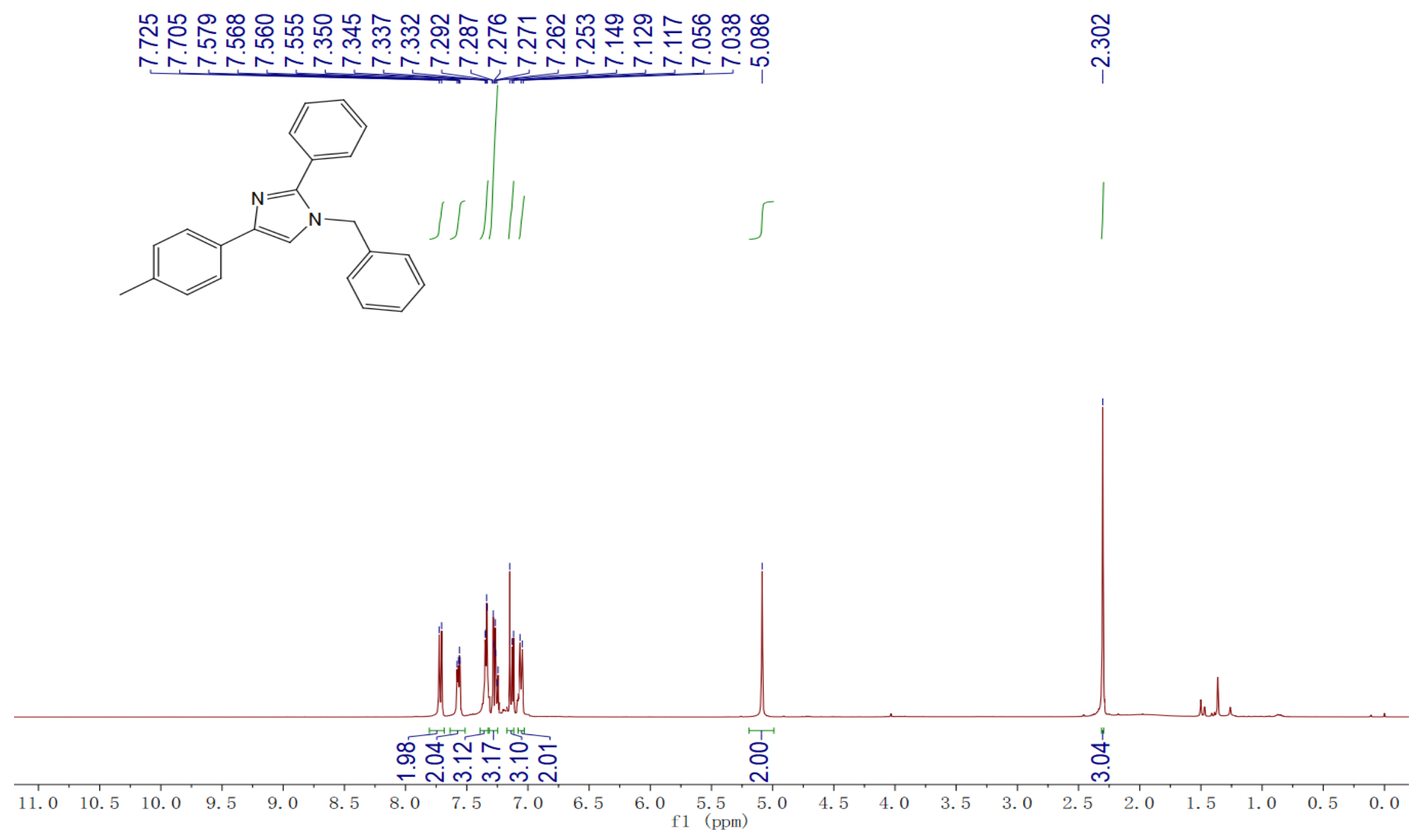

Figure S3 ${ }^{1} \mathrm{H}$ NMR $\left(400 \mathrm{MHz}, \mathrm{CDCl}_{3}\right)$ spectra of $\mathbf{3 b a}$ 


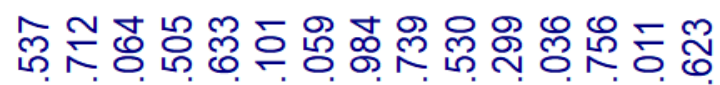

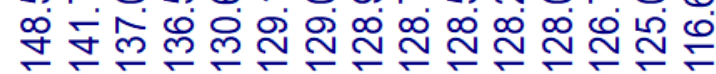

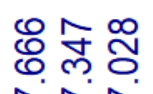

소솟

㞼

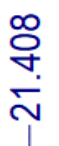

흔앵형유앰융

ণ্ড

$\div \div \div$
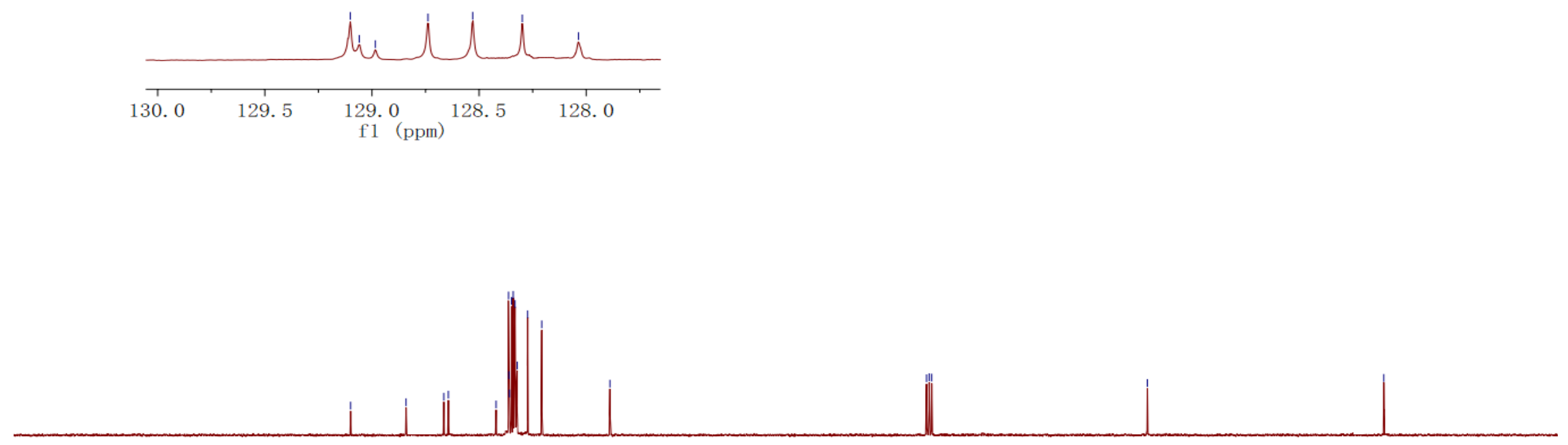

30

Figure S4 ${ }^{13} \mathrm{C}$ NMR $\left(101 \mathrm{MHz}, \mathrm{CDCl}_{3}\right)$ spectra of $\mathbf{3 b a}$ 

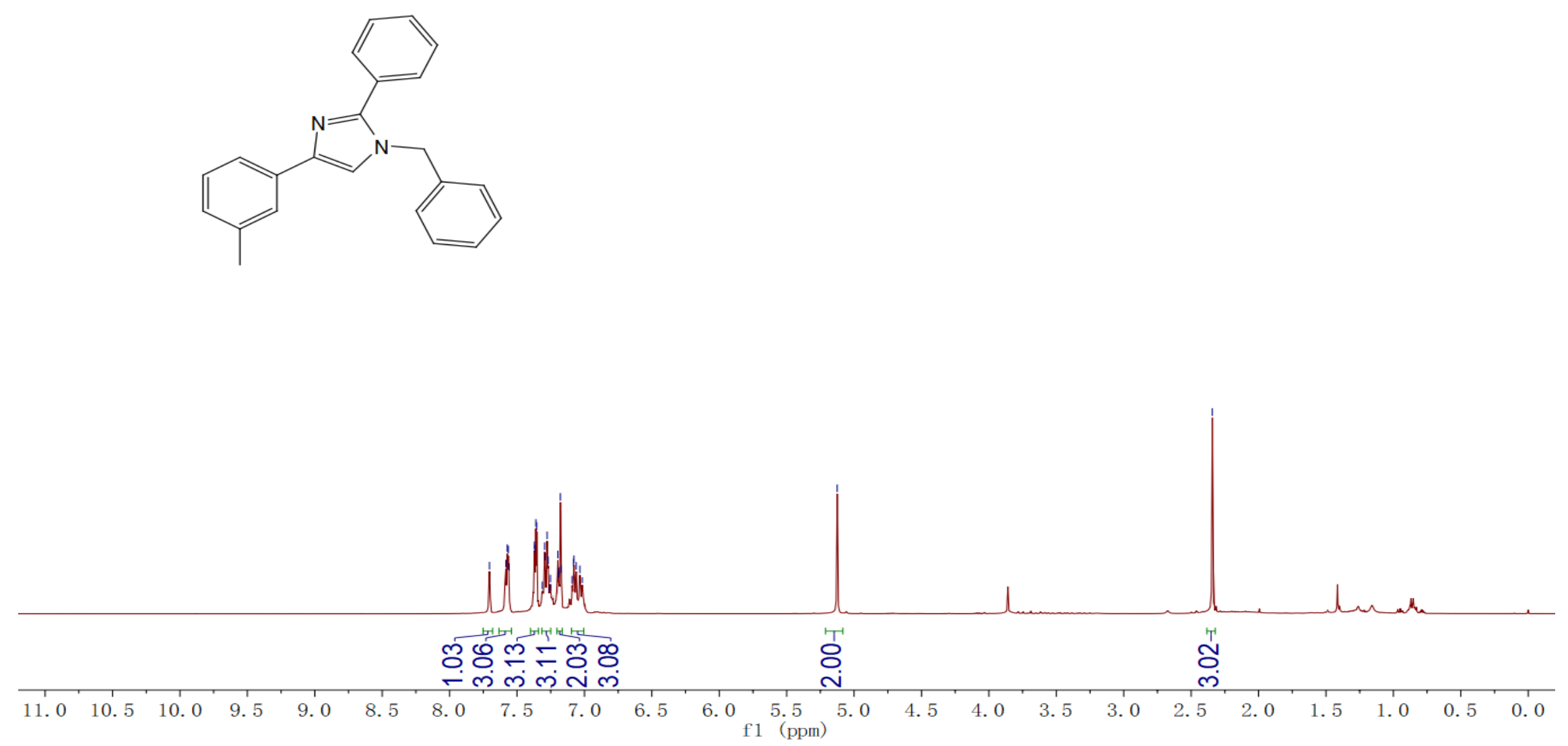

Figure $\mathrm{S} 5{ }^{1} \mathrm{H} \mathrm{NMR}\left(400 \mathrm{MHz}, \mathrm{CDCl}_{3}\right)$ spectra of 3ca 


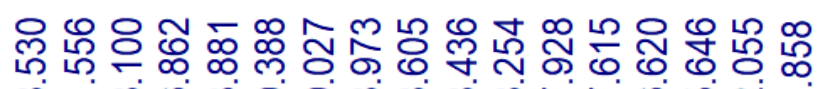

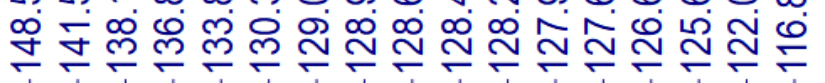

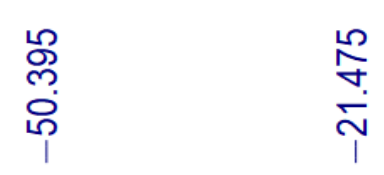

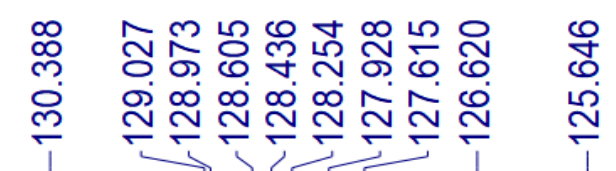
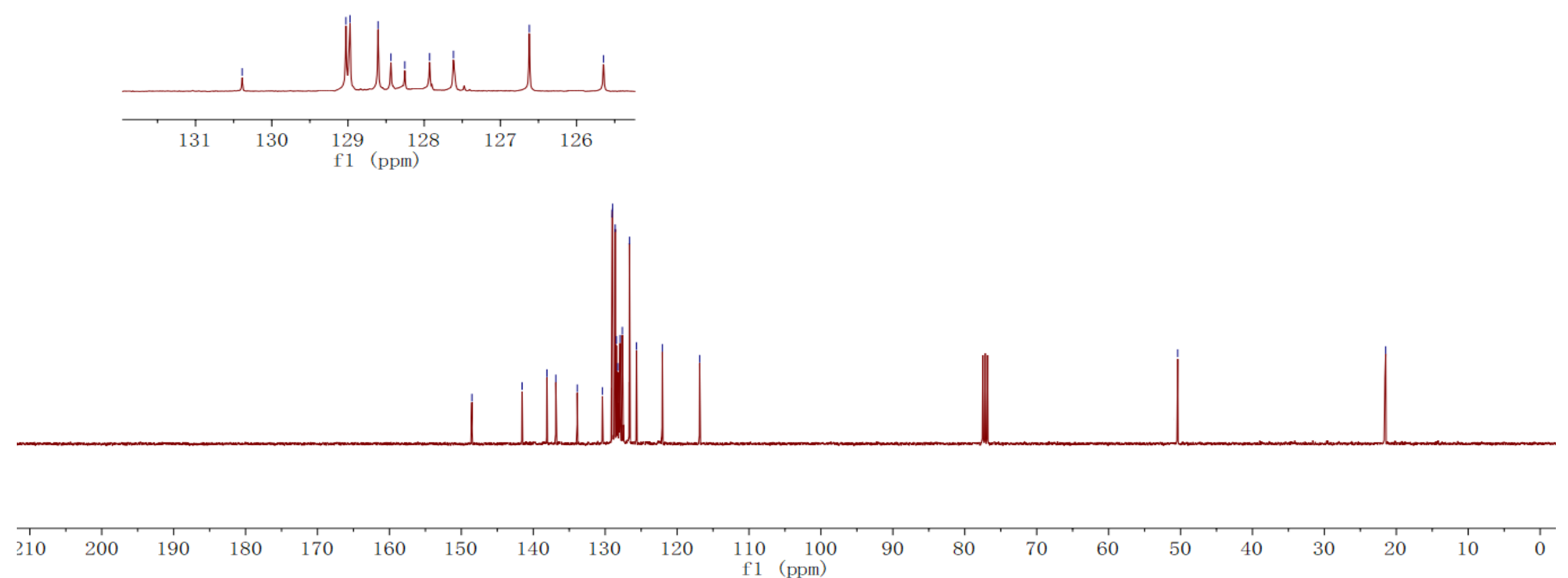

Figure S6 ${ }^{13} \mathrm{C}$ NMR $\left(101 \mathrm{MHz}, \mathrm{CDCl}_{3}\right)$ spectra of 3ca 


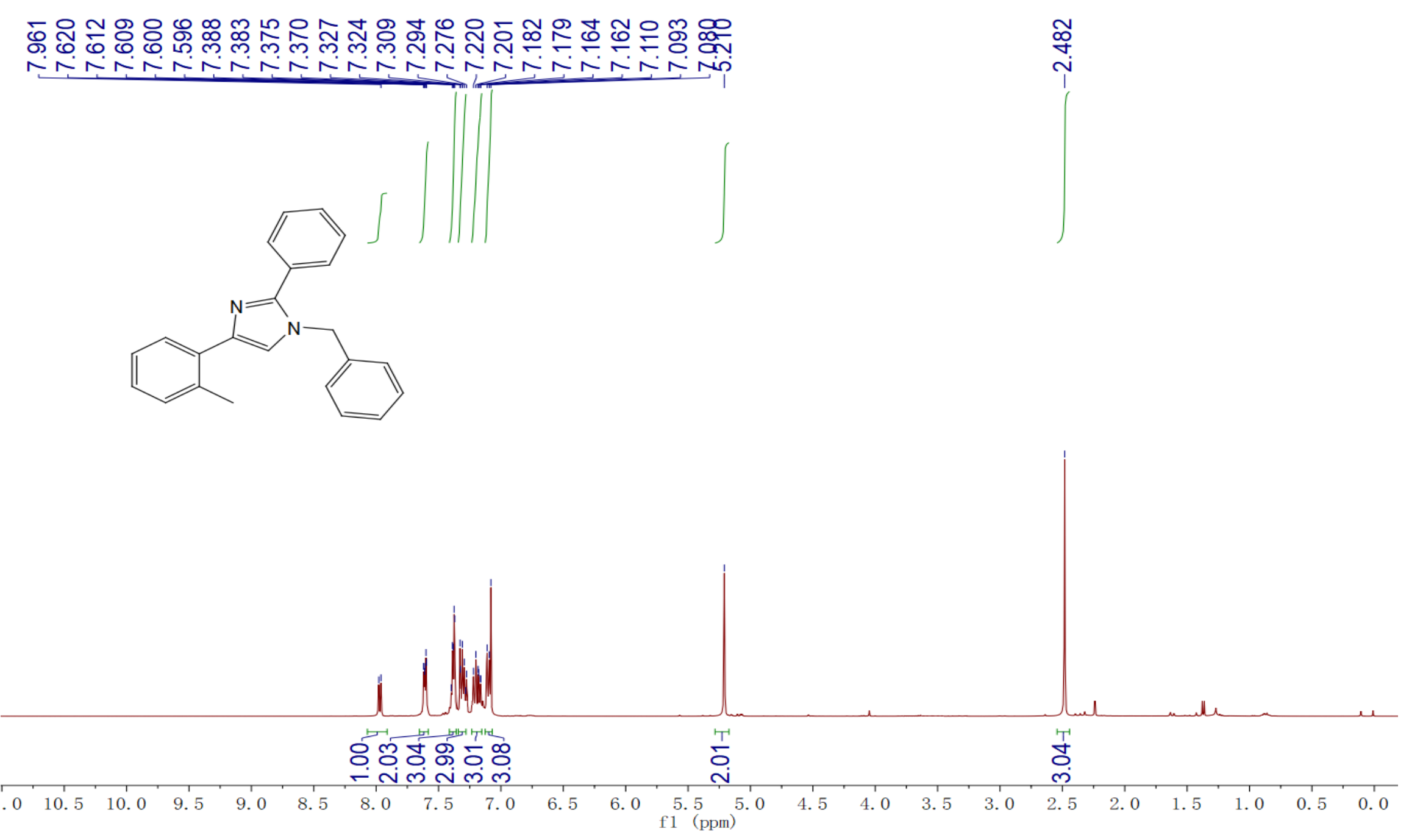

Figure S7 ${ }^{1} \mathrm{H}$ NMR (400 MHz, $\left.\mathrm{CDCl}_{3}\right)$ spectra of 3da 
ชิ

क्ञ
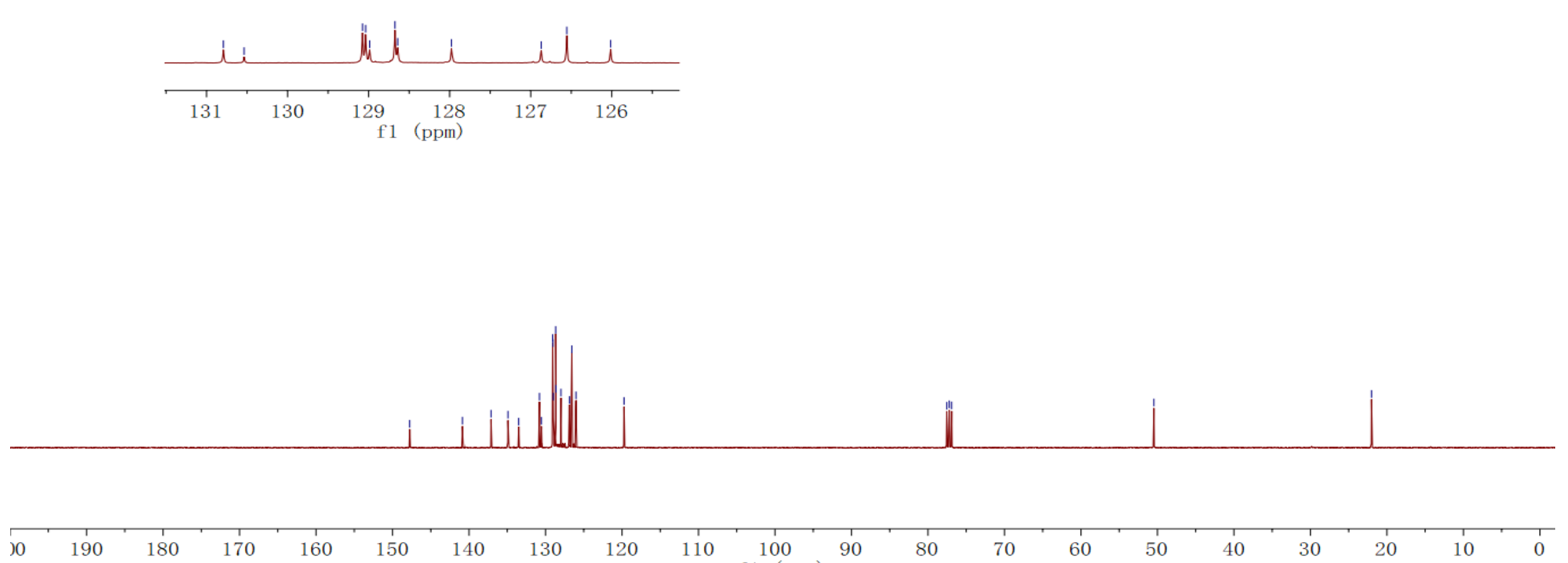

f1 100 (ppm) 90

80

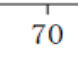

60

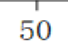

40

30

20

$10 \quad 0$

Figure $\mathrm{S} 8{ }^{13} \mathrm{C}$ NMR $\left(101 \mathrm{MHz}, \mathrm{CDCl}_{3}\right)$ spectra of 3da 
舟乐 $\overline{0}$

Ni
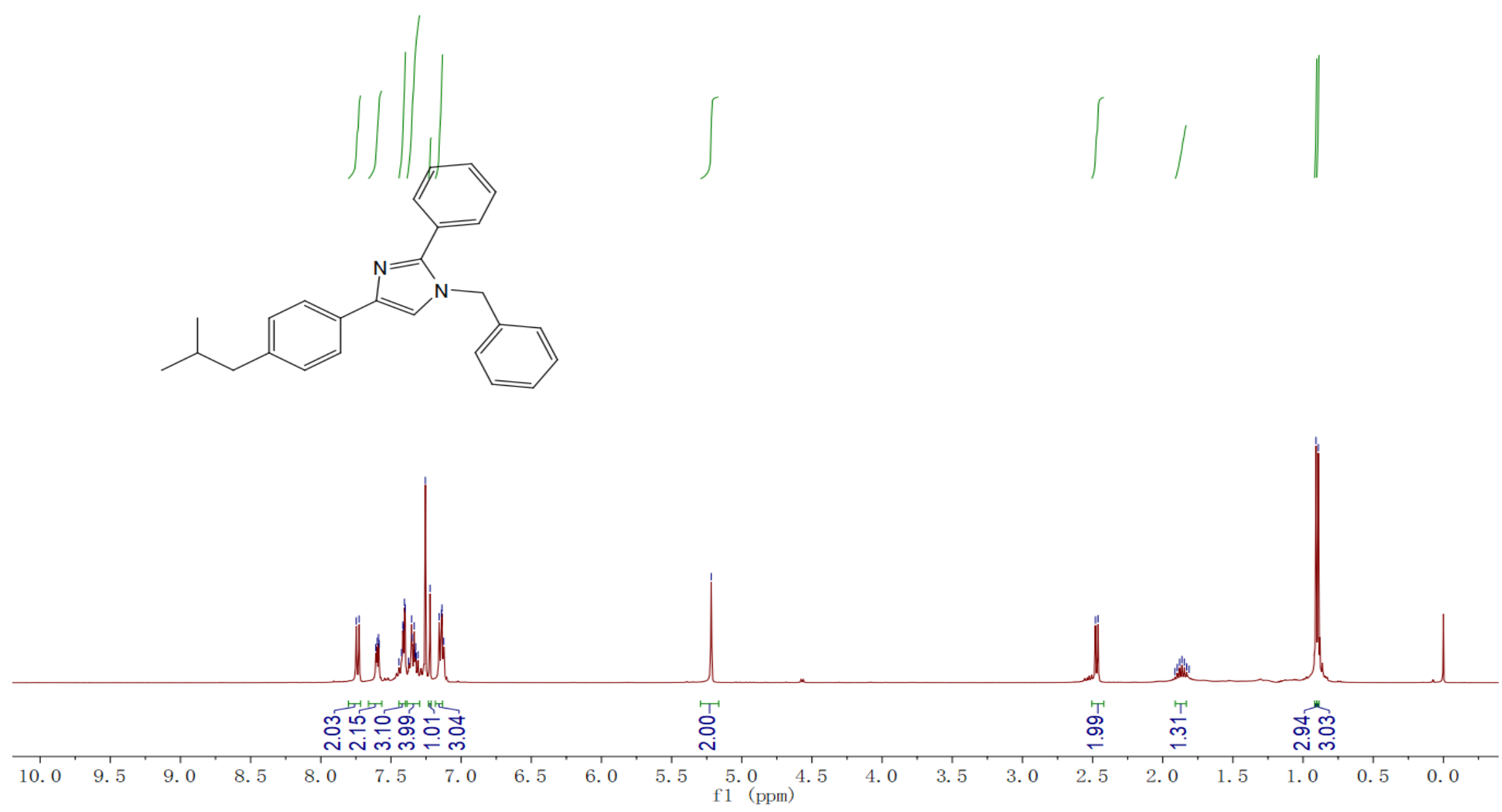

Figure $\mathrm{S} 9{ }^{1} \mathrm{H}$ NMR $\left(400 \mathrm{MHz}, \mathrm{CDCl}_{3}\right)$ spectra of 3ea 


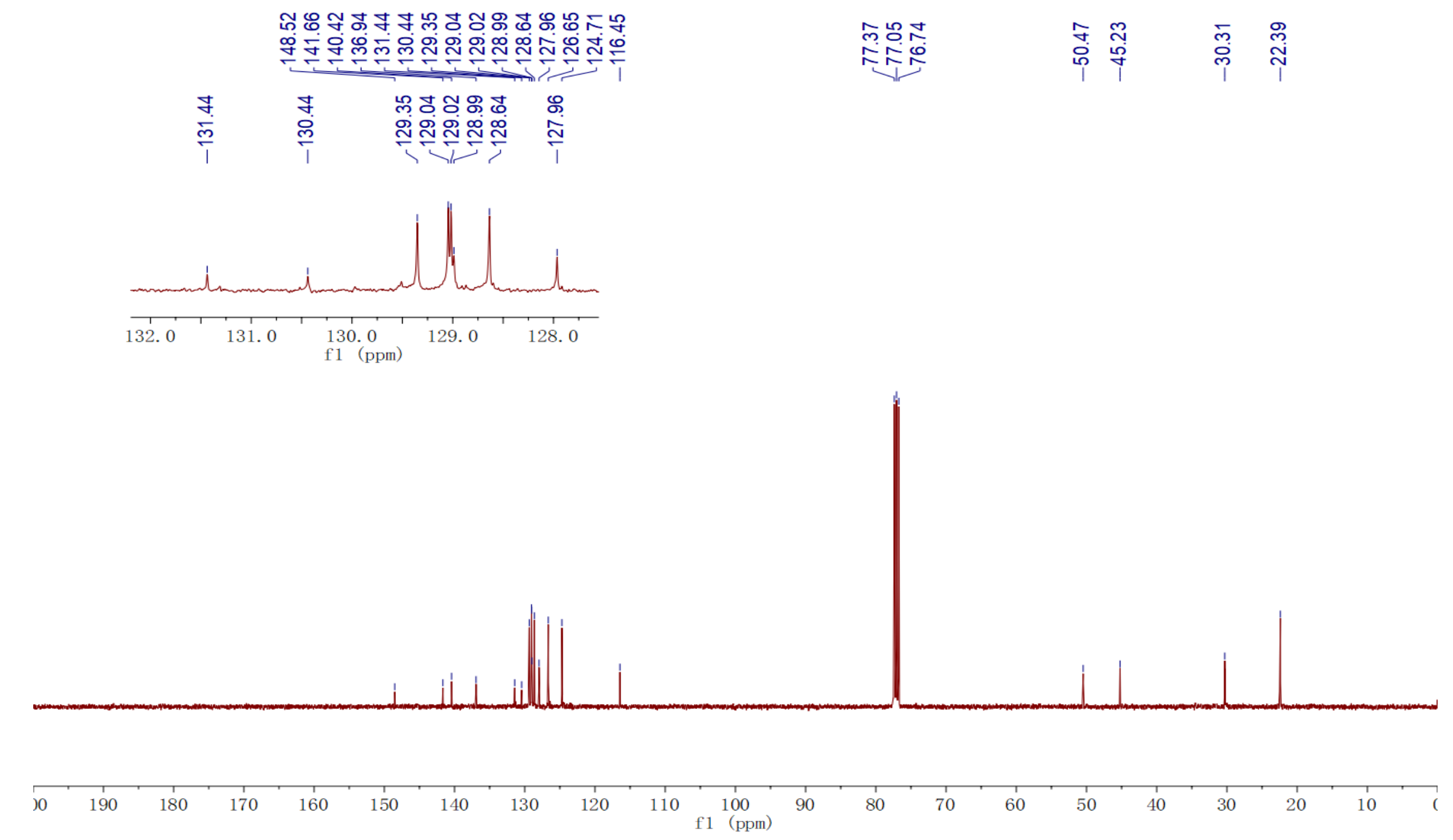

Figure $\mathrm{S} 10{ }^{13} \mathrm{C}$ NMR $\left(101 \mathrm{MHz}, \mathrm{CDCl}_{3}\right)$ spectra of $\mathbf{3 e a}$ 


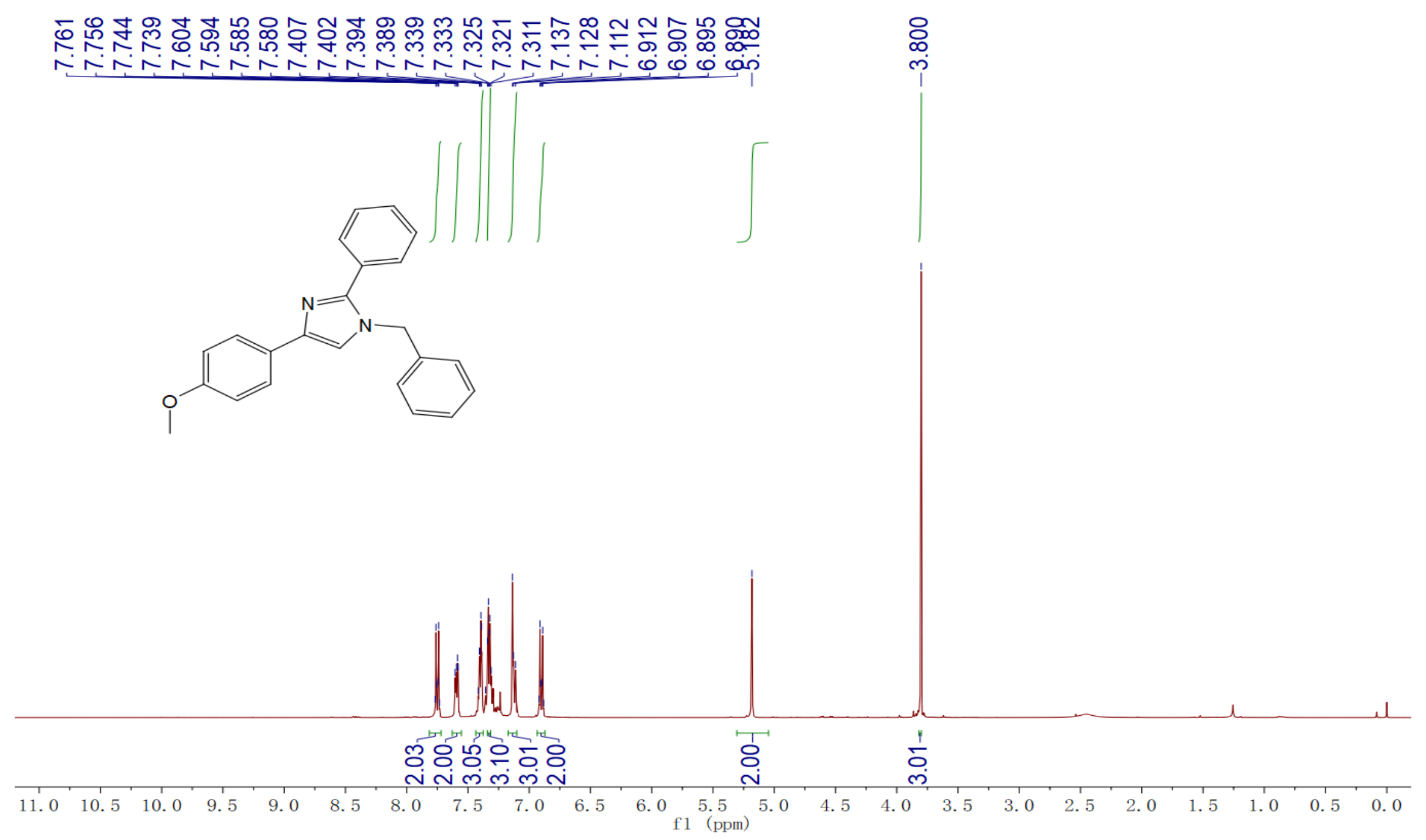

Figure $\mathrm{S} 11{ }^{1} \mathrm{H}$ NMR $\left(400 \mathrm{MHz}, \mathrm{CDCl}_{3}\right)$ spectra of $\mathbf{3 f a}$ 


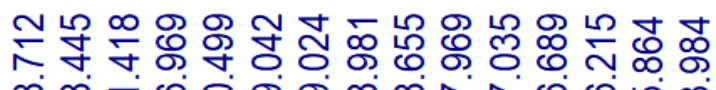
吕守守

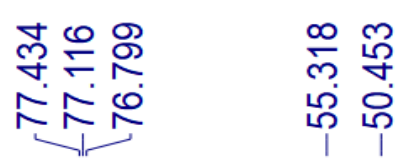
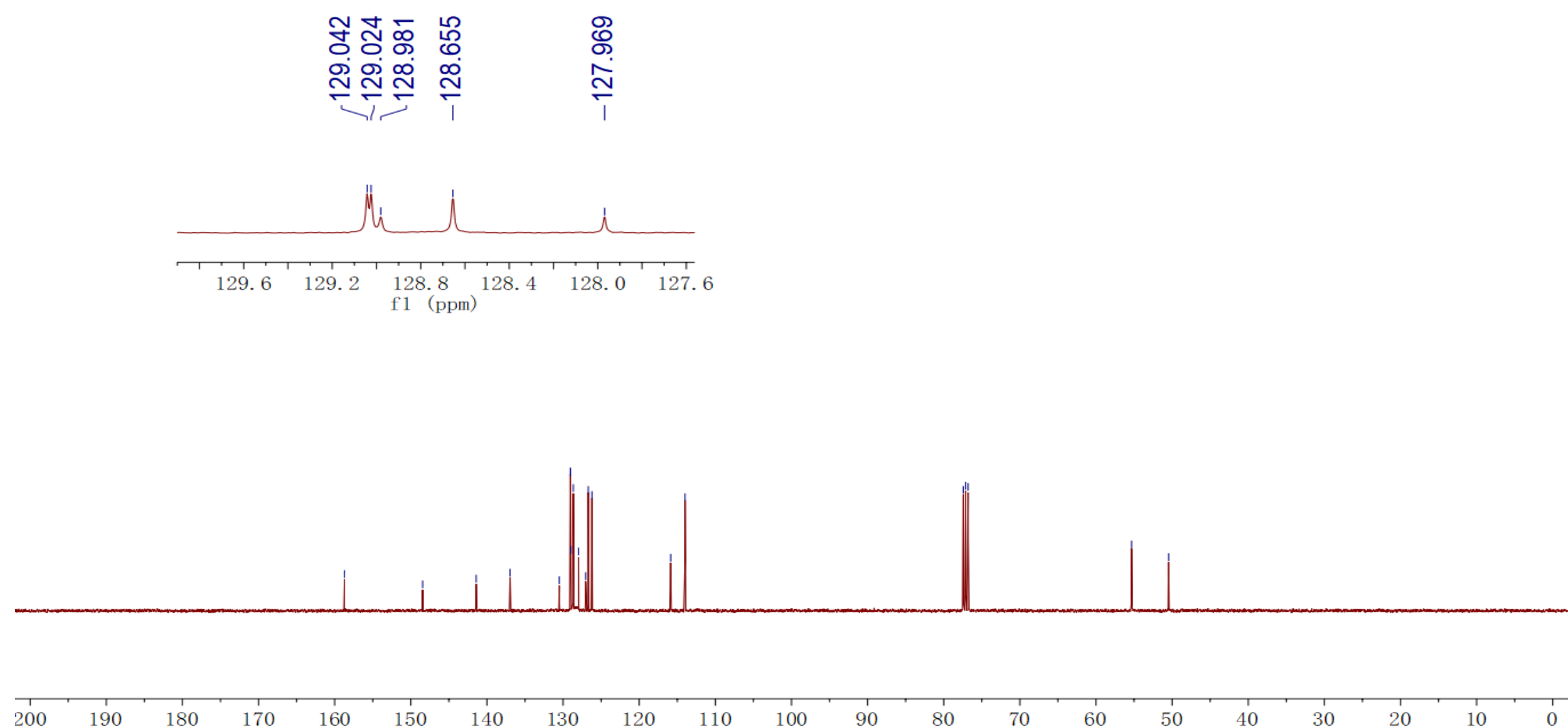

f1 100

$90 \quad 80$

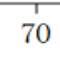

60

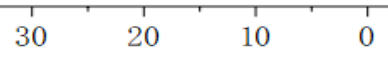

Figure $\mathrm{S} 12{ }^{13} \mathrm{C}$ NMR (101 $\left.\mathrm{MHz}, \mathrm{CDCl}_{3}\right)$ spectra of $\mathbf{3 f a}$ 


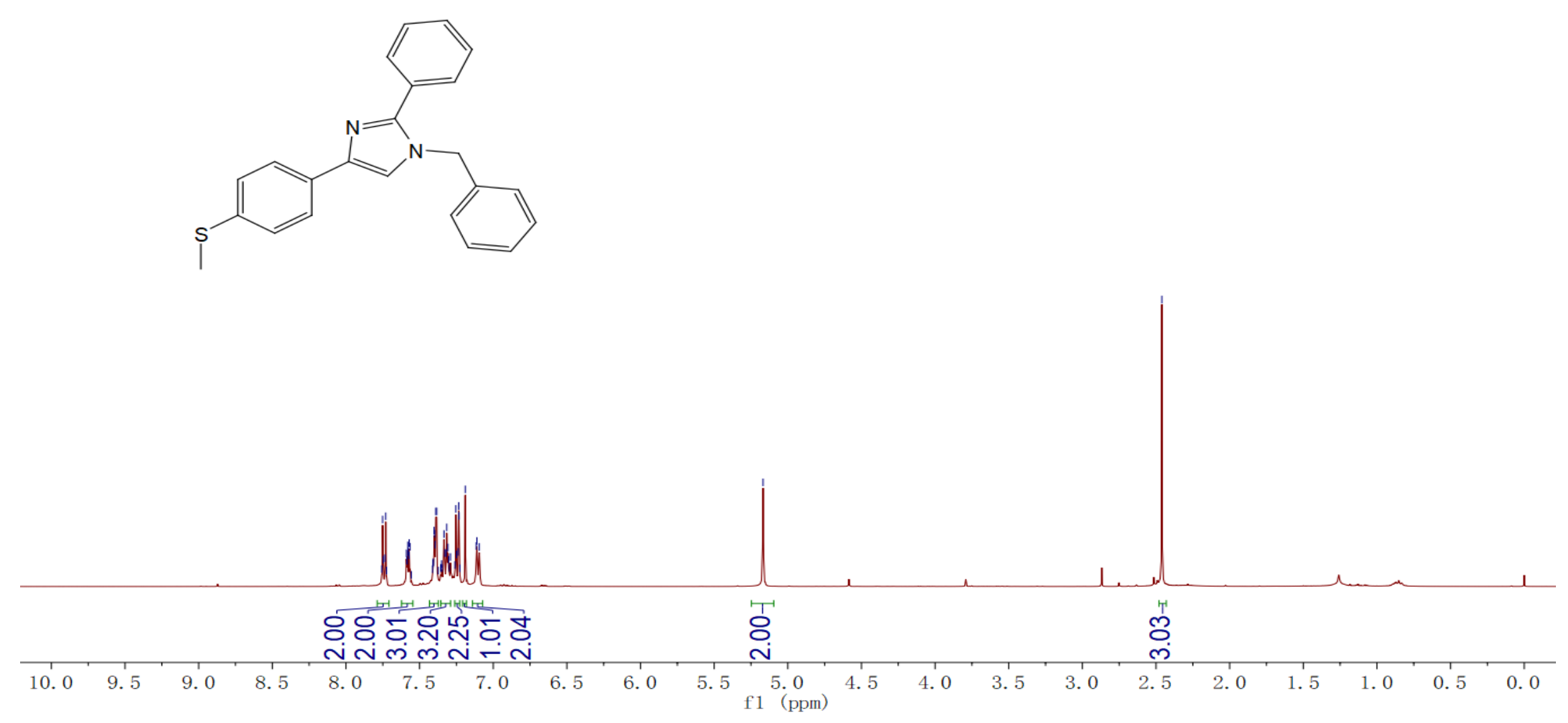

Figure $\mathrm{S} 13{ }^{1} \mathrm{H} \mathrm{NMR}\left(400 \mathrm{MHz}, \mathrm{CDCl}_{3}\right)$ spectra of 3ga 


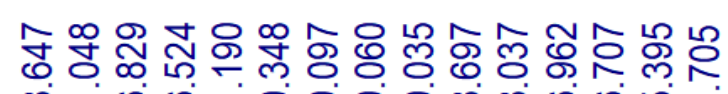

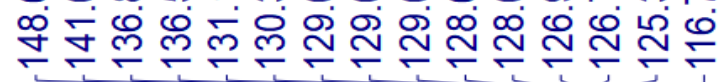

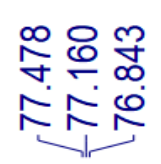

究

ip

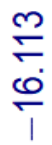

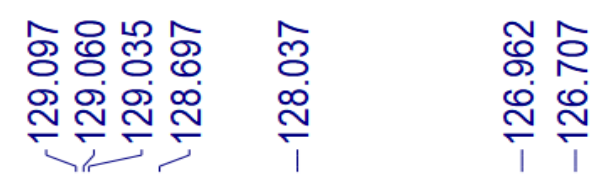

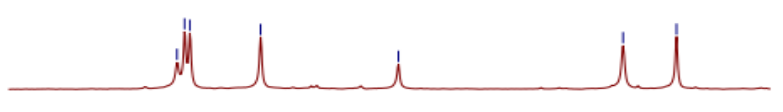

$\begin{array}{lllllll}129.5 & 129.0 & 128.5 & 128.0 & 127.5 & 127.0 & 126.5\end{array}$ $\mathrm{f} 1$ (ppm)

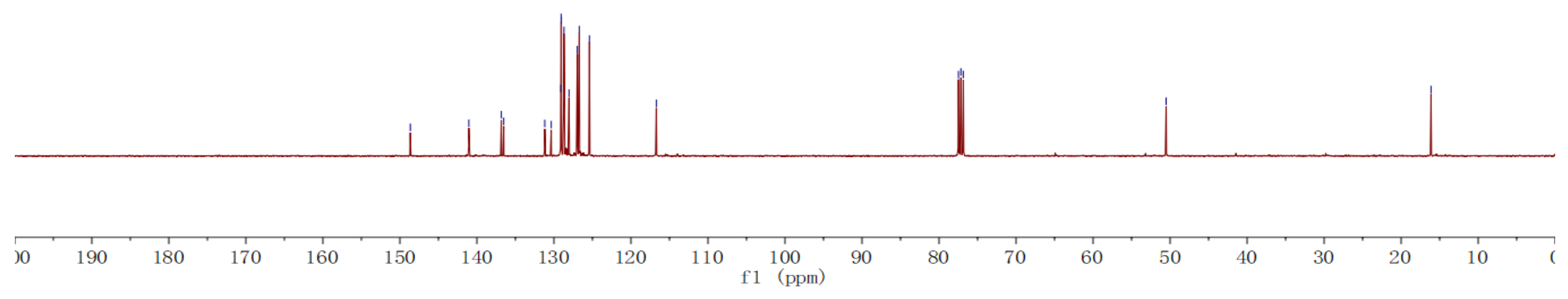

Figure S14 ${ }^{13} \mathrm{C}$ NMR $\left(101 \mathrm{MHz}, \mathrm{CDCl}_{3}\right)$ spectra of 3ga 


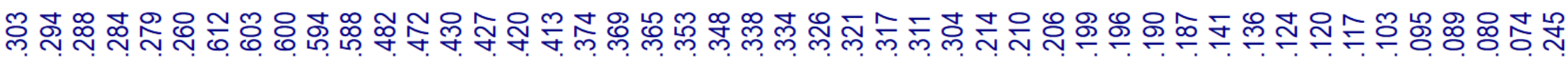

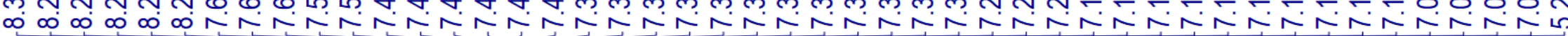

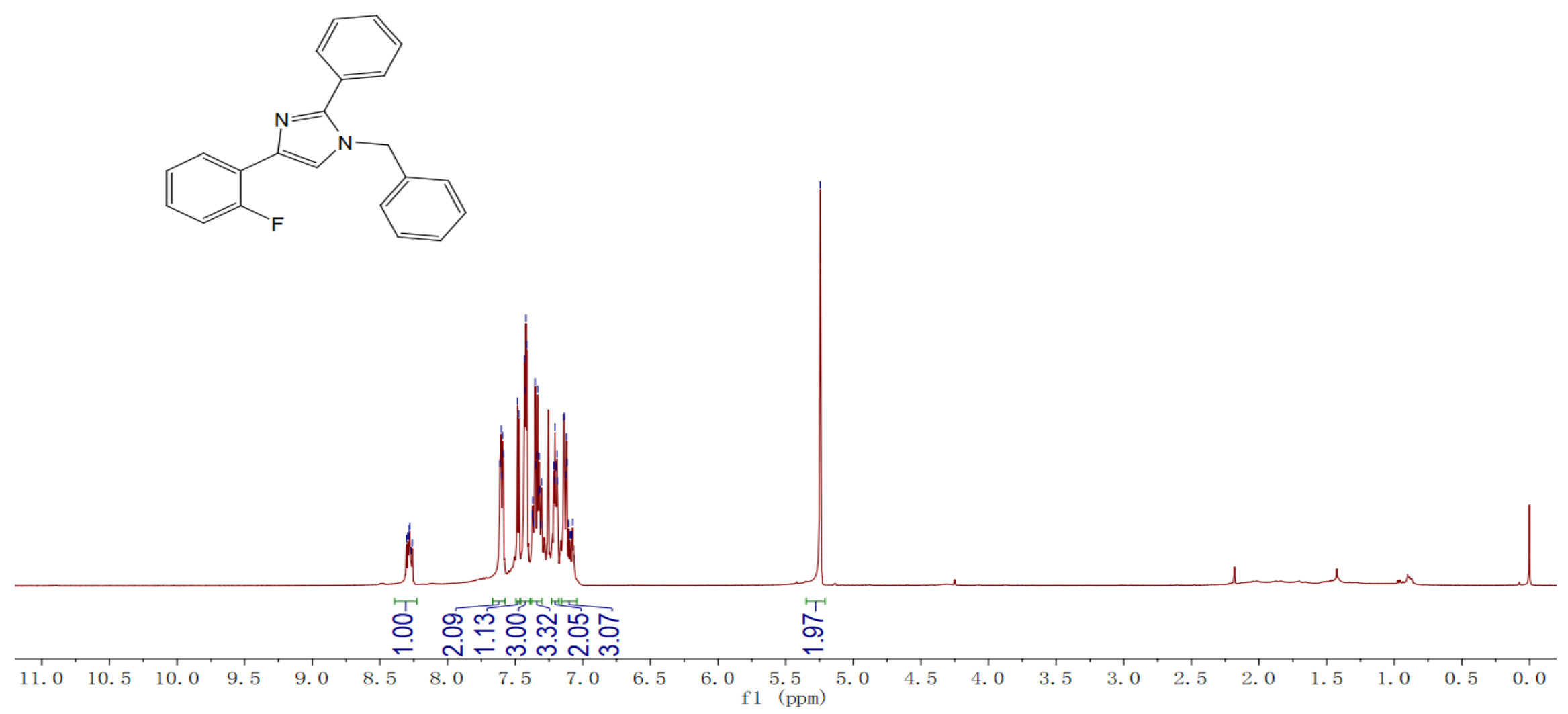

Figure $\mathrm{S} 15{ }^{1} \mathrm{H}$ NMR $\left(400 \mathrm{MHz}, \mathrm{CDCl}_{3}\right)$ spectra of 3 ha 

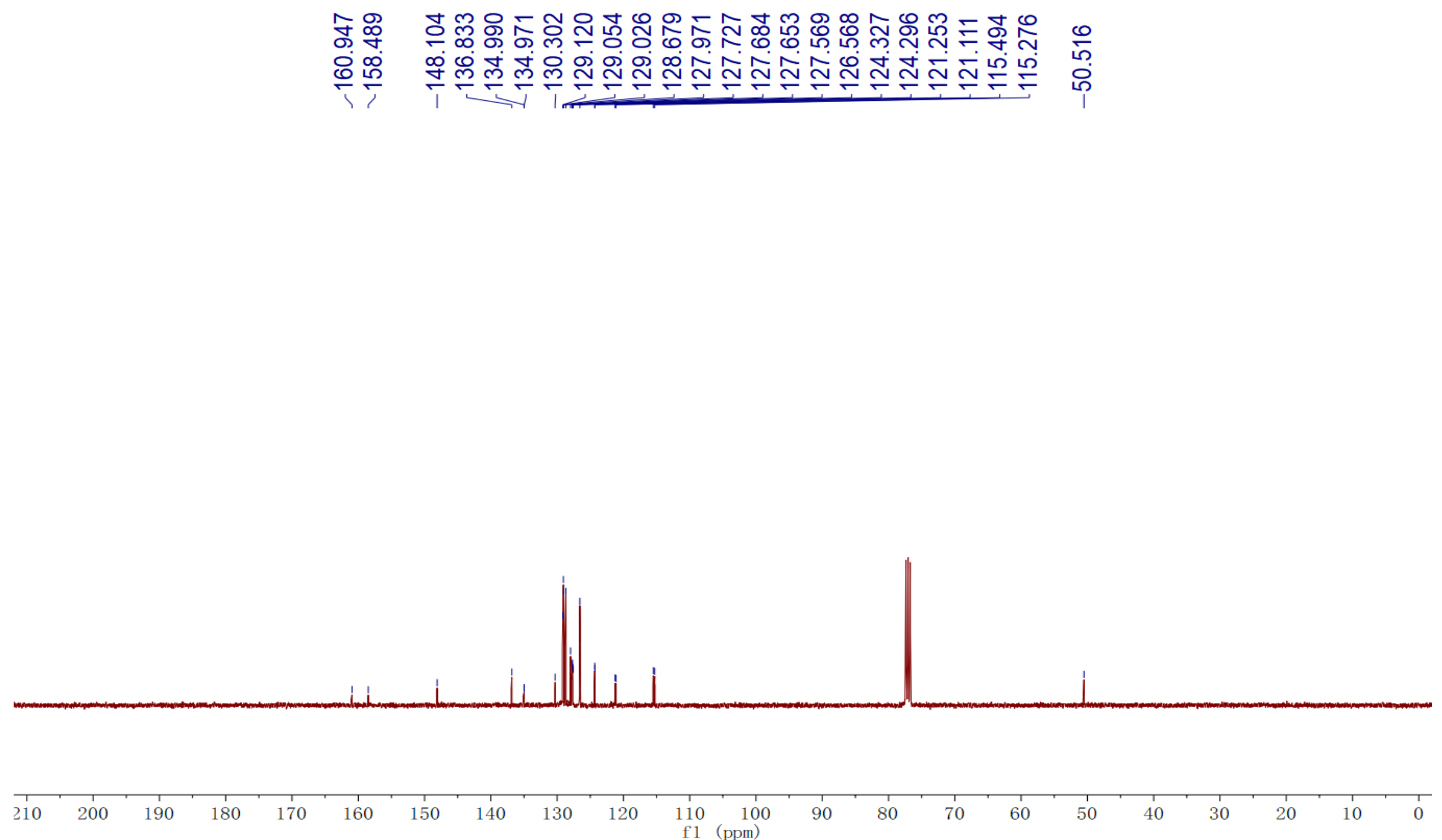

Figure $\mathrm{S} 16{ }^{13} \mathrm{C}$ NMR $\left(101 \mathrm{MHz}, \mathrm{CDCl}_{3}\right)$ spectra of $\mathbf{3 h a}$ 

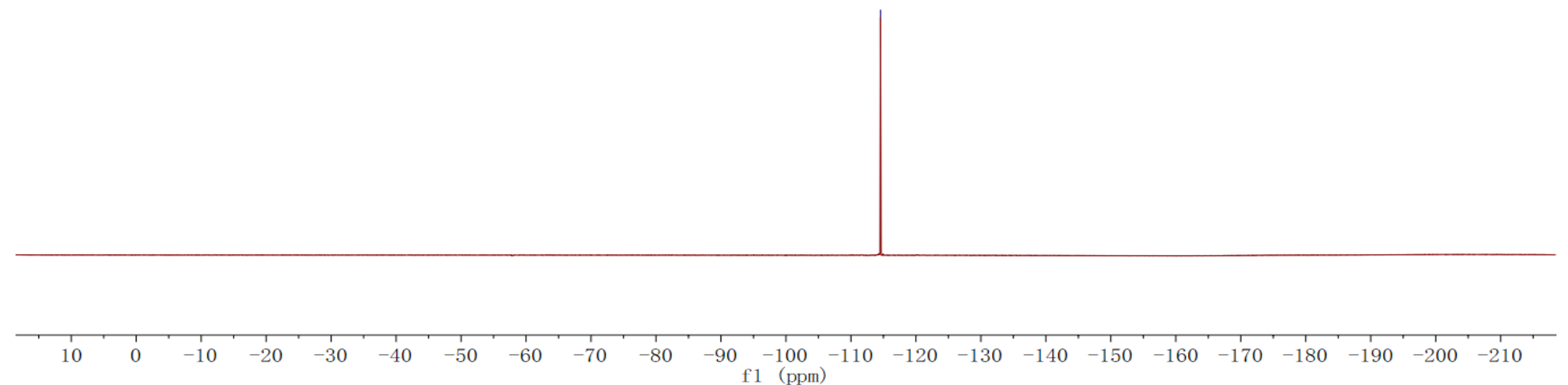

Figure S17 ${ }^{19}$ F NMR (376 MHz, $\mathrm{CDCl}_{3}$ ) spectra of 3ha 


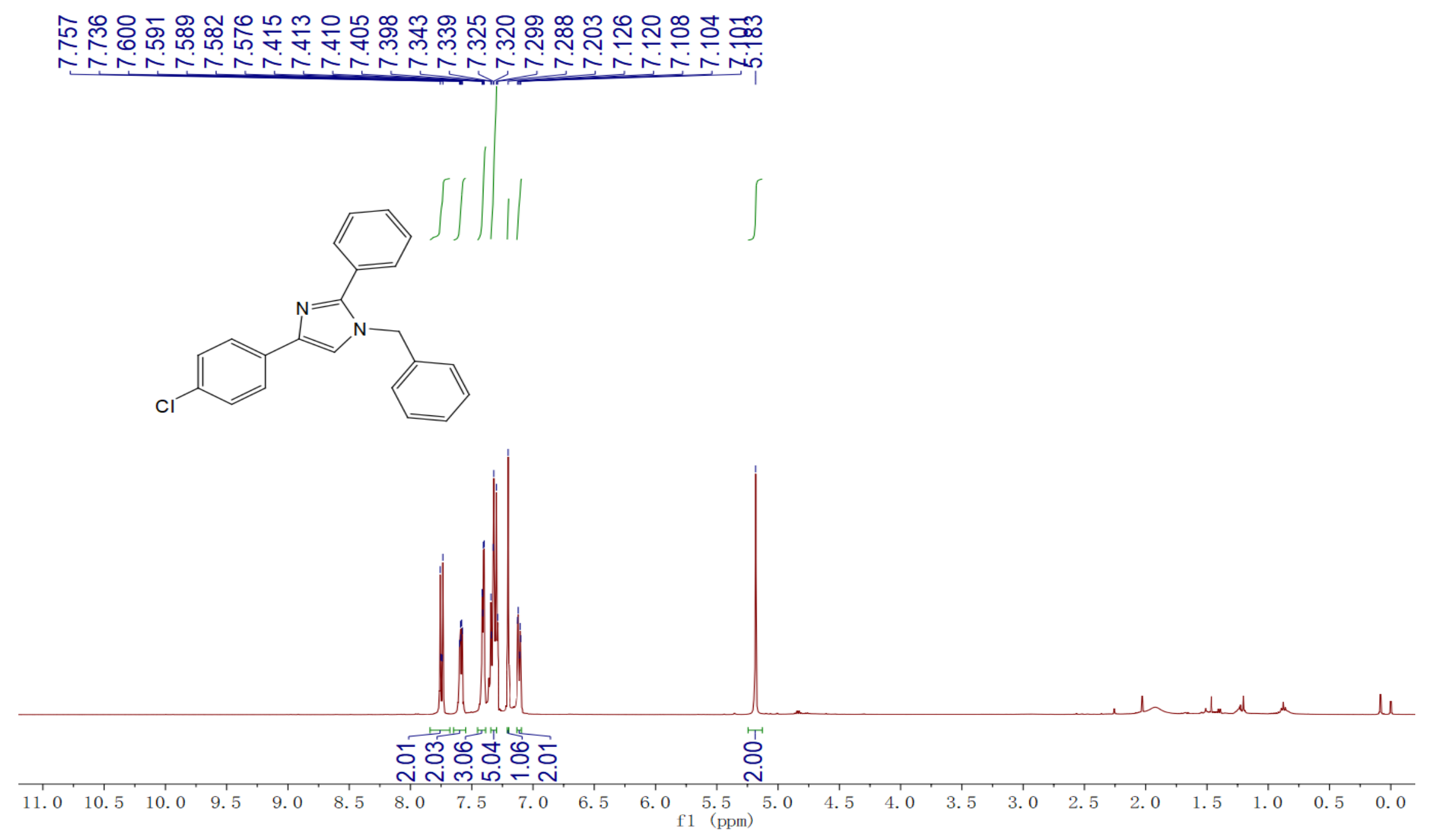

Figure $\mathrm{S} 18{ }^{1} \mathrm{H}$ NMR $\left(400 \mathrm{MHz}, \mathrm{CDCl}_{3}\right)$ spectra of 3ia 


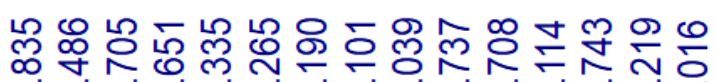

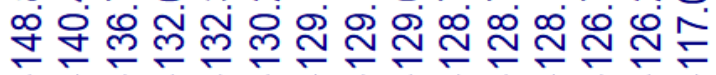

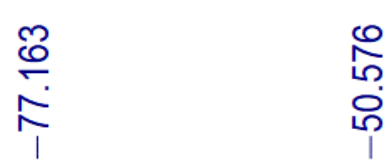
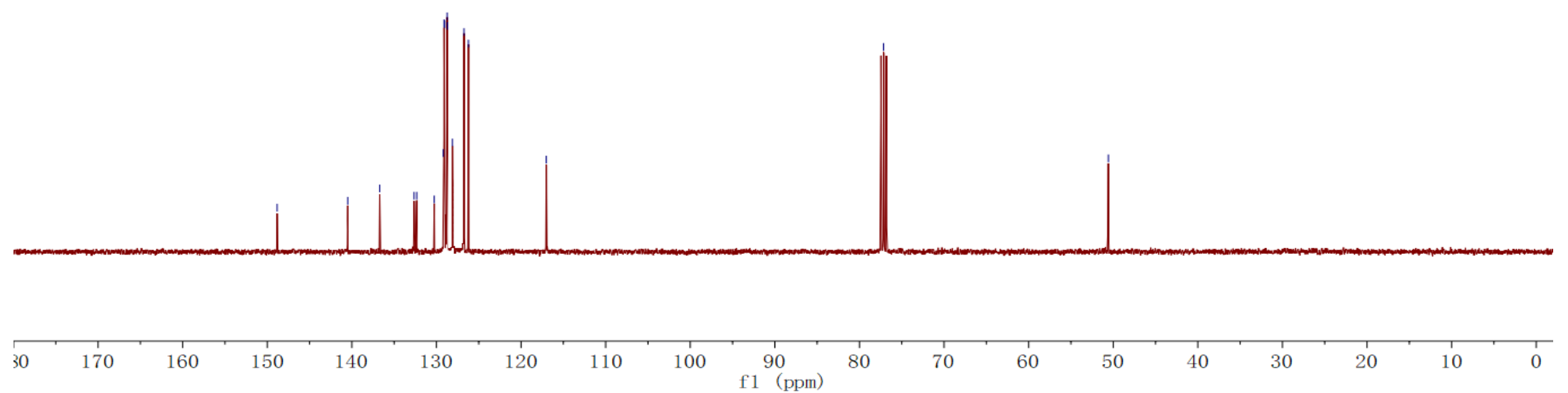

Figure $\mathrm{S} 19{ }^{13} \mathrm{C}$ NMR $\left(101 \mathrm{MHz}, \mathrm{CDCl}_{3}\right)$ spectra of 3ia 


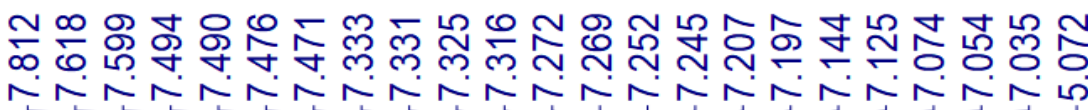
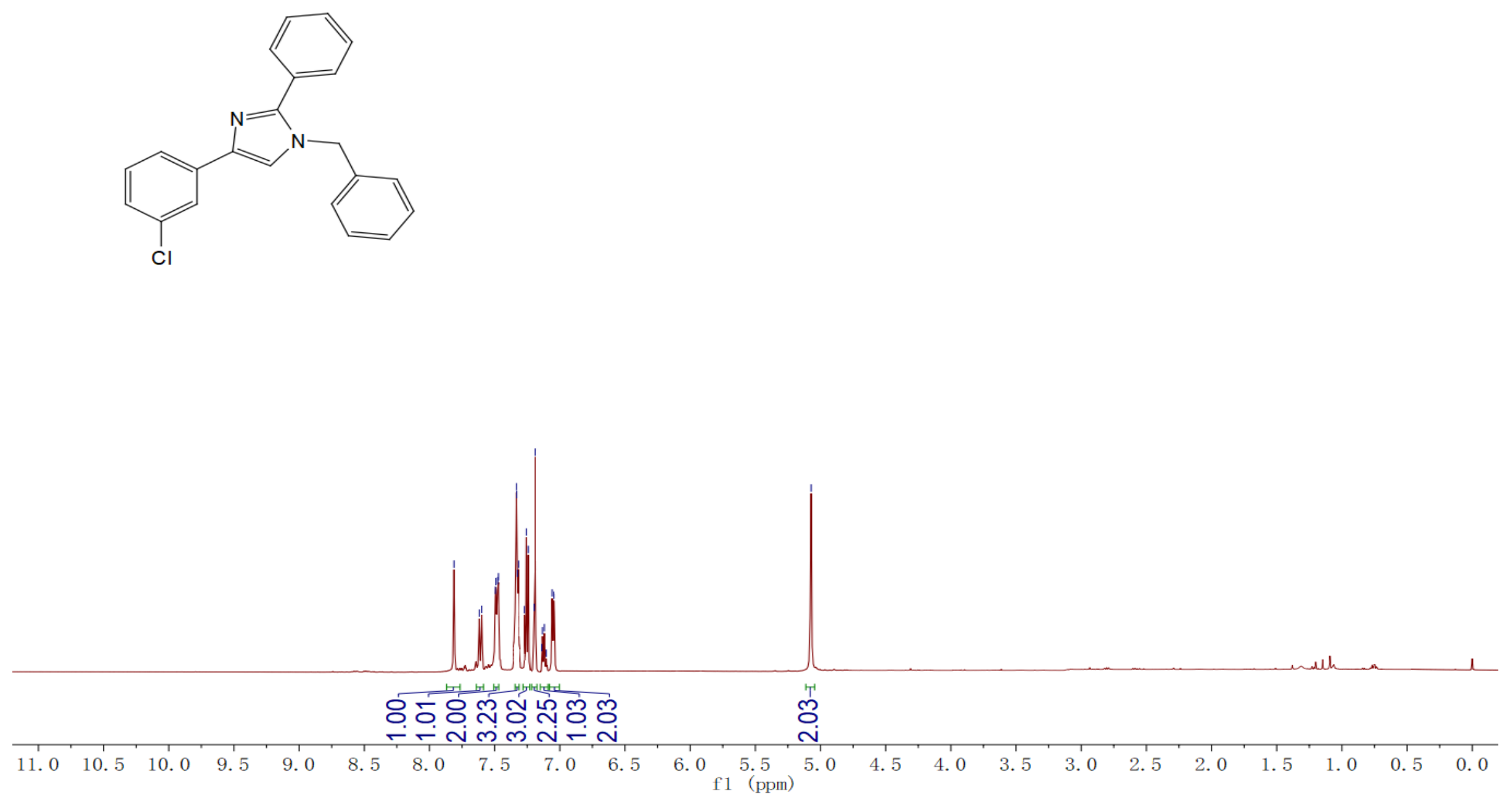

Figure $\mathrm{S} 20{ }^{1} \mathrm{H}$ NMR $\left(400 \mathrm{MHz}, \mathrm{CDCl}_{3}\right)$ spectra of $\mathbf{3 j a}$ 


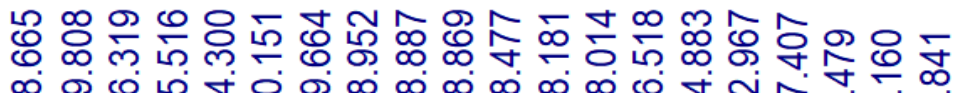

宁 m户̣

ส్ల

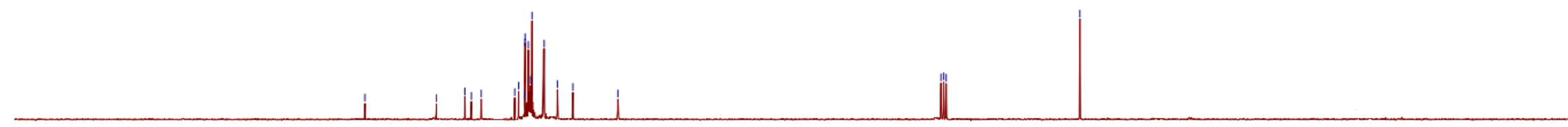

$190 \quad 180 \quad 170 \quad 160-150-140$

$100 \quad 90$

80

70

60

50

$30 \quad 20$

Figure $\mathrm{S} 21{ }^{13} \mathrm{C}$ NMR $\left(101 \mathrm{MHz}, \mathrm{CDCl}_{3}\right)$ spectra of $\mathbf{3 j a}$ 
足品怘

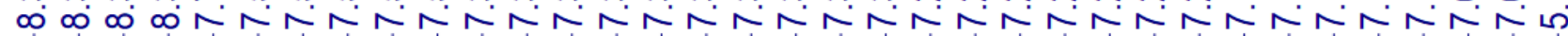
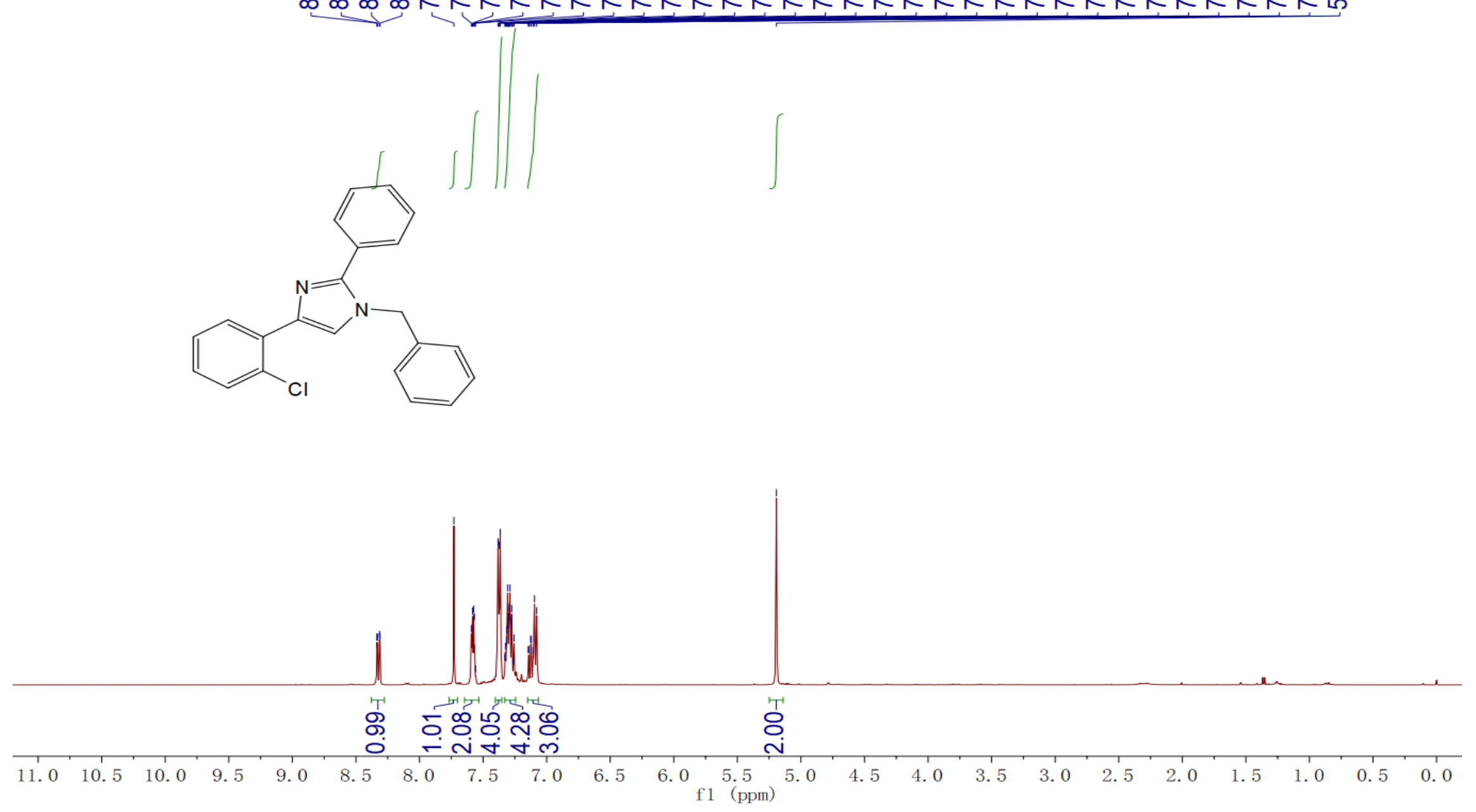

Figure $\mathrm{S} 22{ }^{1} \mathrm{H}$ NMR $\left(400 \mathrm{MHz}, \mathrm{CDCl}_{3}\right)$ spectra of $\mathbf{3 k a}$ 


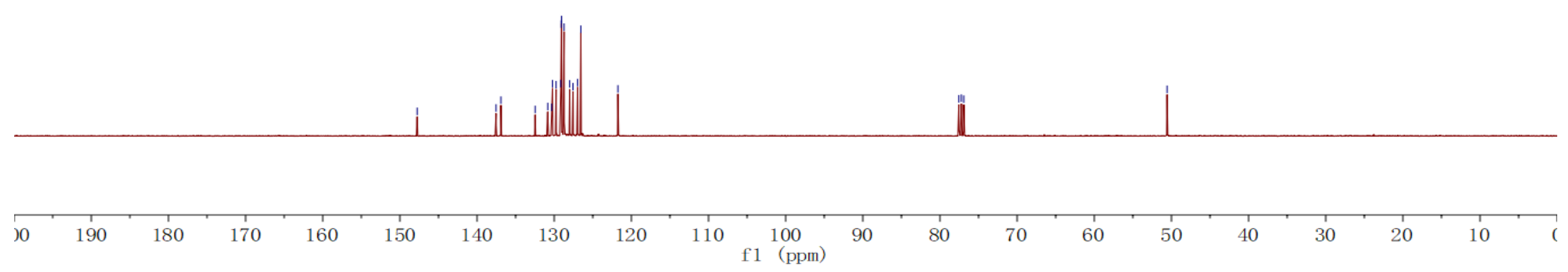

Figure $\mathrm{S} 23{ }^{13} \mathrm{C}$ NMR $\left(101 \mathrm{MHz}, \mathrm{CDCl}_{3}\right)$ spectra of 3ka 


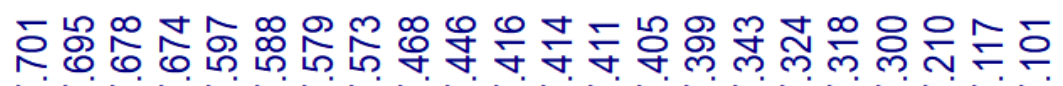

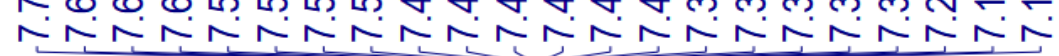
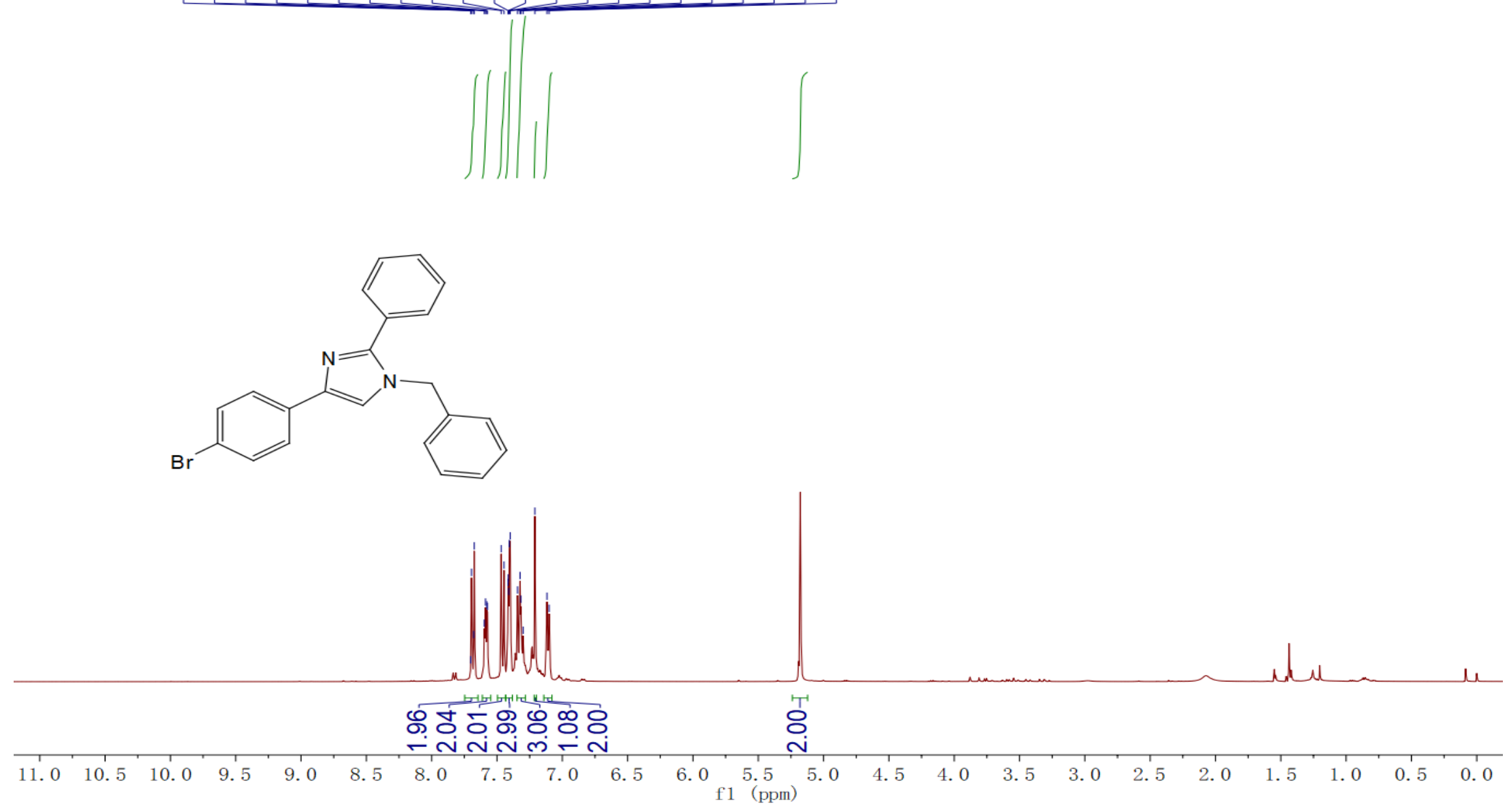

Figure $\mathrm{S} 24{ }^{1} \mathrm{H}$ NMR $\left(400 \mathrm{MHz}, \mathrm{CDCl}_{3}\right)$ spectra of 3la 

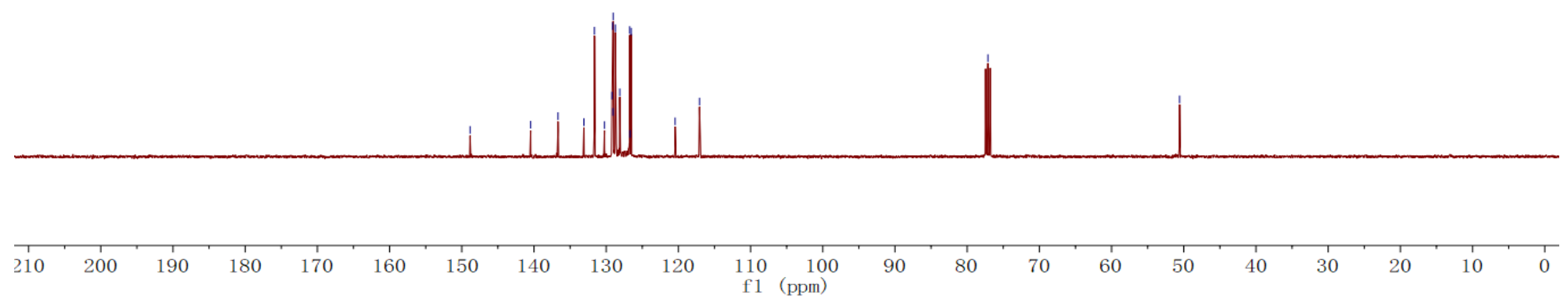

Figure S25 ${ }^{13} \mathrm{C}$ NMR $\left(101 \mathrm{MHz}, \mathrm{CDCl}_{3}\right)$ spectra of 3la 
లై

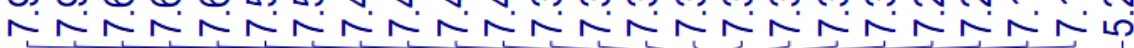
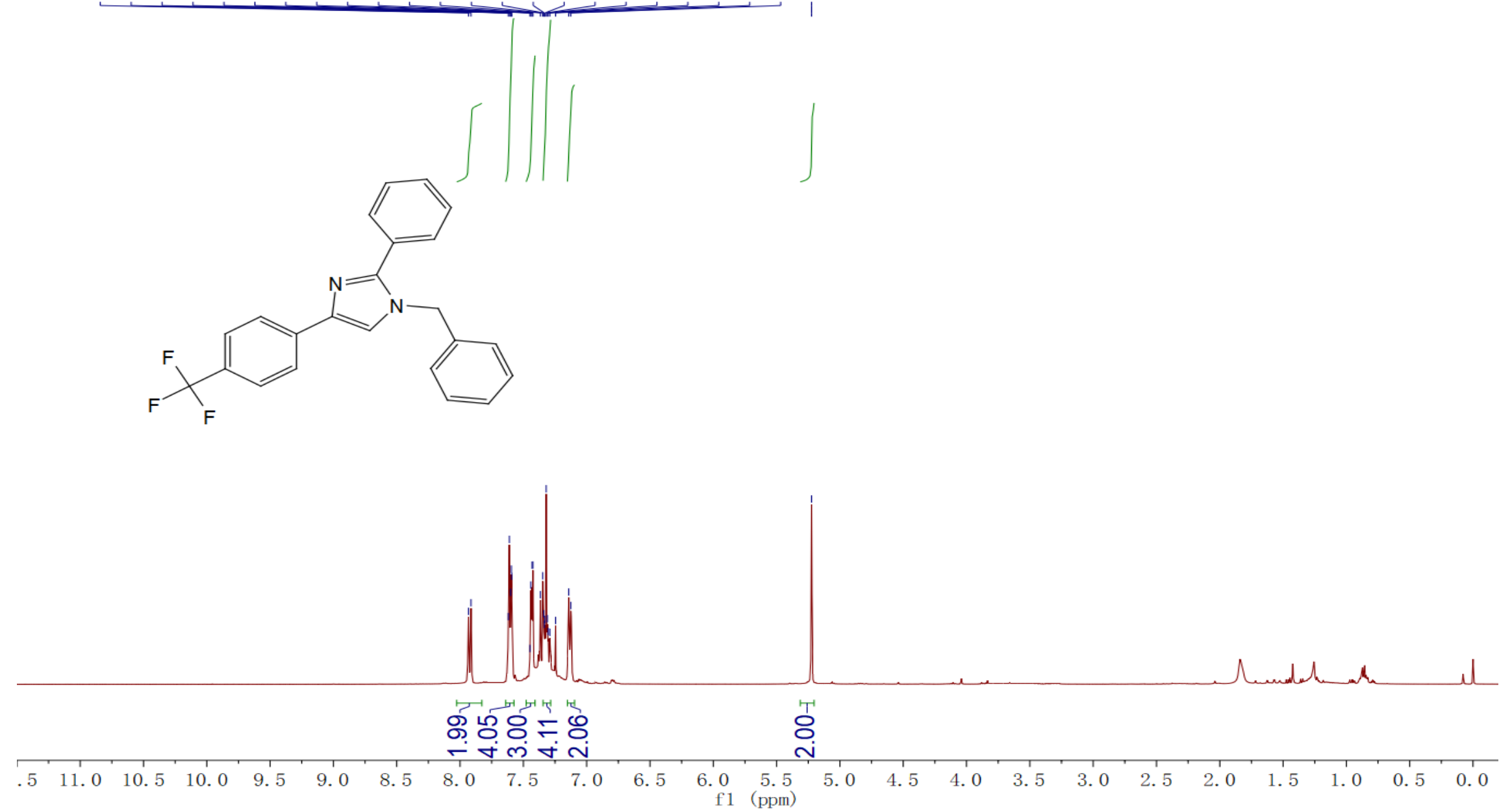

Figure $\mathrm{S} 26{ }^{1} \mathrm{H}$ NMR $\left(400 \mathrm{MHz}, \mathrm{CDCl}_{3}\right)$ spectra of $\mathbf{3 m a}$ 

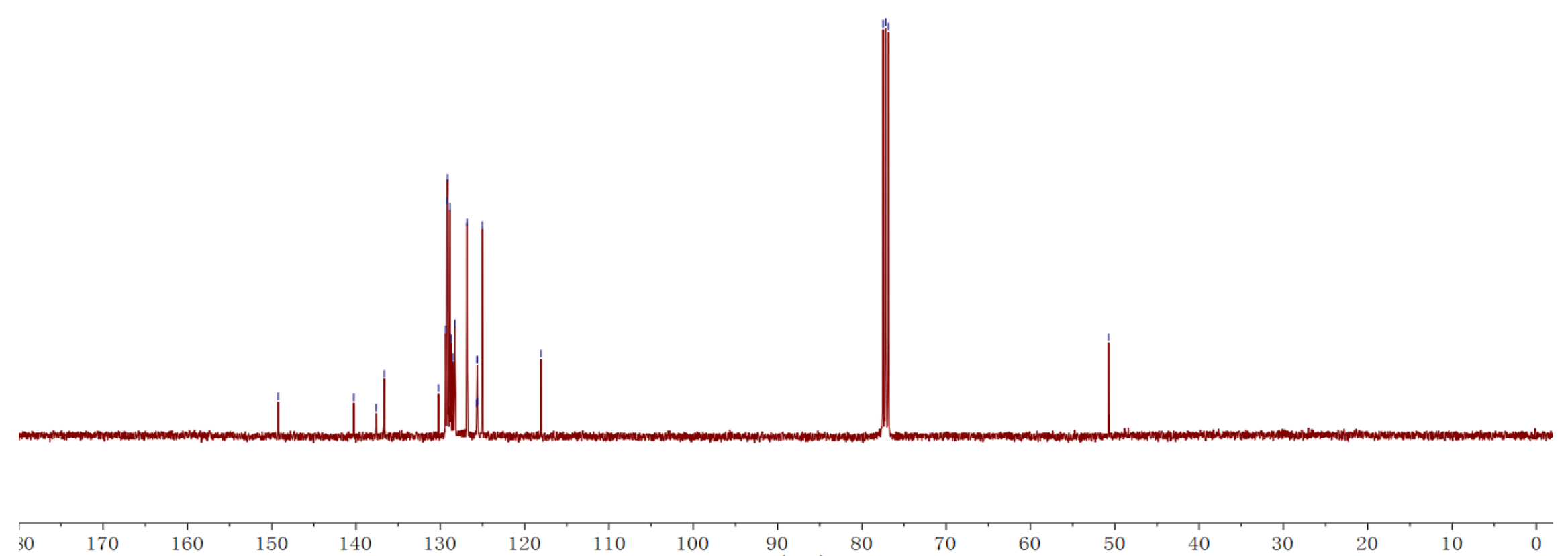

90 1 (pp

80

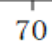

60

50

40

30

20

10

Figure S27 ${ }^{13} \mathrm{C}$ NMR (101 MHz, $\left.\mathrm{CDCl}_{3}\right)$ spectra of $\mathbf{3 m a}$ 

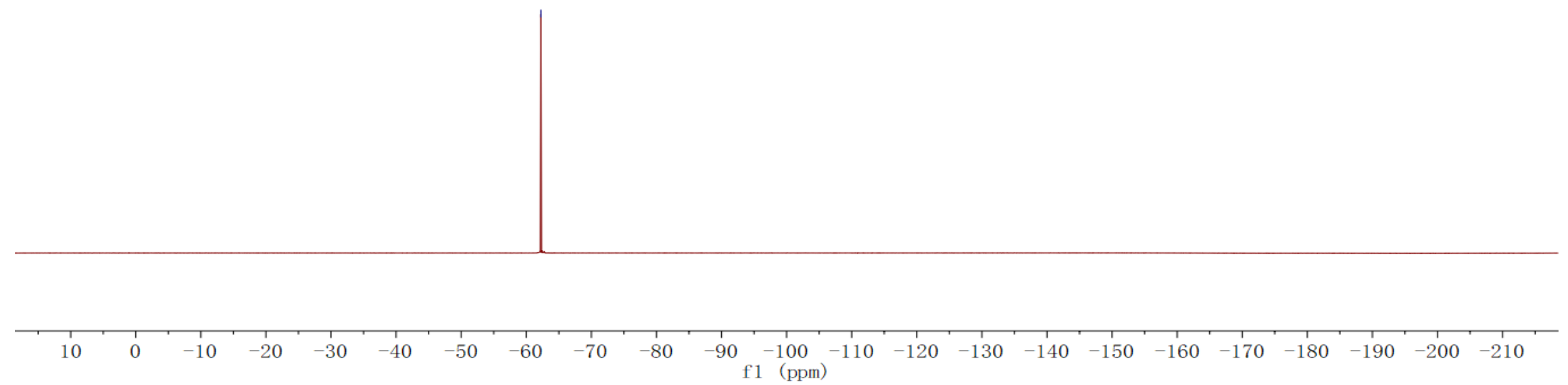

Figure S28 ${ }^{19} \mathrm{~F}$ NMR $\left(376 \mathrm{MHz}, \mathrm{CDCl}_{3}\right)$ spectra of $\mathbf{3 m a}$ 


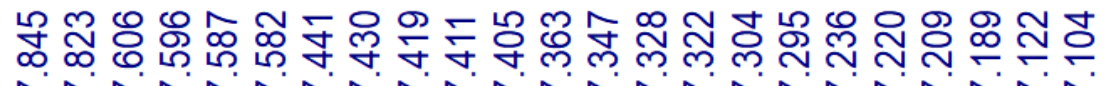

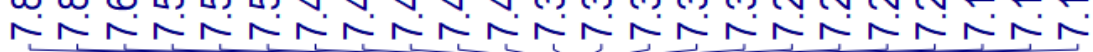
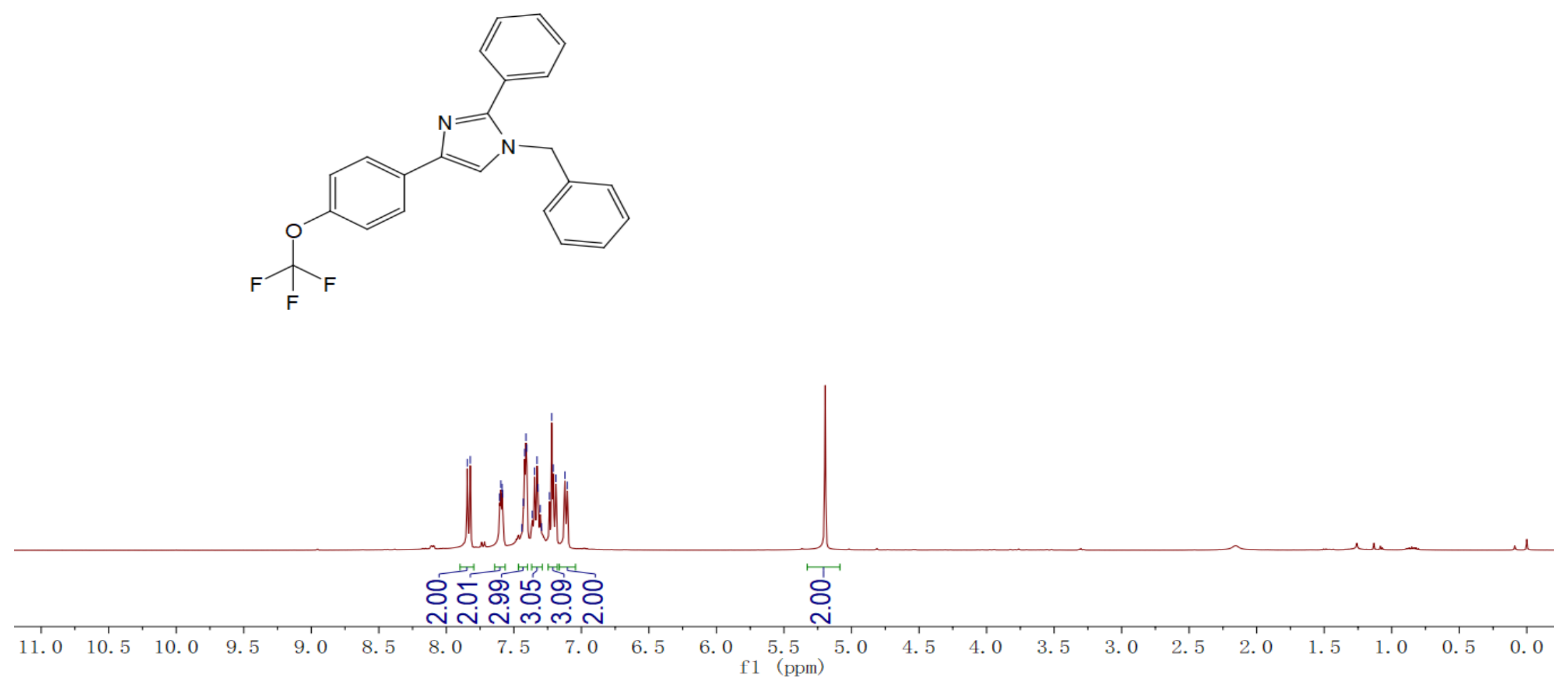

Figure S29 ${ }^{1} \mathrm{H}$ NMR $\left(400 \mathrm{MHz}, \mathrm{CDCl}_{3}\right)$ spectra of 3na 


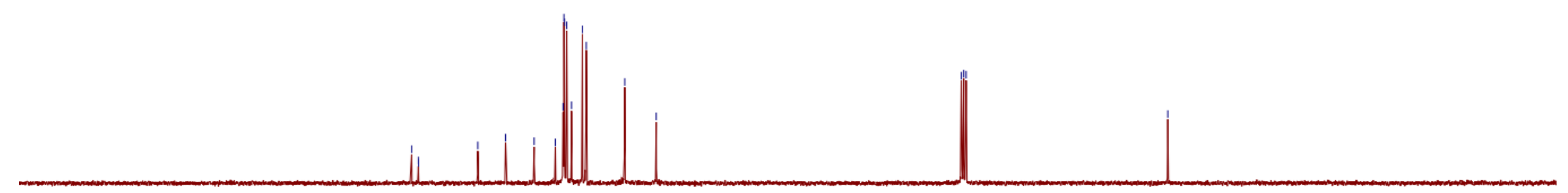

\begin{tabular}{lllllll}
\hline 0 & 190 & 180 & 170 & 160 & 150 & 140
\end{tabular}

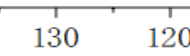

110

100

80

70

60

50

40

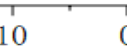

Figure $\mathrm{S} 30{ }^{13} \mathrm{C}$ NMR (101 MHz, $\left.\mathrm{CDCl}_{3}\right)$ spectra of 3na 

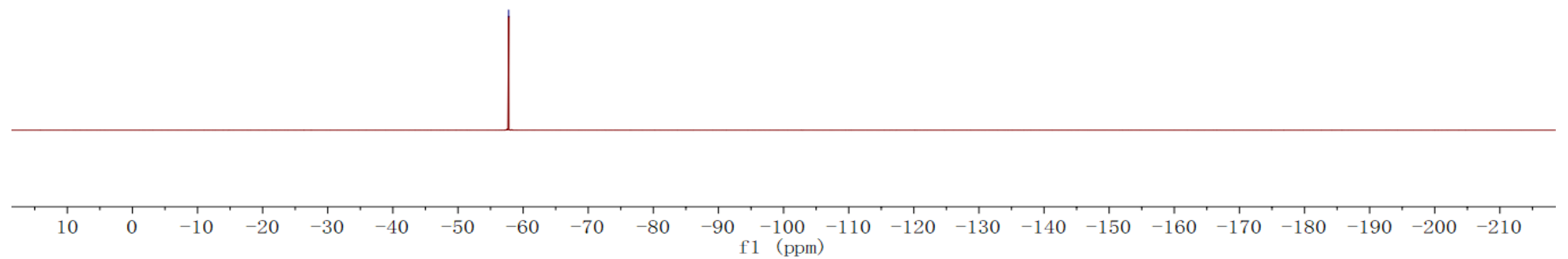

Figure S31 ${ }^{19} \mathrm{~F}$ NMR $\left(376 \mathrm{MHz}, \mathrm{CDCl}_{3}\right)$ spectra of 3na 


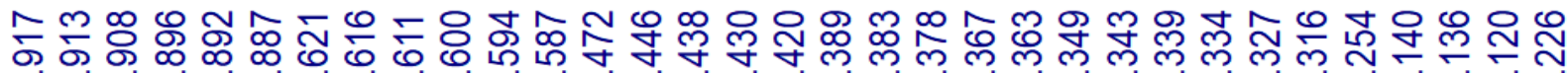

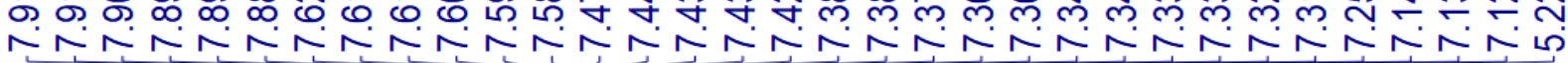

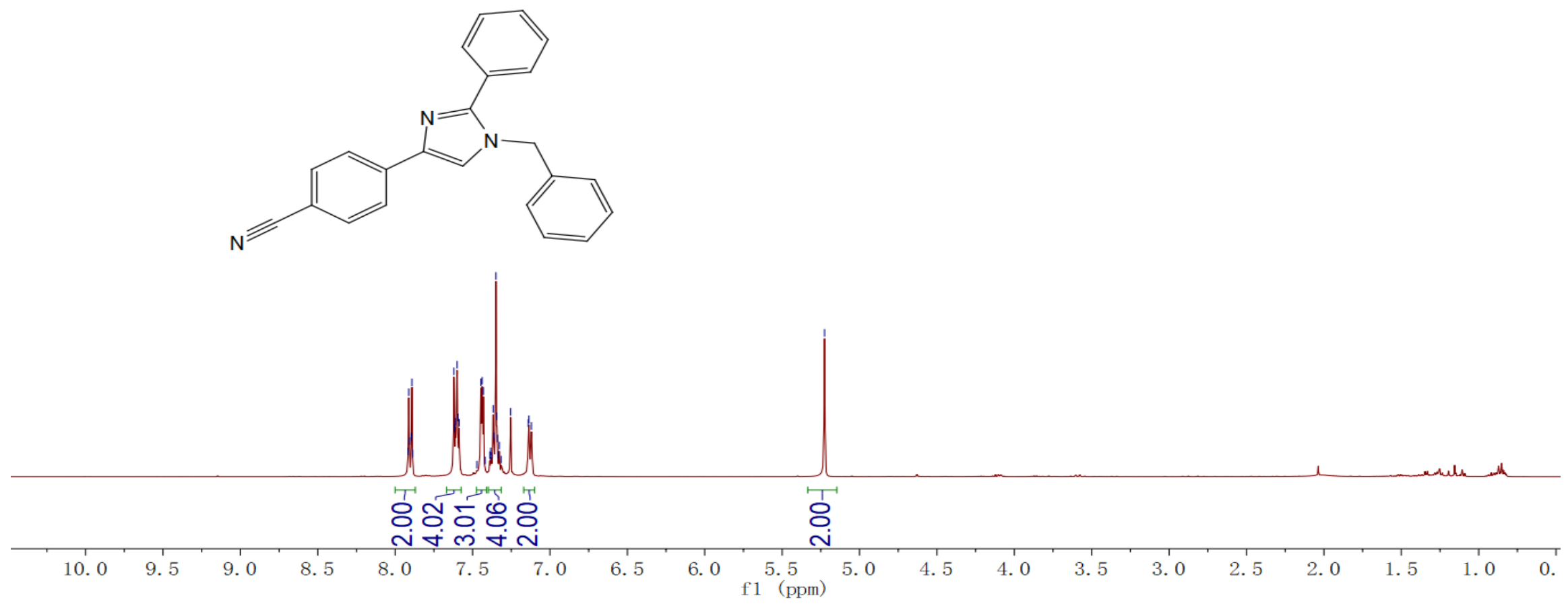

Figure $\mathrm{S} 32{ }^{1} \mathrm{H}$ NMR $\left(400 \mathrm{MHz}, \mathrm{CDCl}_{3}\right)$ spectra of $3 \mathbf{o a}$ 


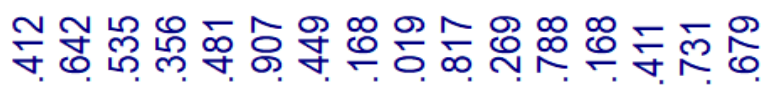

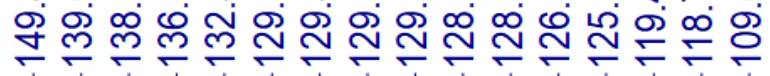

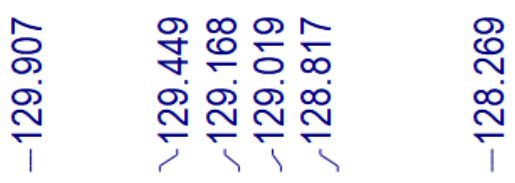
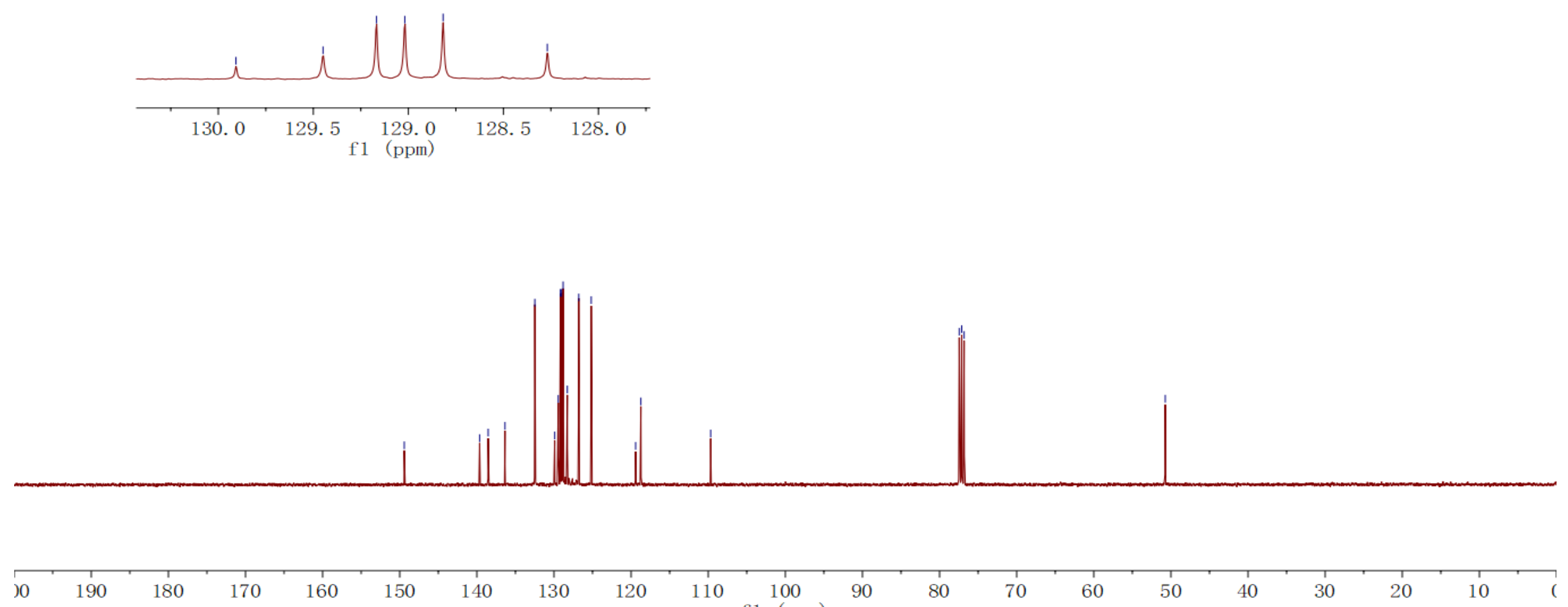

100

90
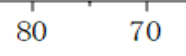

60

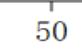

40

Figure S33 ${ }^{13} \mathrm{C}$ NMR $\left(101 \mathrm{MHz}, \mathrm{CDCl}_{3}\right)$ spectra of 3oa 


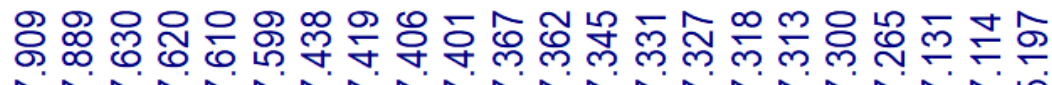

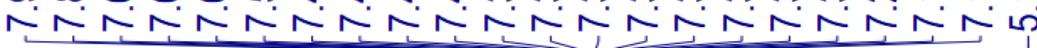
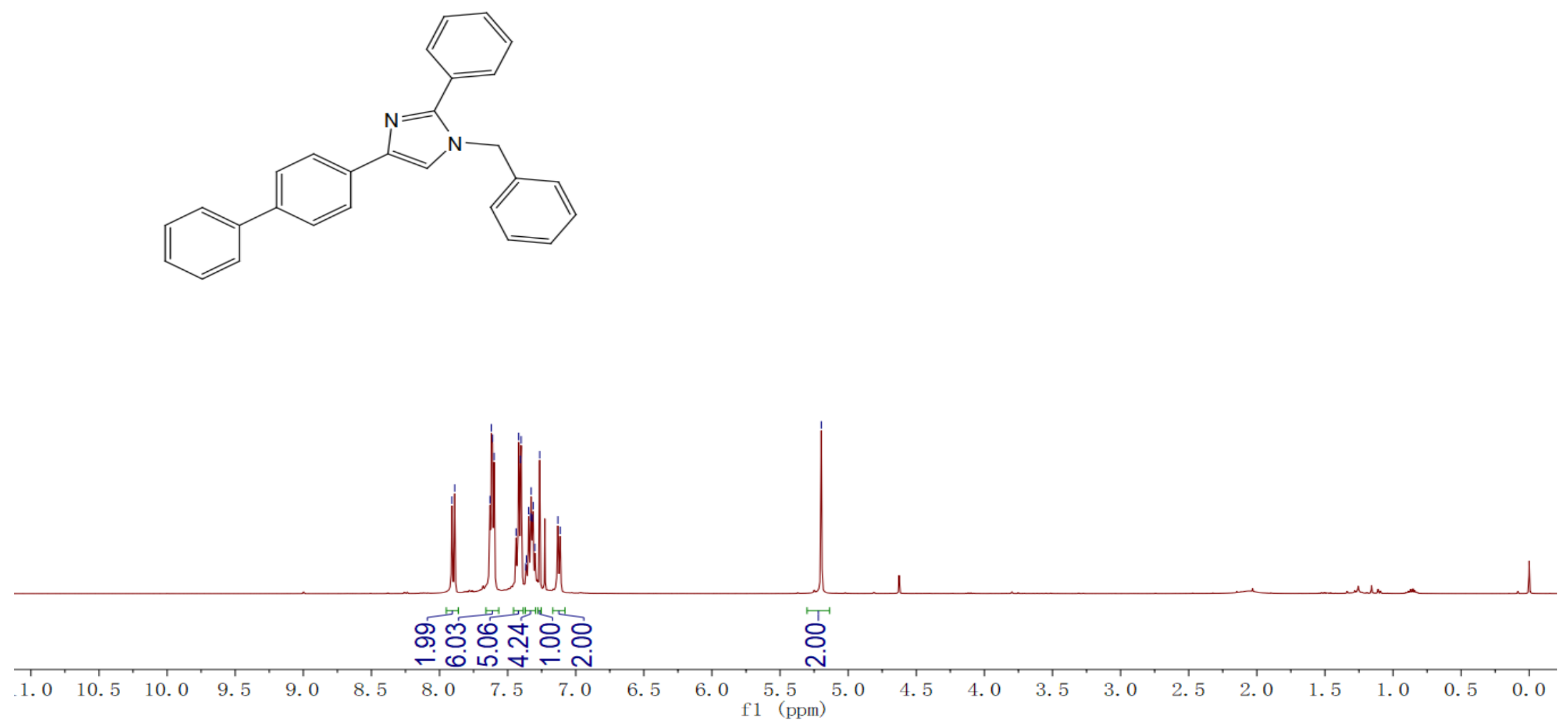

Figure $\mathrm{S} 34{ }^{1} \mathrm{H}$ NMR $\left(400 \mathrm{MHz}, \mathrm{CDCl}_{3}\right)$ spectra of 3pa 


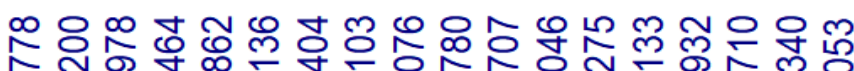

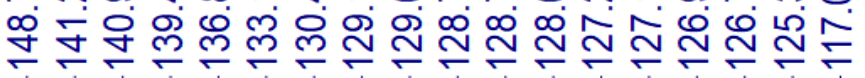

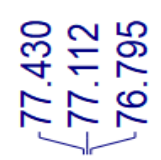

果

in

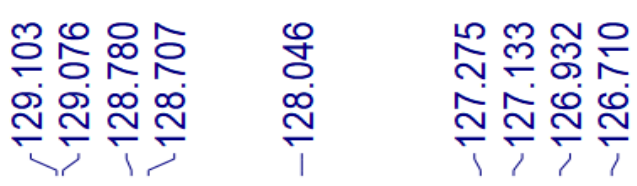

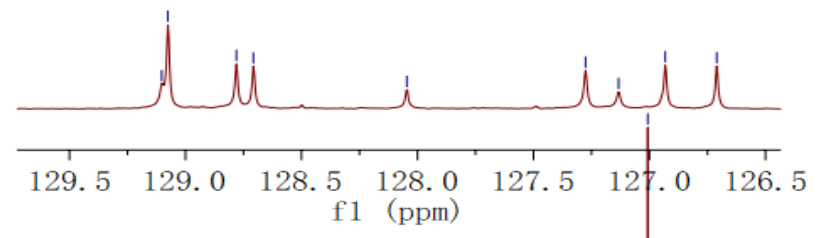

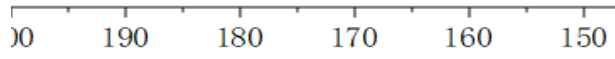

140

130

120

110

100

$90 \quad 80$

70

60

50

40

30

Figure $\mathrm{S} 35{ }^{13} \mathrm{C}$ NMR $\left(101 \mathrm{MHz}, \mathrm{CDCl}_{3}\right)$ spectra of 3pa 


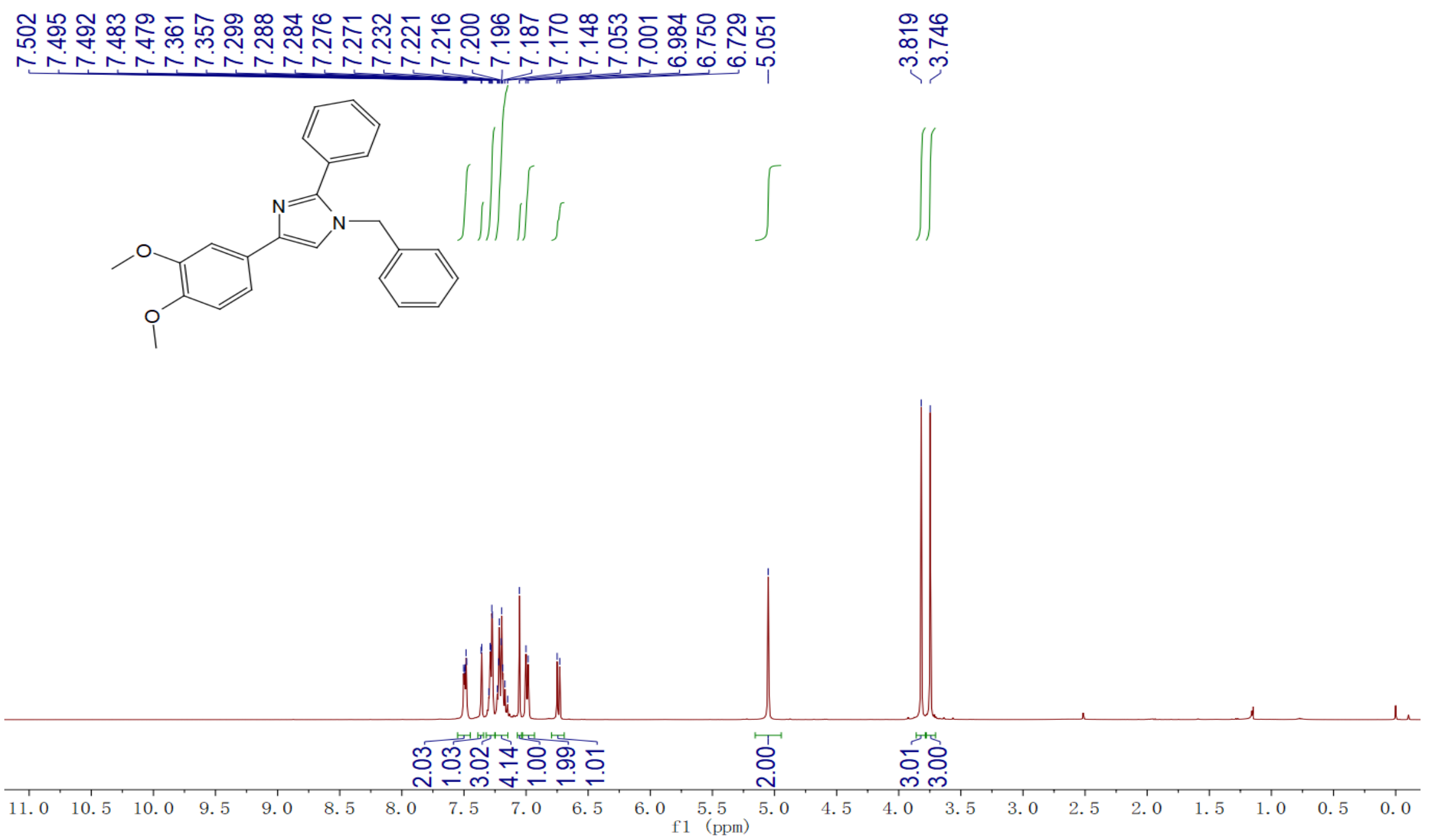

Figure S36 ${ }^{1} \mathrm{H}$ NMR (400 MHz, $\left.\mathrm{CDCl}_{3}\right)$ spectra of $\mathbf{3 q a}$ 


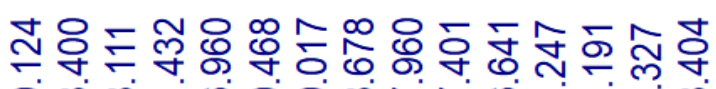
守导垨守宛
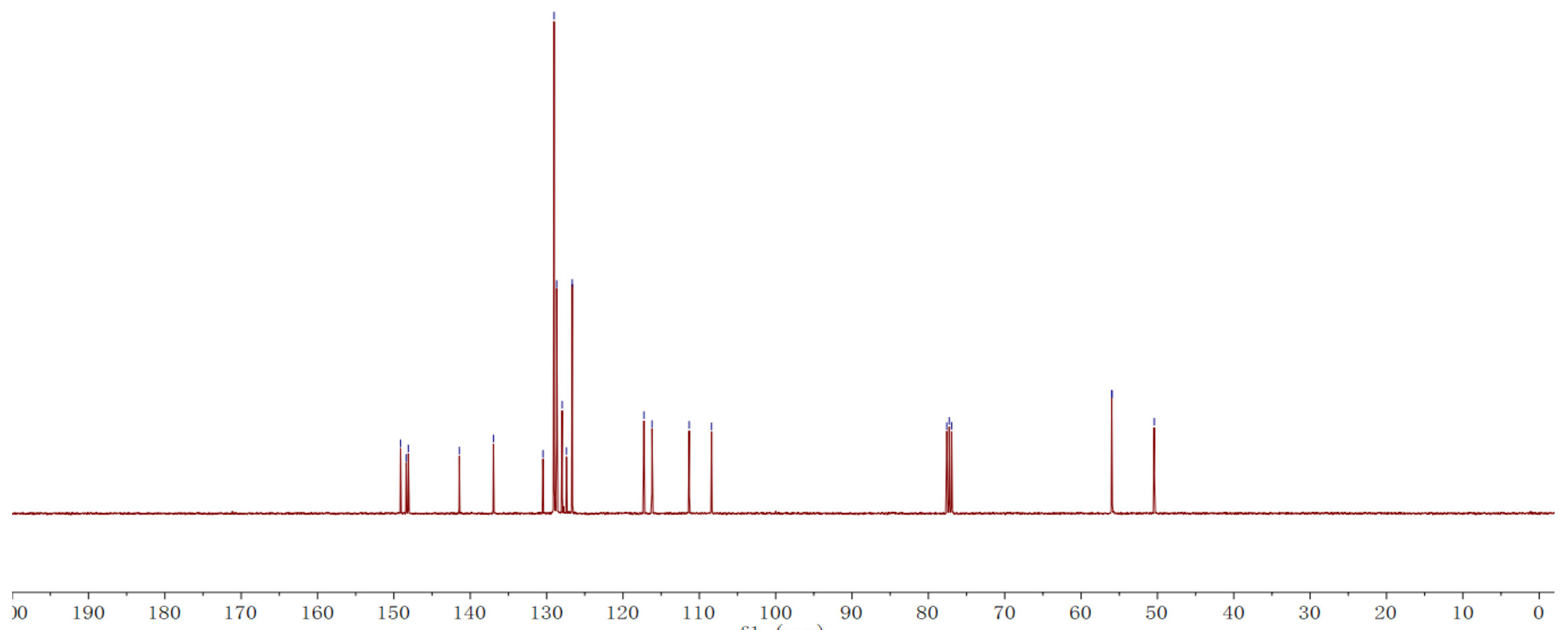

Figure $\mathrm{S} 37{ }^{13} \mathrm{C}$ NMR (101 MHz, $\left.\mathrm{CDCl}_{3}\right)$ spectra of $\mathbf{3 q a}$ 


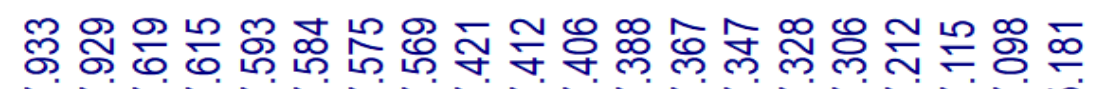

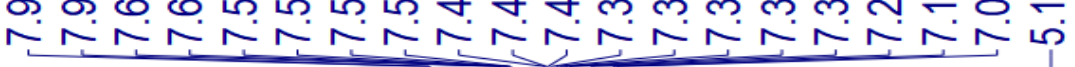
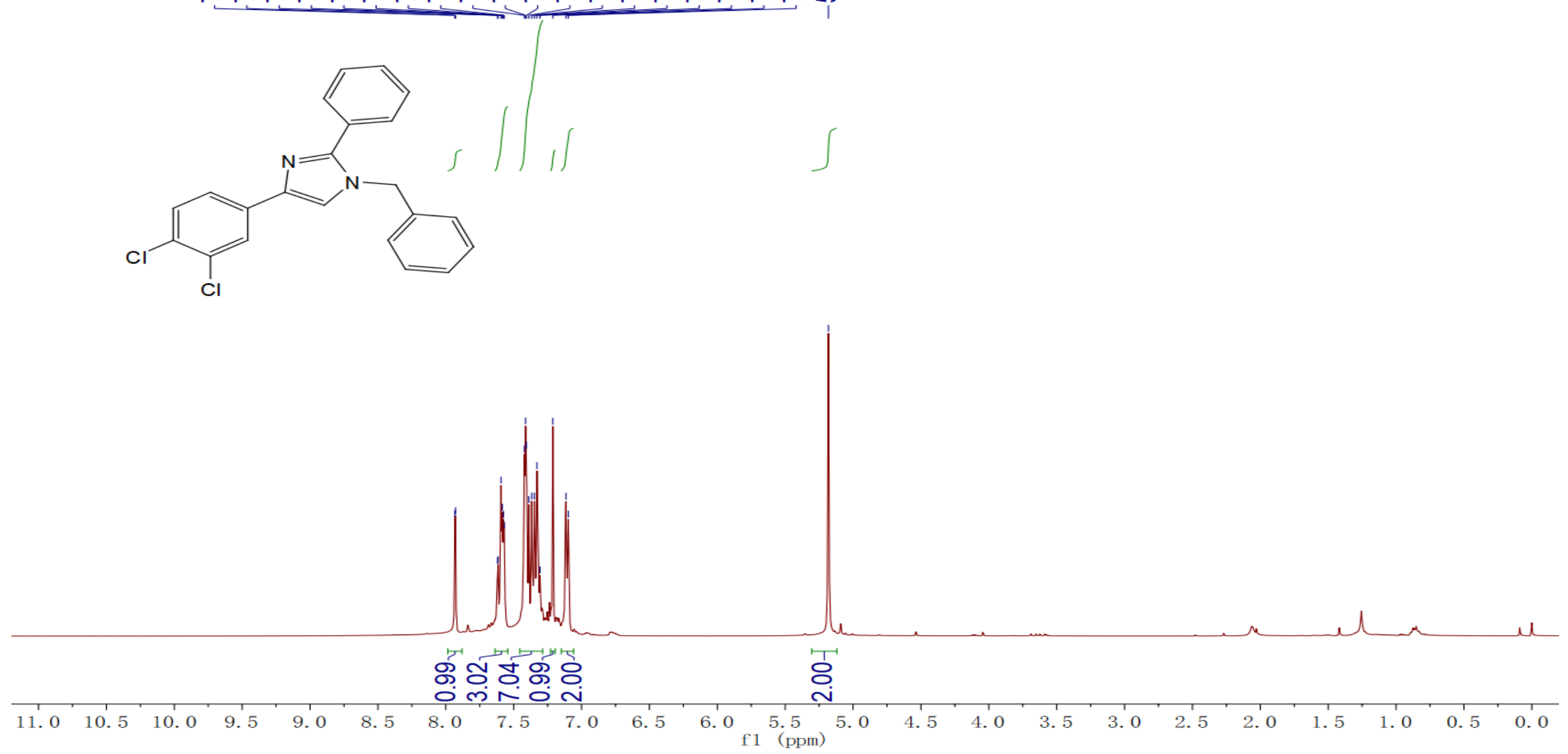

Figure $\mathrm{S} 38{ }^{1} \mathrm{H}$ NMR $\left(400 \mathrm{MHz}, \mathrm{CDCl}_{3}\right)$ spectra of 3ra 


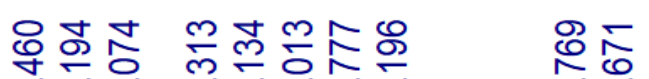

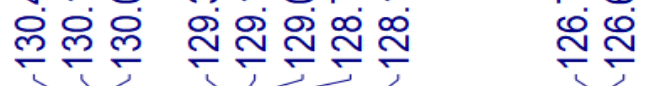
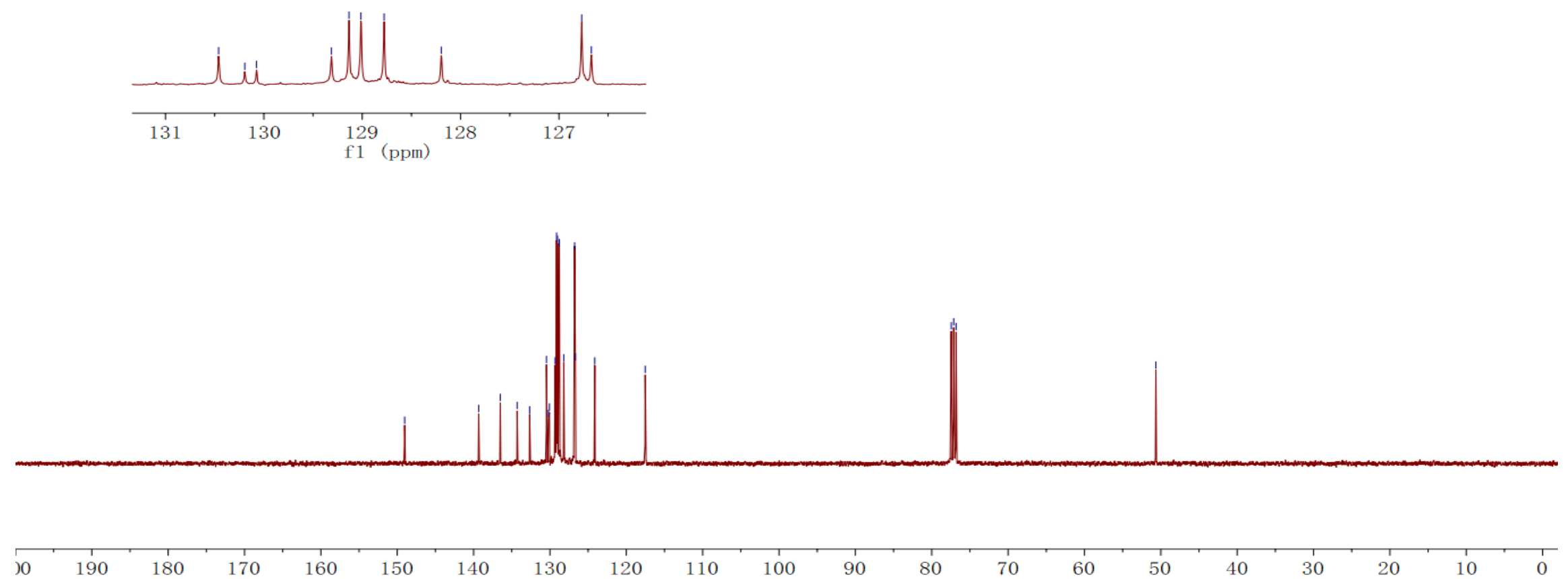

Figure S39 ${ }^{13} \mathrm{C}$ NMR $\left(101 \mathrm{MHz}, \mathrm{CDCl}_{3}\right)$ spectra of 3ra 


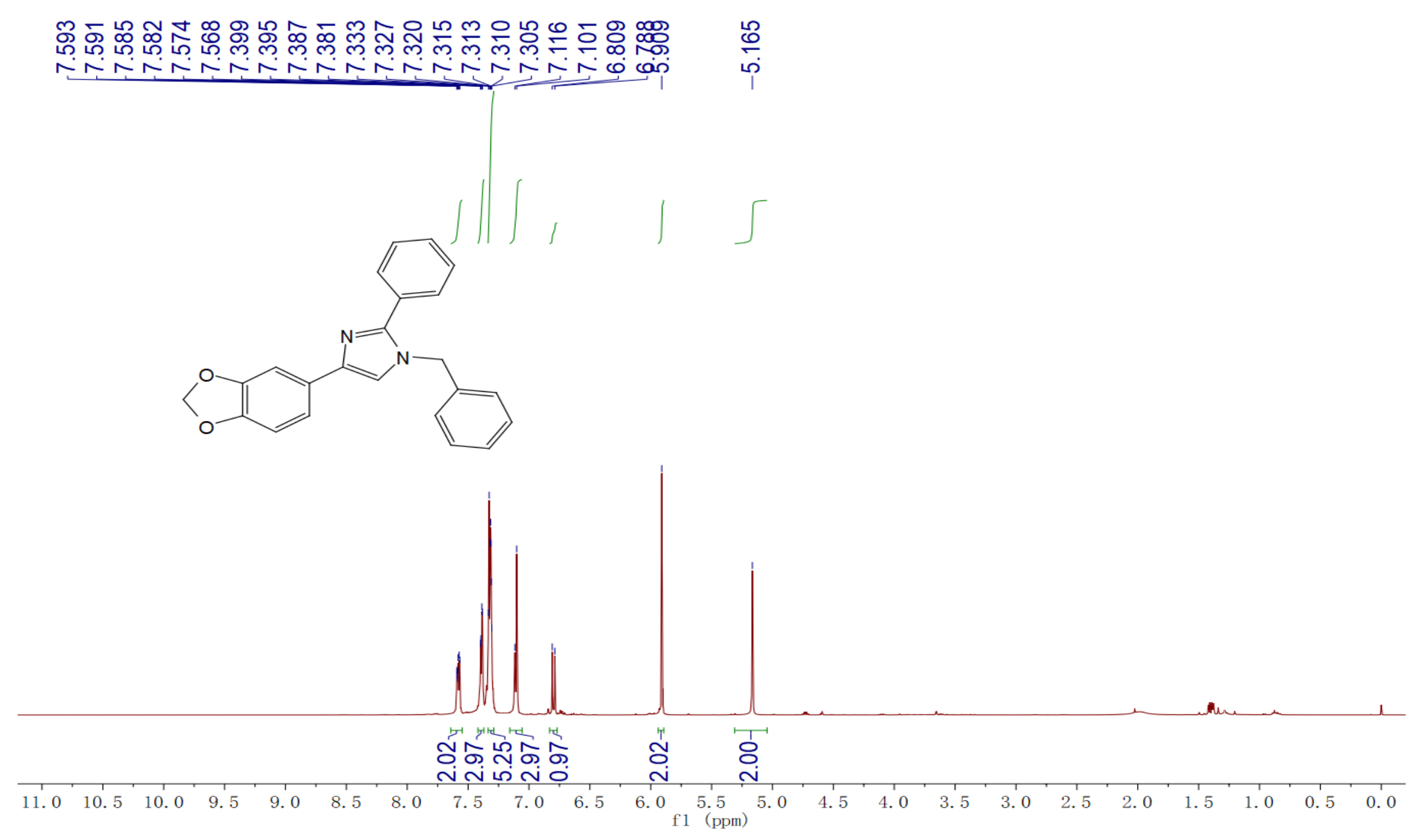

Figure $\mathrm{S} 40{ }^{1} \mathrm{H}$ NMR $\left(400 \mathrm{MHz}, \mathrm{CDCl}_{3}\right)$ spectra of 3sa 

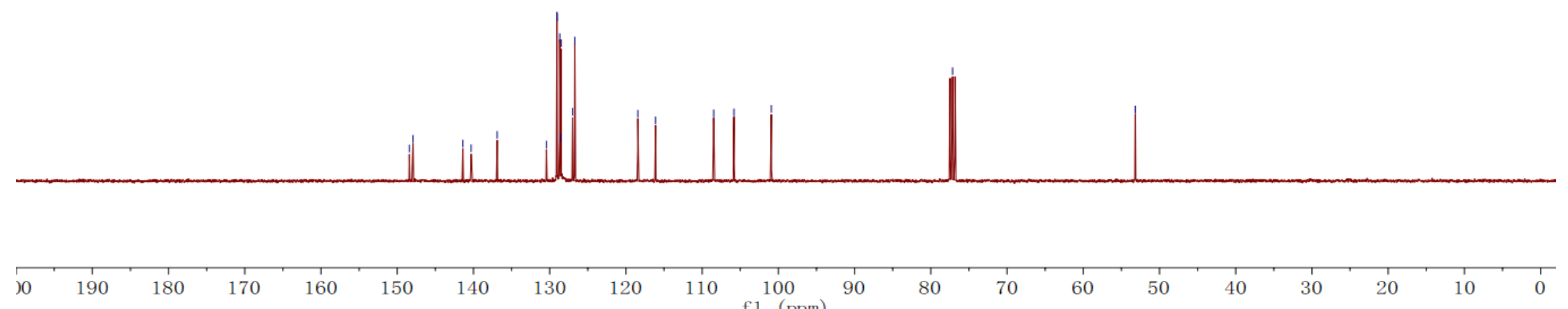

Figure $\mathrm{S} 41{ }^{13} \mathrm{C}$ NMR $\left(101 \mathrm{MHz}, \mathrm{CDCl}_{3}\right)$ spectra of 3sa 


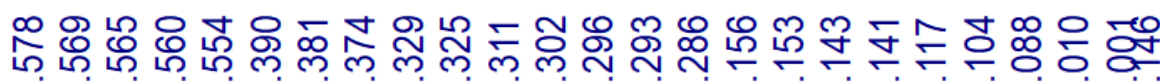

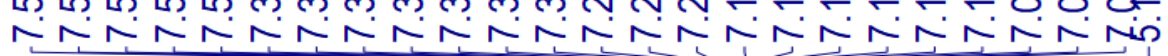
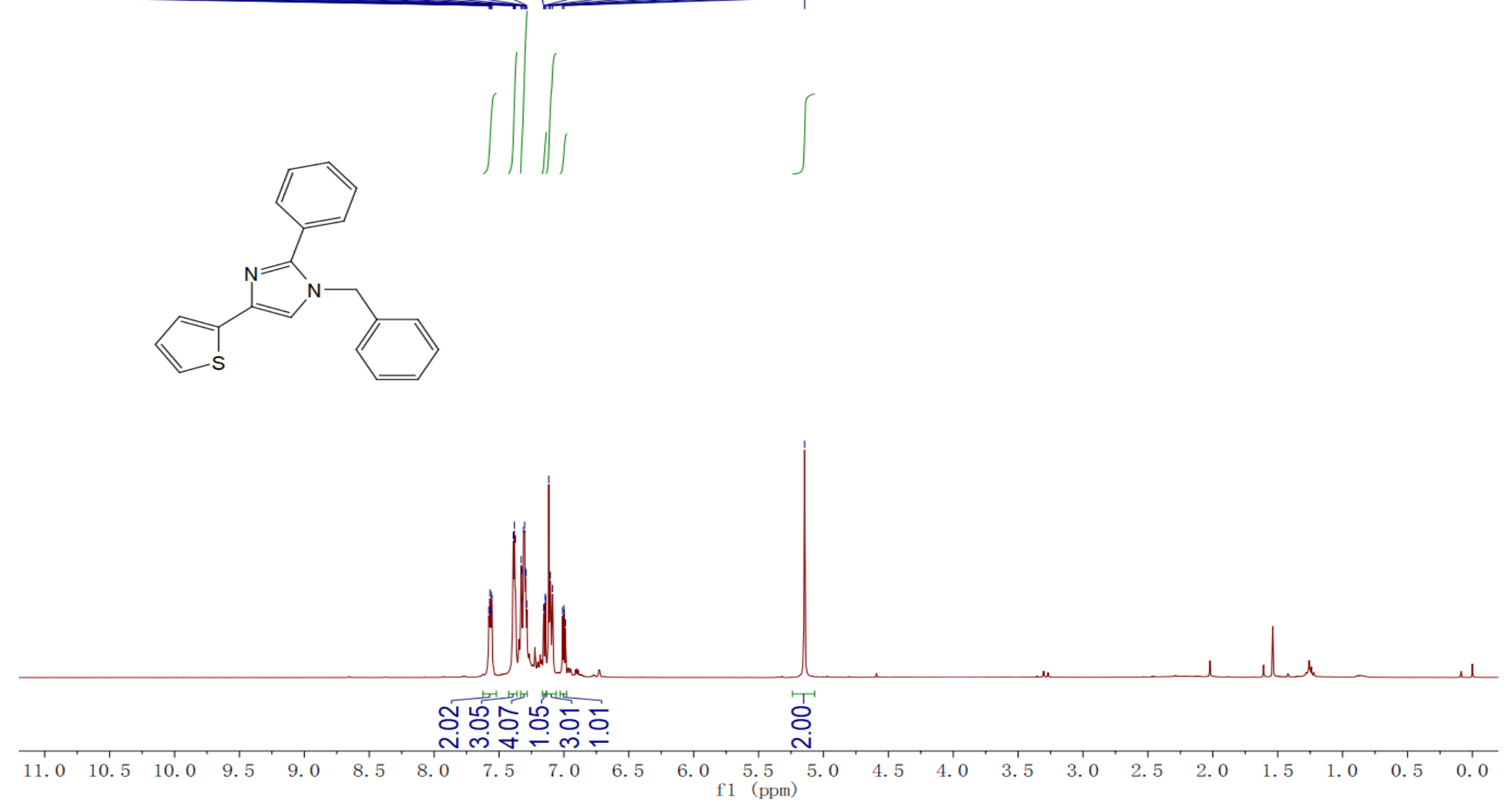

Figure $\mathrm{S} 42{ }^{1} \mathrm{H}$ NMR $\left(400 \mathrm{MHz}, \mathrm{CDCl}_{3}\right)$ spectra of 3ta 


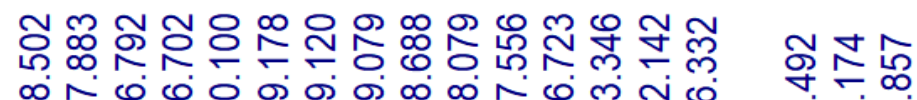

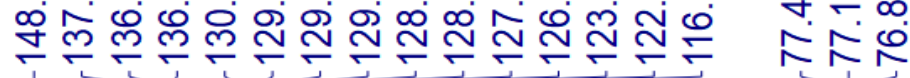

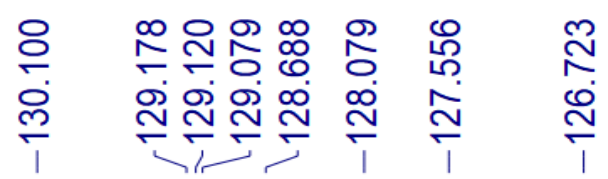

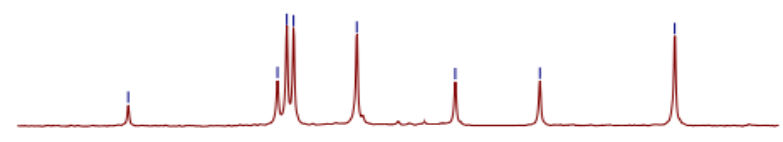

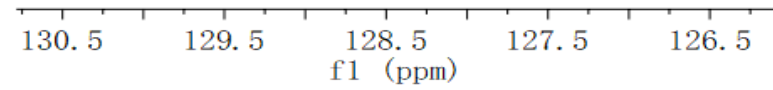
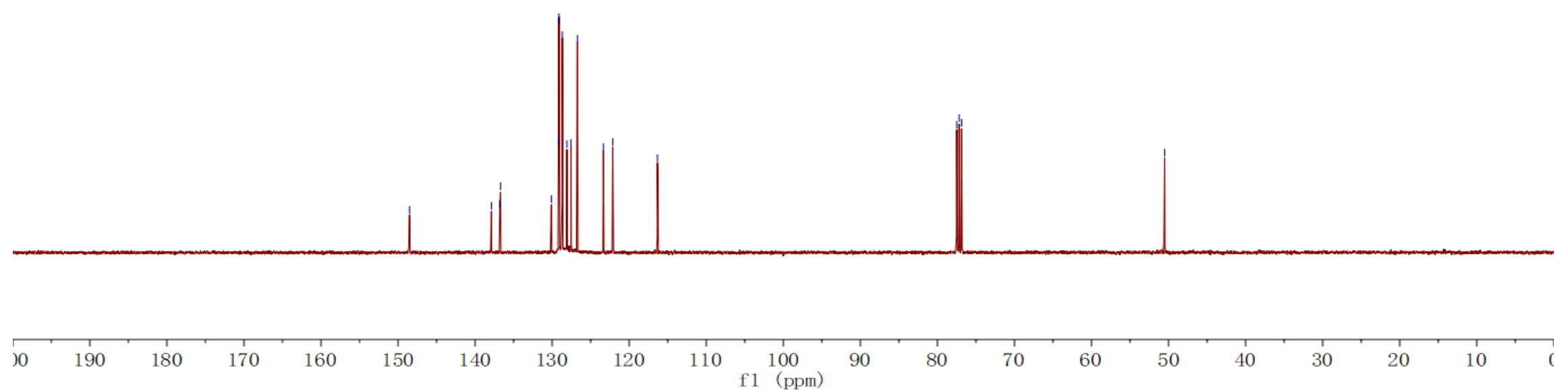

Figure $\mathrm{S} 43{ }^{13} \mathrm{C}$ NMR $\left(101 \mathrm{MHz}, \mathrm{CDCl}_{3}\right)$ spectra of 3ta 


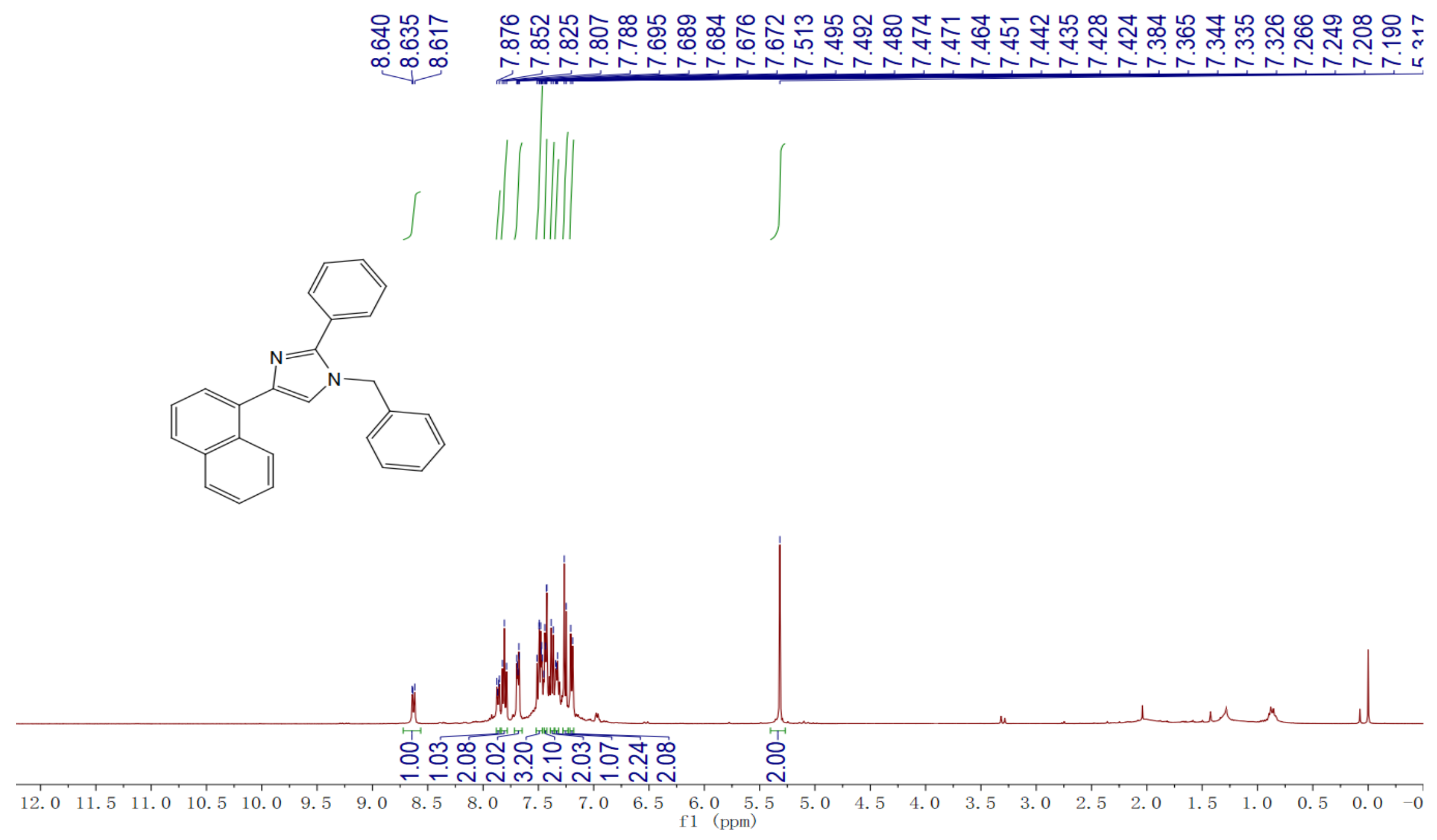

Figure S44 ${ }^{1} \mathrm{H}$ NMR (400 MHz, $\mathrm{CDCl}_{3}$ ) spectra of 3ua 


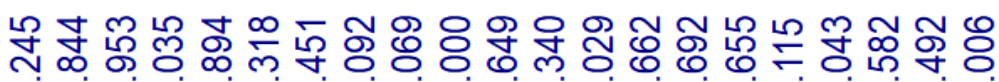

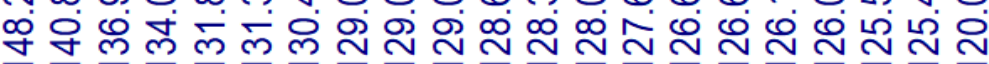

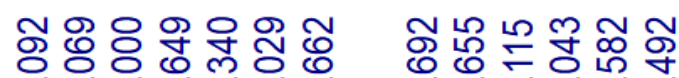

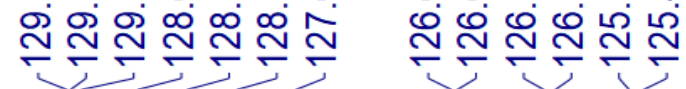
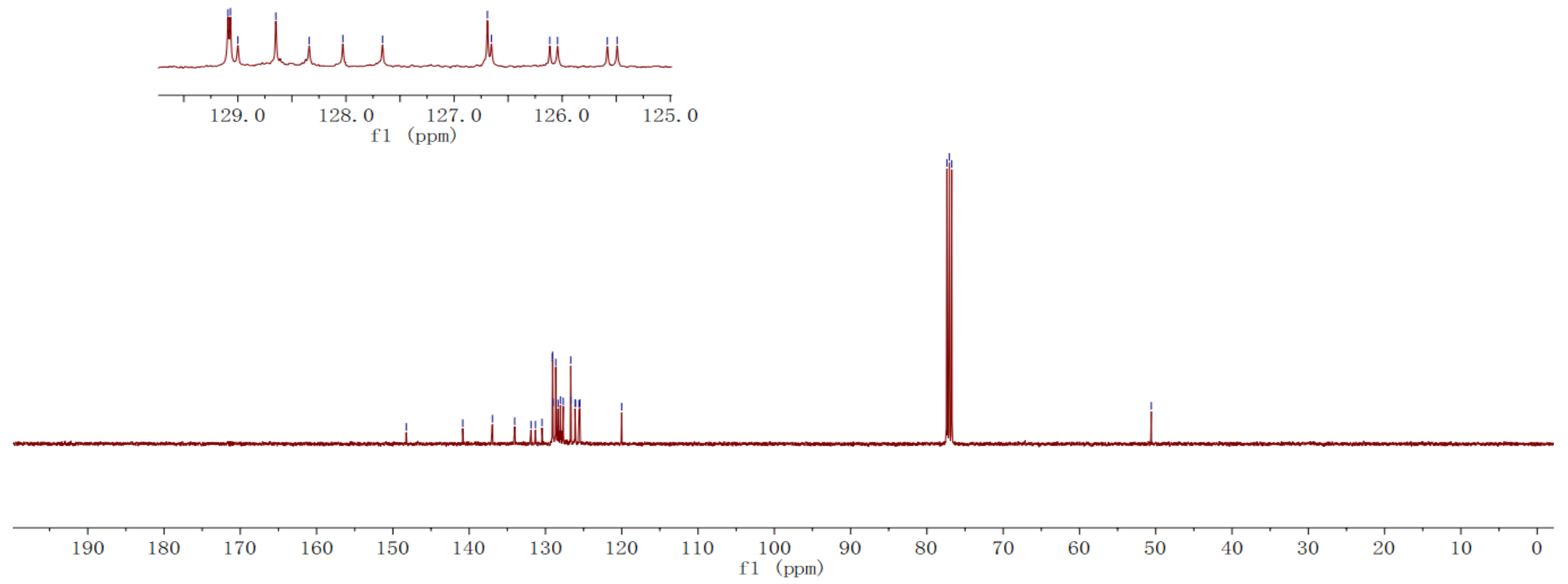

Figure $\mathrm{S} 45{ }^{13} \mathrm{C}$ NMR $\left(101 \mathrm{MHz}, \mathrm{CDCl}_{3}\right)$ spectra of 3ua 


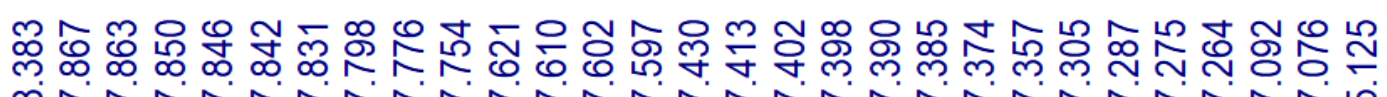

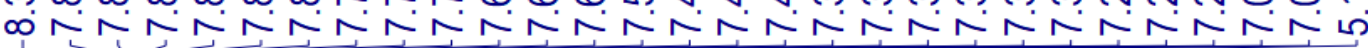
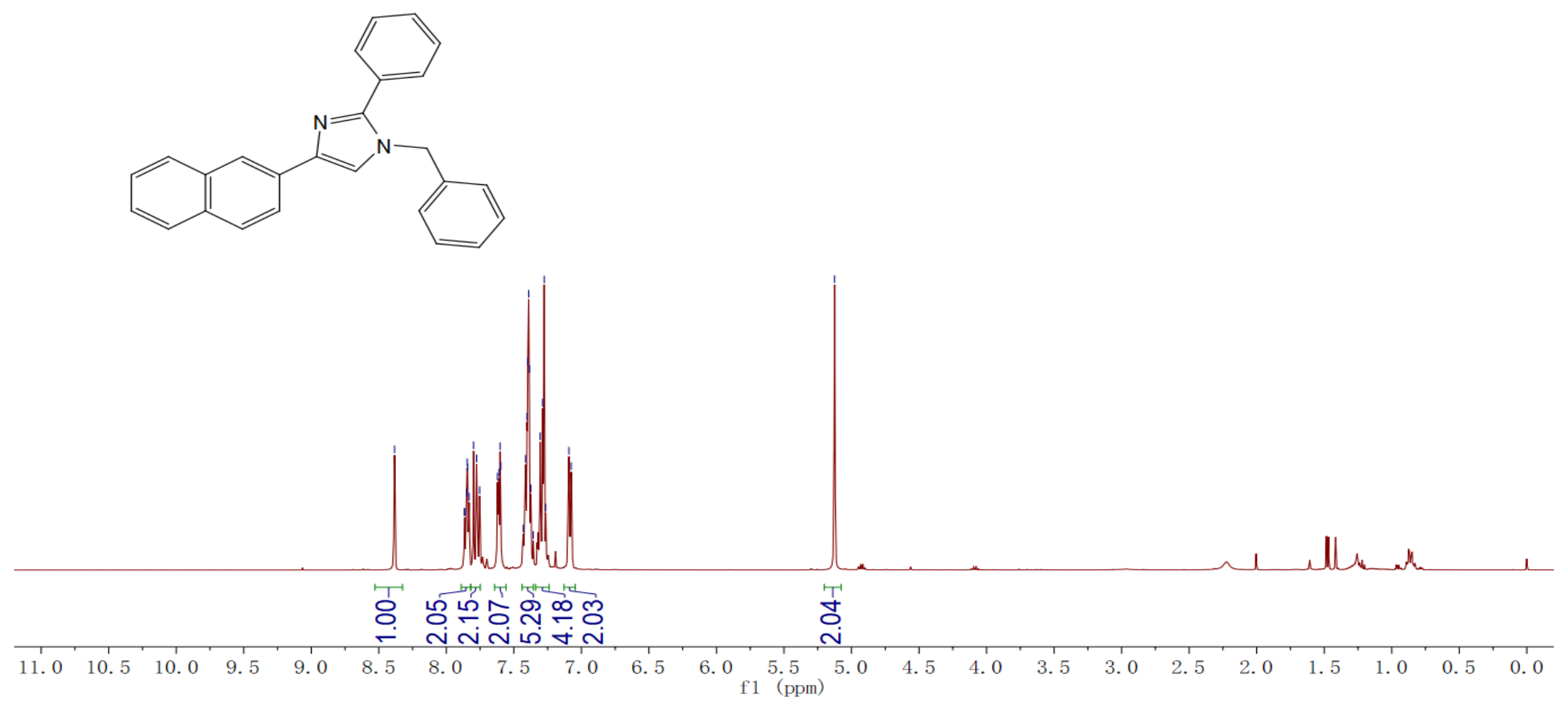

Figure $\mathrm{S} 46{ }^{1} \mathrm{H}$ NMR $\left(400 \mathrm{MHz}, \mathrm{CDCl}_{3}\right)$ spectra of 3va 


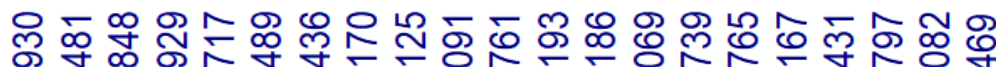

守守宛

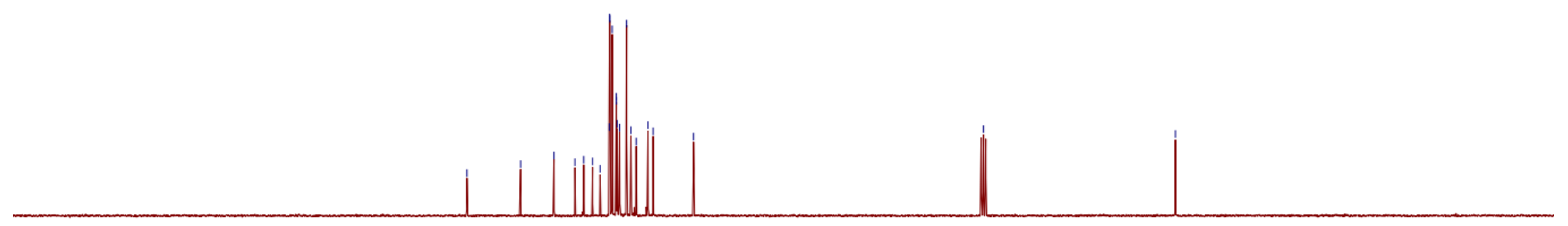

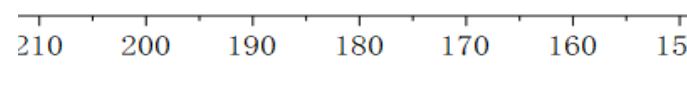
$130 \quad 120$

Figure $\mathrm{S} 47{ }^{13} \mathrm{C}$ NMR $\left(101 \mathrm{MHz}, \mathrm{CDCl}_{3}\right)$ spectra of 3va 

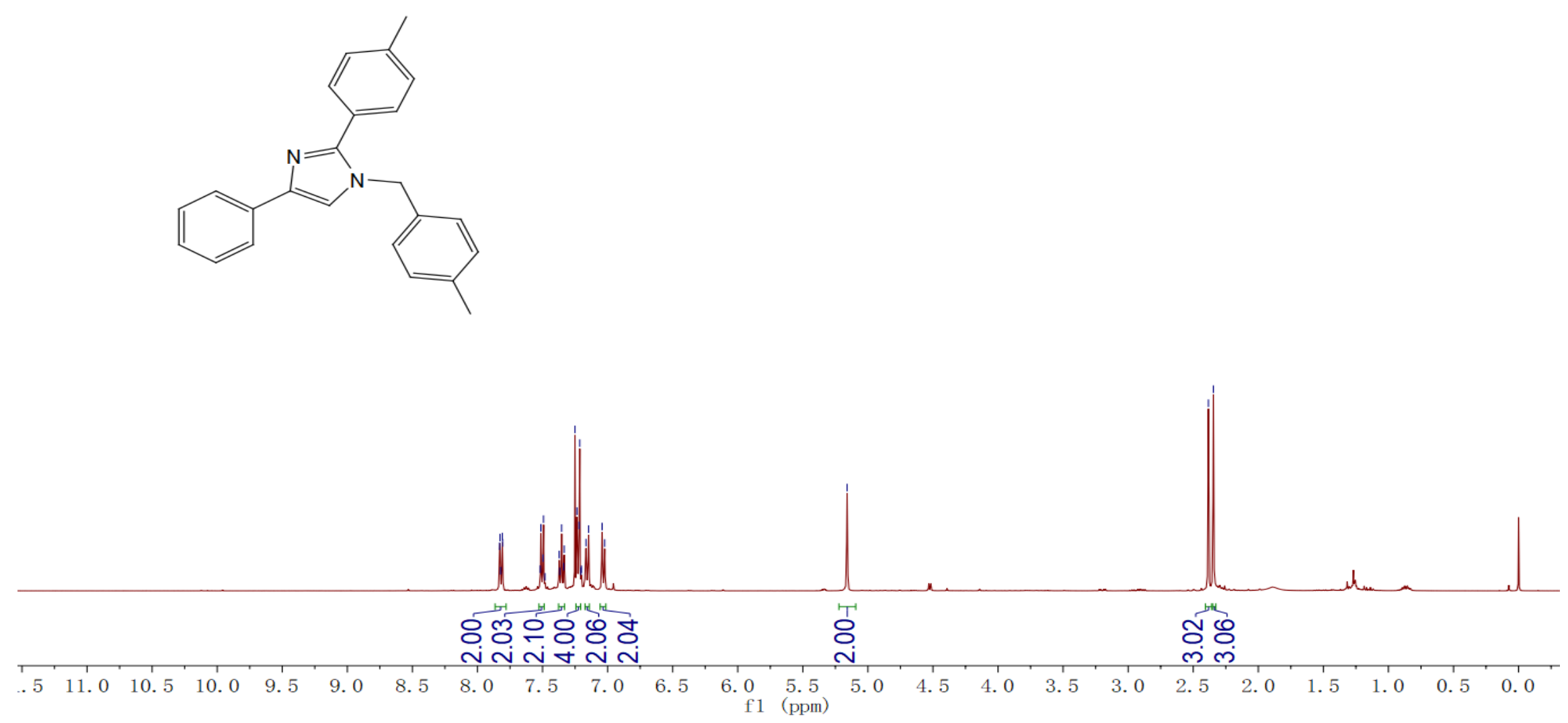

Figure $\mathrm{S} 48{ }^{1} \mathrm{H}$ NMR $\left(400 \mathrm{MHz}, \mathrm{CDCl}_{3}\right)$ spectra of $\mathbf{3 a b}$ 


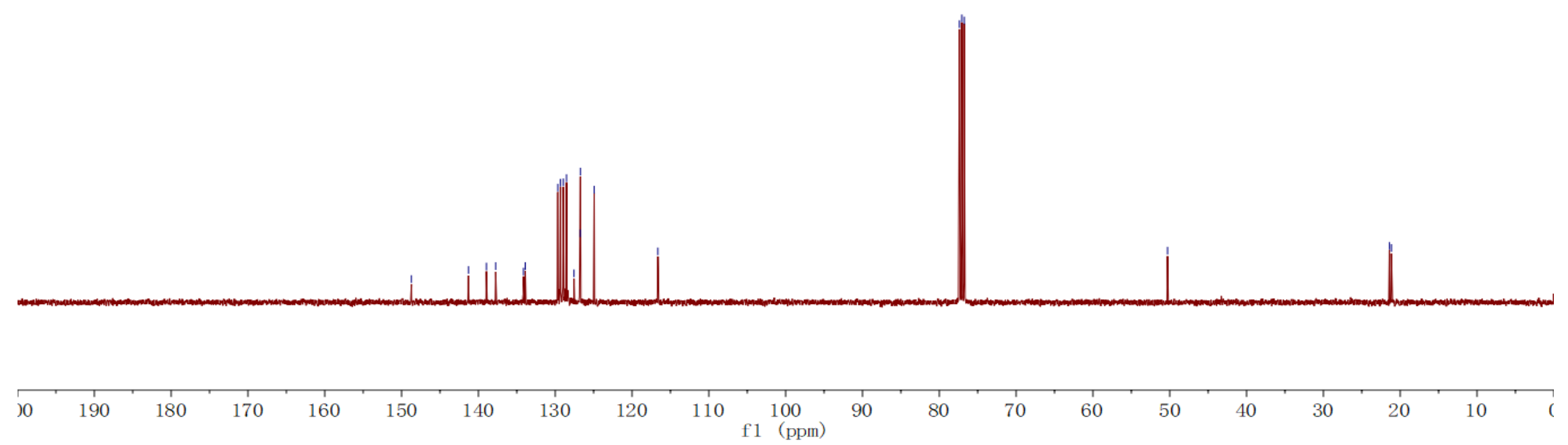

Figure $\mathrm{S} 49{ }^{13} \mathrm{C}$ NMR $\left(101 \mathrm{MHz}, \mathrm{CDCl}_{3}\right)$ spectra of $\mathbf{3 a b}$ 


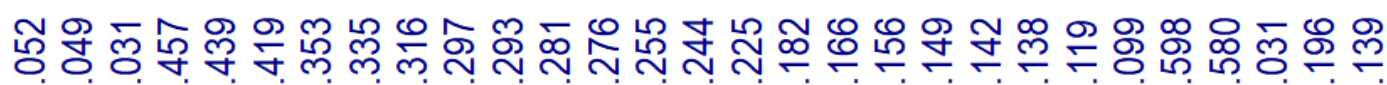

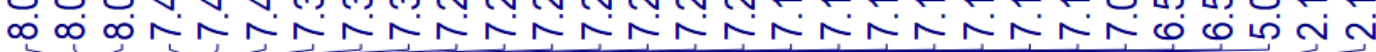
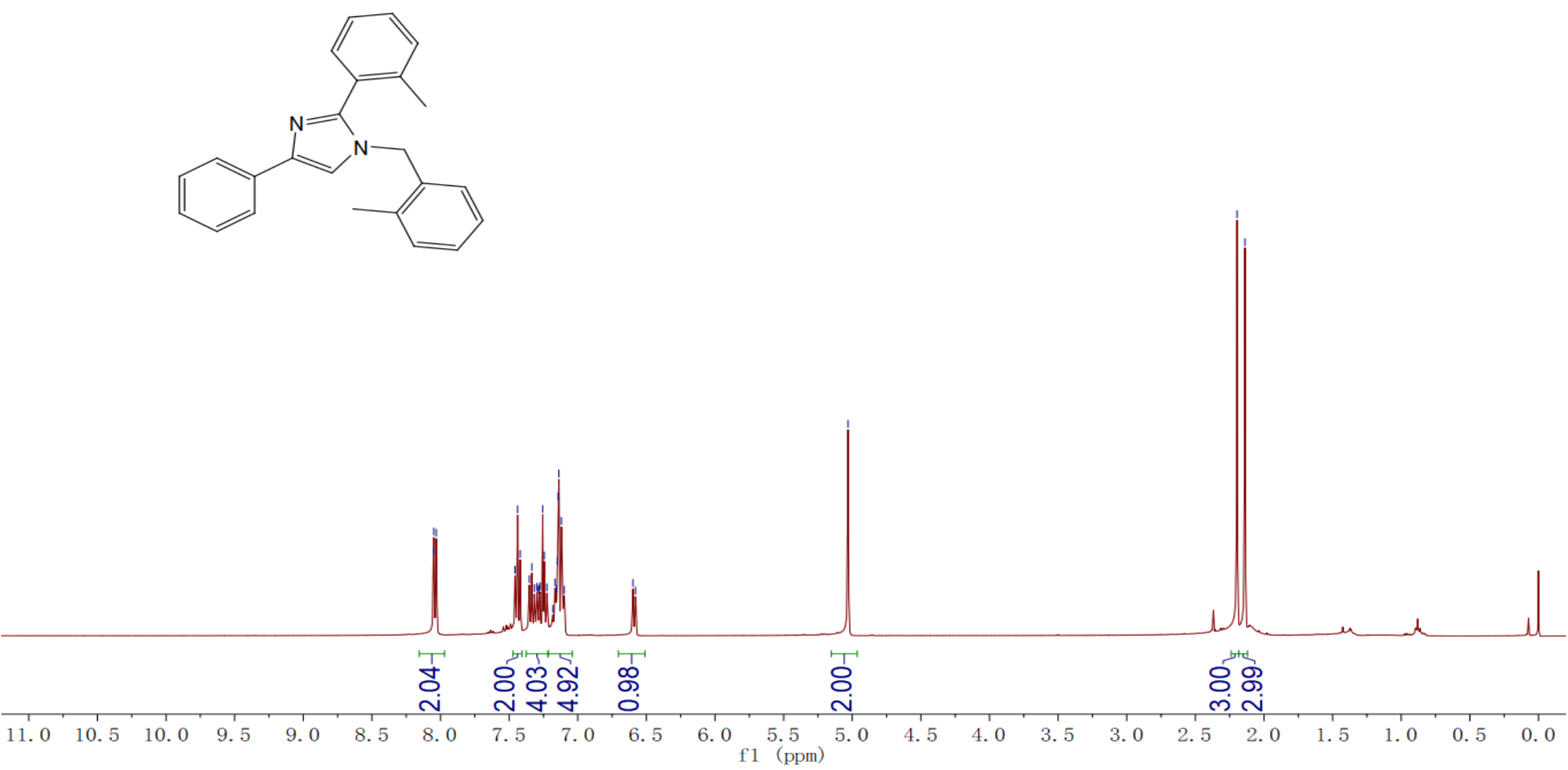

Figure $\mathrm{S} 50{ }^{1} \mathrm{H}$ NMR $\left(400 \mathrm{MHz}, \mathrm{CDCl}_{3}\right)$ spectra of $\mathbf{3 a c}$ 


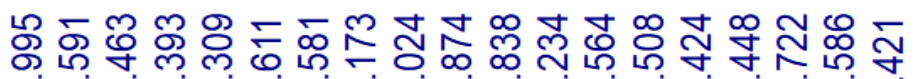

ம்

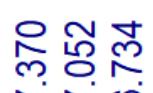

송

@্ত

₹ี

문

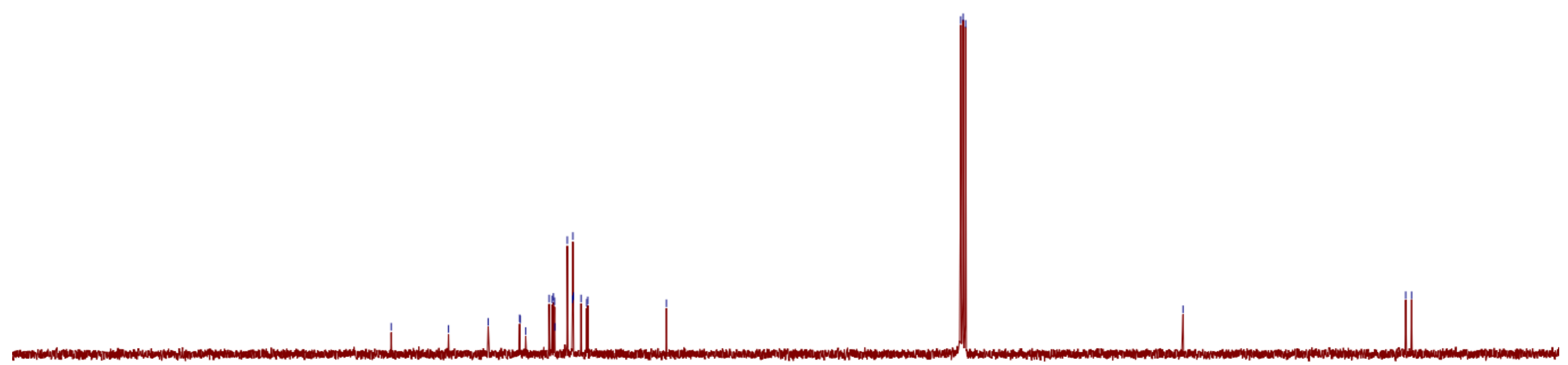

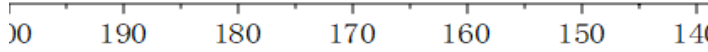

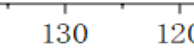

110

100

$90 \quad 80$

$80 \quad 70$

60

50

40

30

$20 \div 10$

Figure S5 ${ }^{13} \mathrm{C}$ NMR $\left(101 \mathrm{MHz}, \mathrm{CDCl}_{3}\right)$ spectra of 3ac 


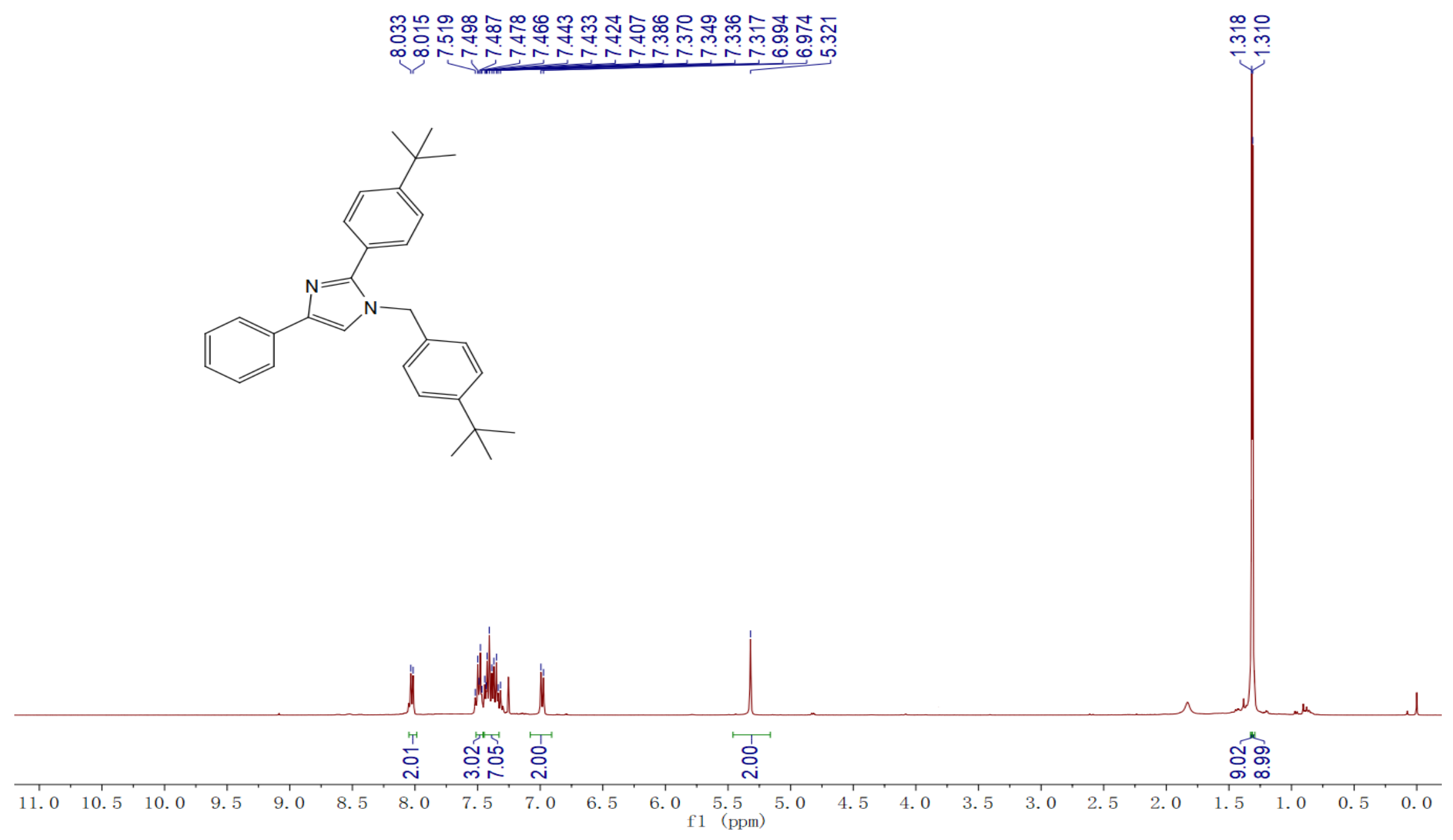

Figure S52 ${ }^{1} \mathrm{H}$ NMR (400 MHz, $\mathrm{CDCl}_{3}$ ) spectra of 3ad 


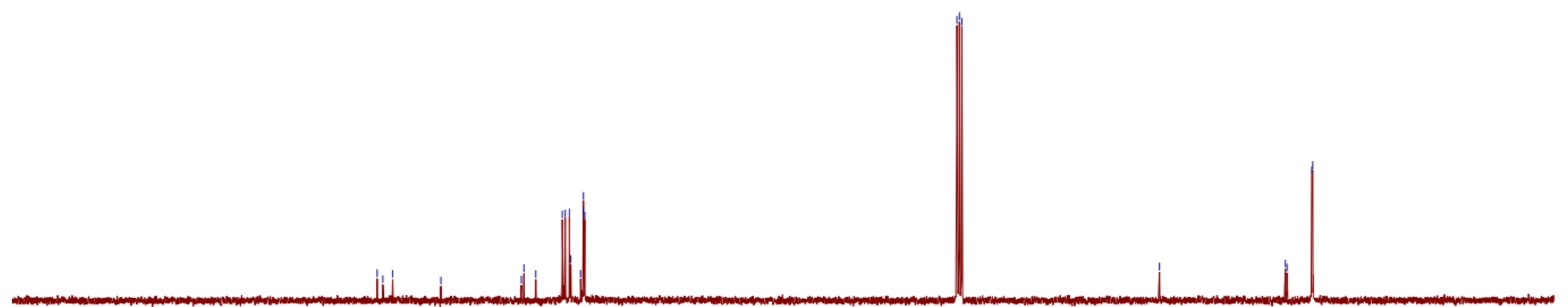

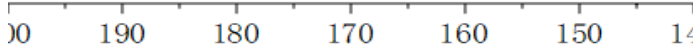

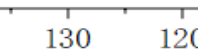

110 $\mathrm{f} 1 \stackrel{100}{(\mathrm{ppm})}$

80

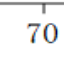

60

50

40

30

Figure $\mathrm{S} 53{ }^{13} \mathrm{C}$ NMR $\left(101 \mathrm{MHz}, \mathrm{CDCl}_{3}\right)$ spectra of $\mathbf{3 a d}$ 


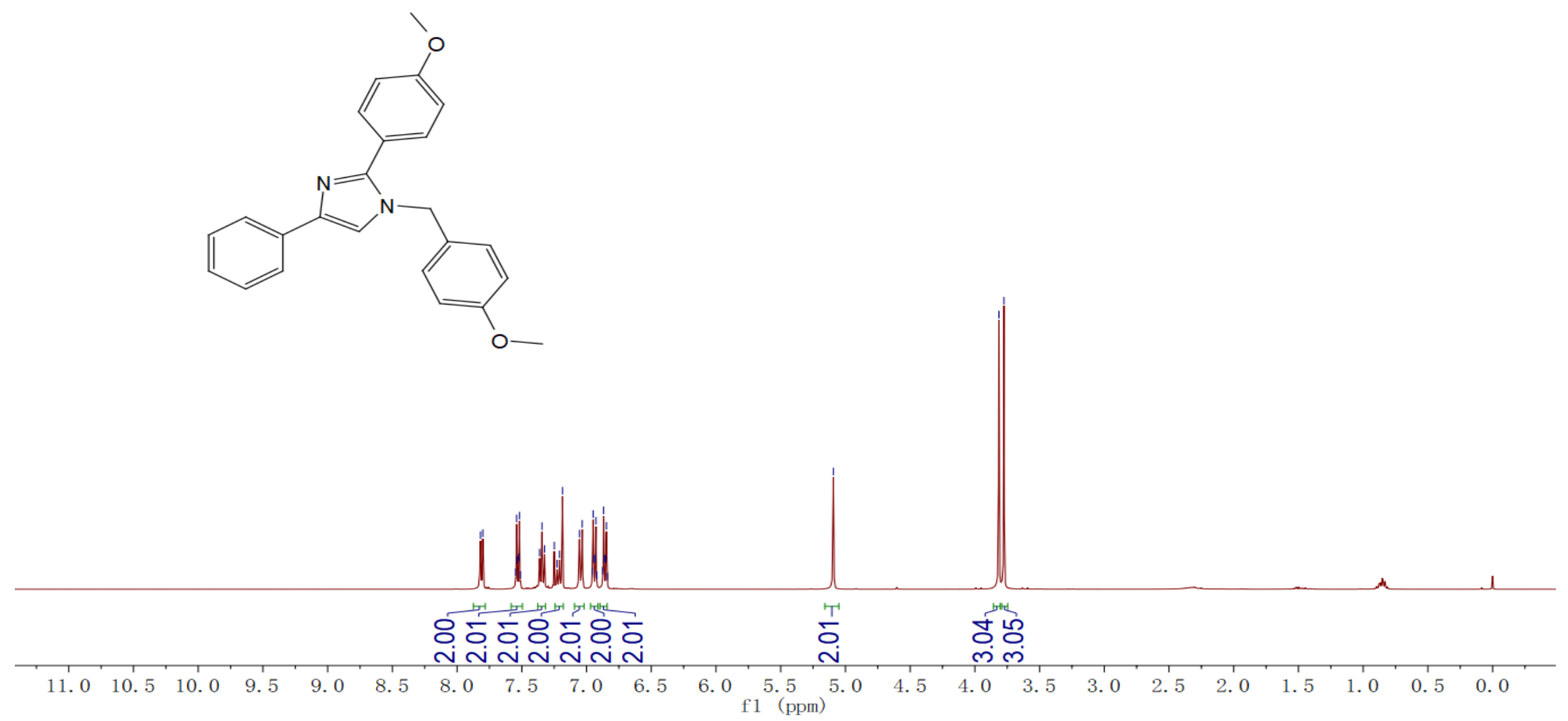

Figure S54 ${ }^{1} \mathrm{H}$ NMR $\left(400 \mathrm{MHz}, \mathrm{CDCl}_{3}\right)$ spectra of 3ae 


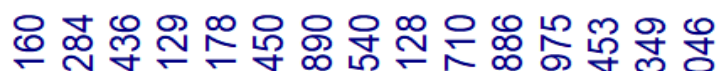

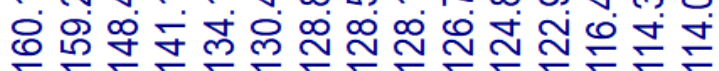

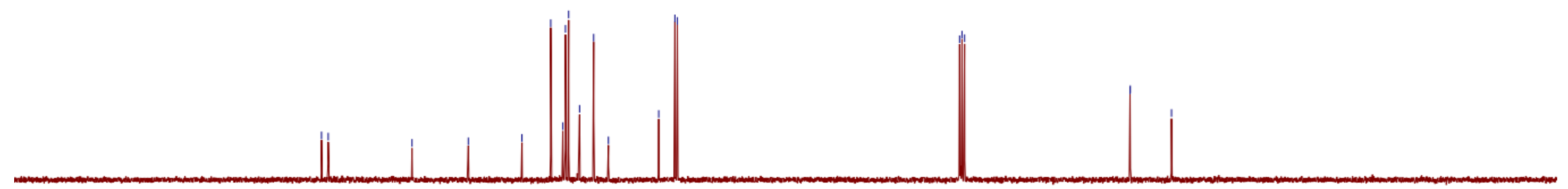

$10 \quad 190-180-170-160-150=140$

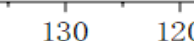

110

100

$90 \quad 80$

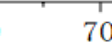

Figure $\mathrm{S} 54{ }^{13} \mathrm{C}$ NMR (101 $\left.\mathrm{MHz}, \mathrm{CDCl}_{3}\right)$ spectra of 3ae 
ఋ.

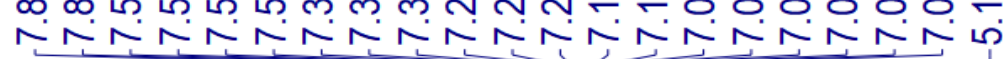
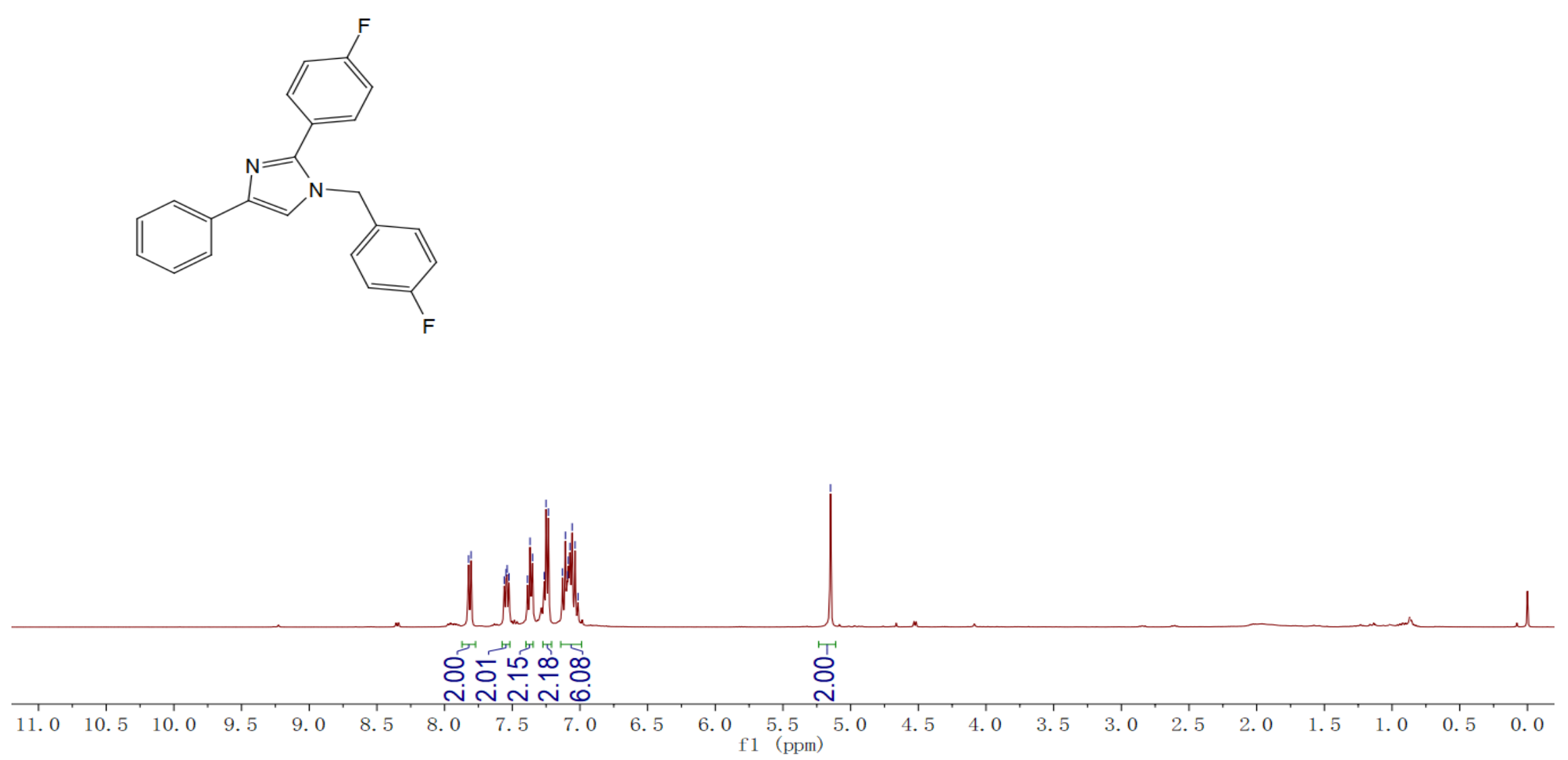

Figure S55 ${ }^{1} \mathrm{H}$ NMR (400 MHz, $\left.\mathrm{CDCl}_{3}\right)$ spectra of 3af 


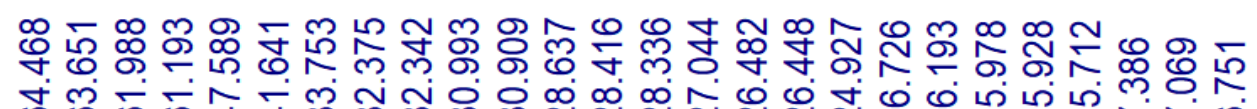

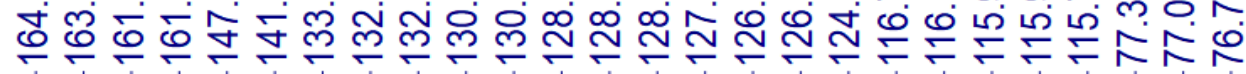

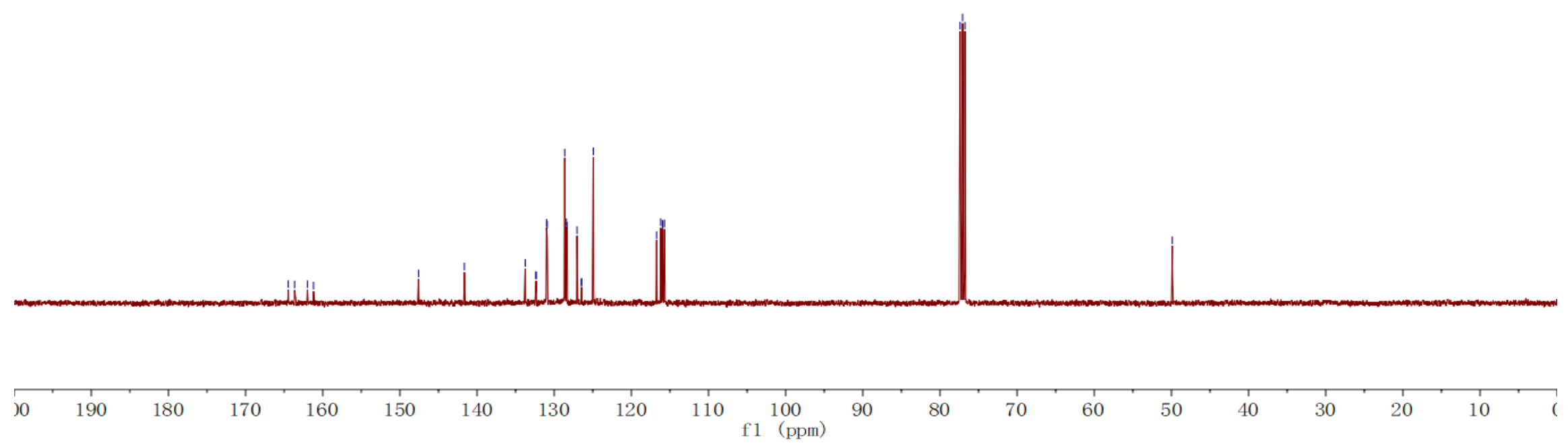

Figure S56 ${ }^{13} \mathrm{C}$ NMR $\left(101 \mathrm{MHz}, \mathrm{CDCl}_{3}\right)$ spectra of 3af 


$$
\text { 迸猋 }
$$

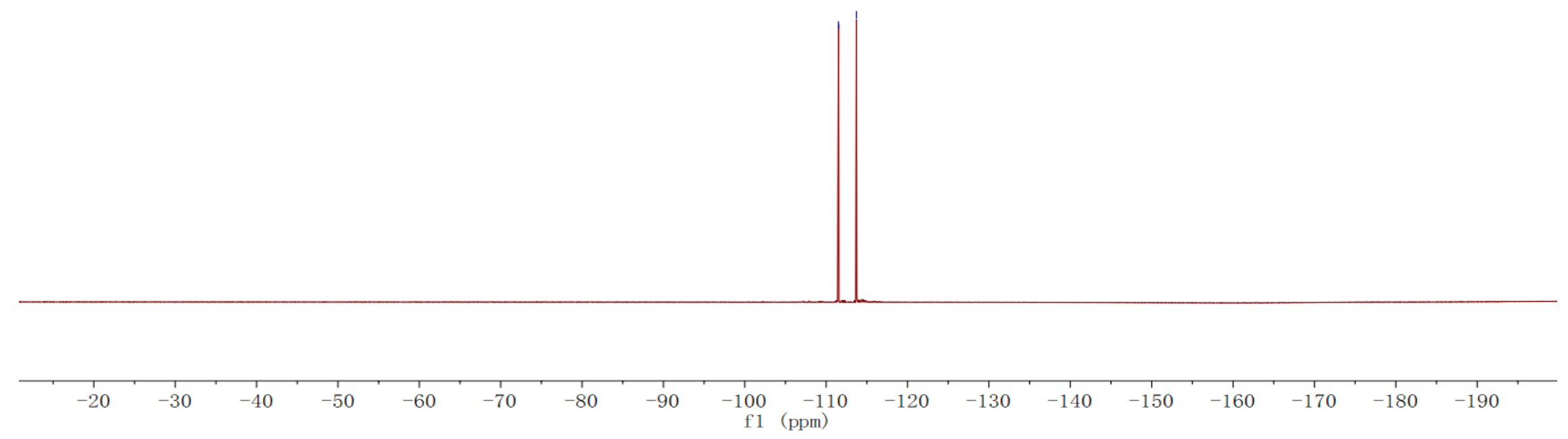

Figure S57 ${ }^{19} \mathrm{~F}$ NMR $\left(376 \mathrm{MHz}, \mathrm{CDCl}_{3}\right)$ spectra of $\mathbf{3 a f}$ 

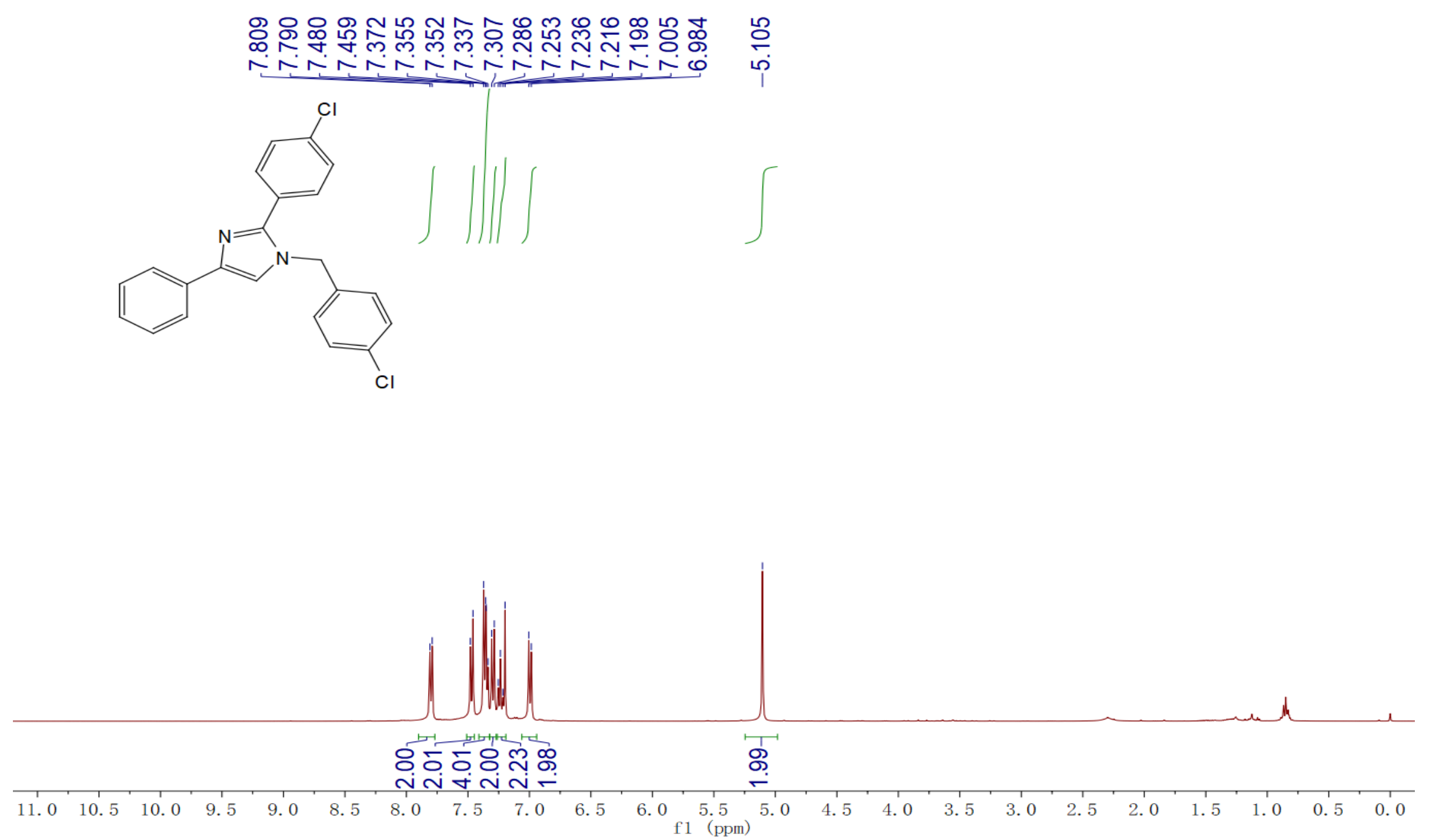

Figure S58 ${ }^{1} \mathrm{H}$ NMR (400 MHz, $\mathrm{CDCl}_{3}$ ) spectra of $\mathbf{3 a g}$ 


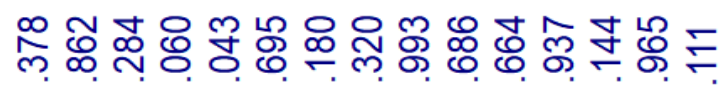

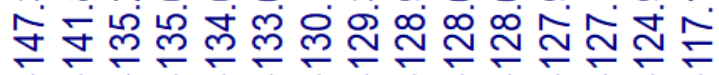

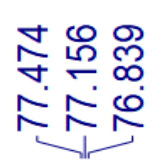

요
$\stackrel{9}{g}$

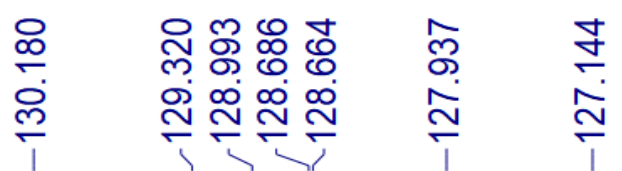
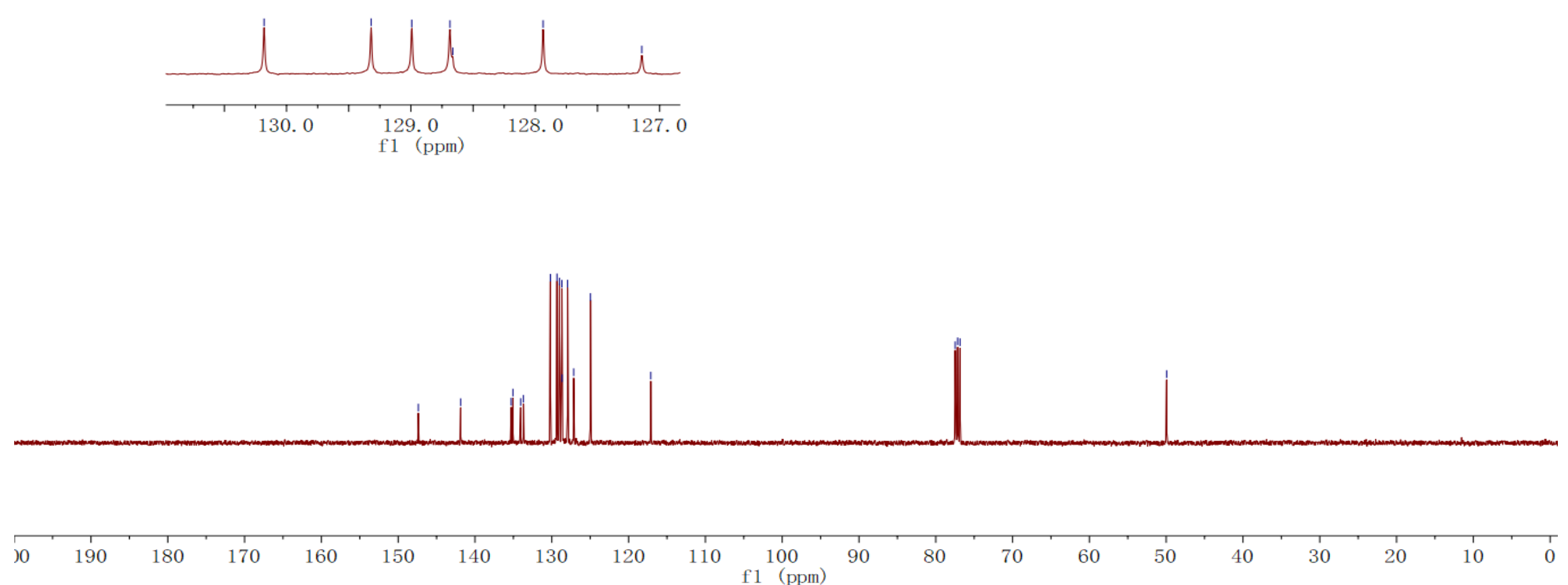

Figure S58 ${ }^{13} \mathrm{C}$ NMR $\left(101 \mathrm{MHz}, \mathrm{CDCl}_{3}\right)$ spectra of $\mathbf{3 a g}$ 
훙요.

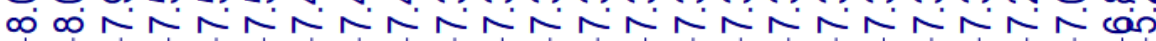
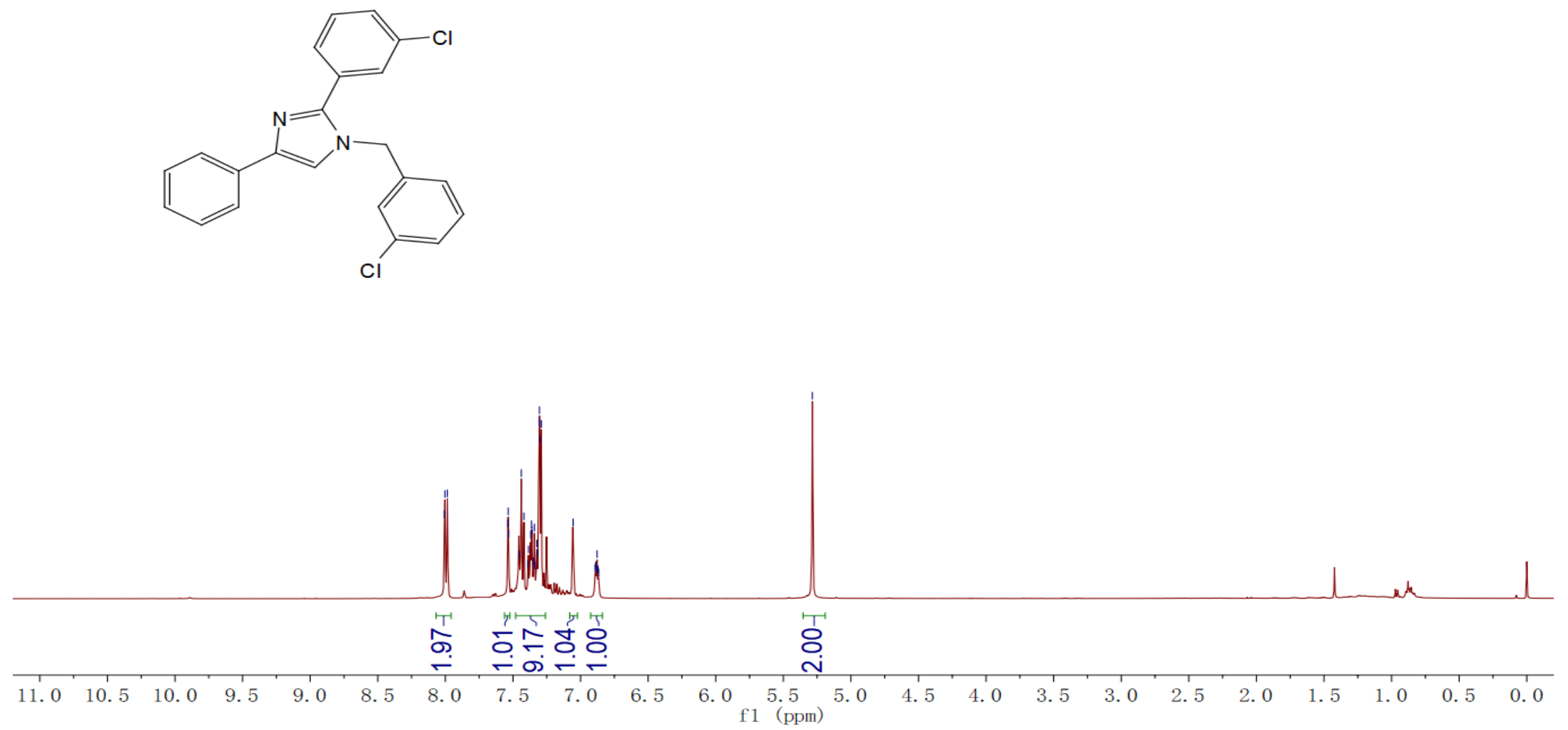

Figure S59 ${ }^{1} \mathrm{H}$ NMR (400 MHz, $\left.\mathrm{CDCl}_{3}\right)$ spectra of $\mathbf{3 a h}$ 


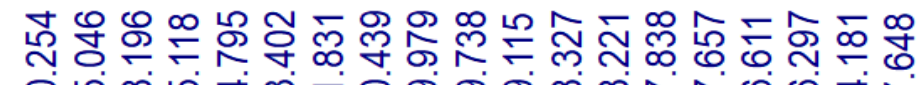

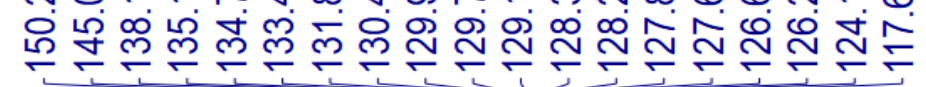

m.

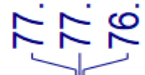

웅

in

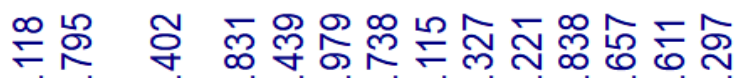

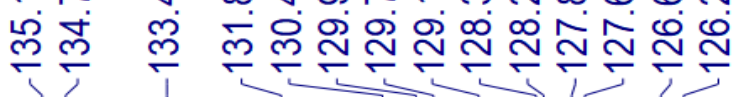

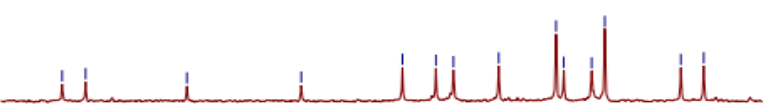

$\begin{array}{llllllllllllllll}135 & 134 & 133 & 132 & 131 & 130 & 129 & 128 & 127 & 126\end{array}$

f1 (ppm)

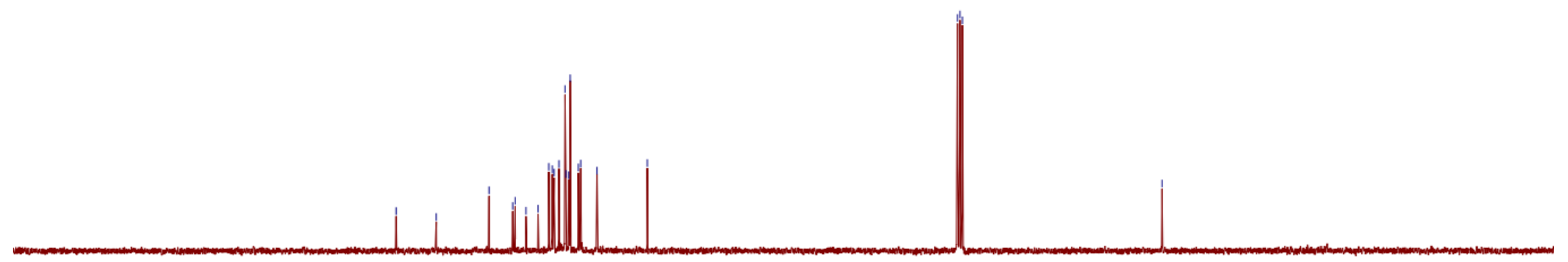

$\begin{array}{lllll}10 & 190 & 180 & 170 & 160\end{array}$

$10 \quad 100$

$90 \quad 80$

70

60

50

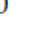

30

Figure $\mathrm{S} 60{ }^{13} \mathrm{C}$ NMR $\left(101 \mathrm{MHz}, \mathrm{CDCl}_{3}\right)$ spectra of 3ah 


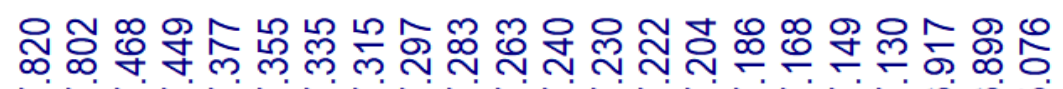

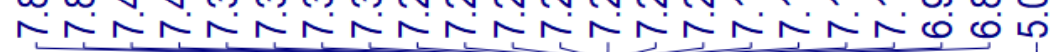
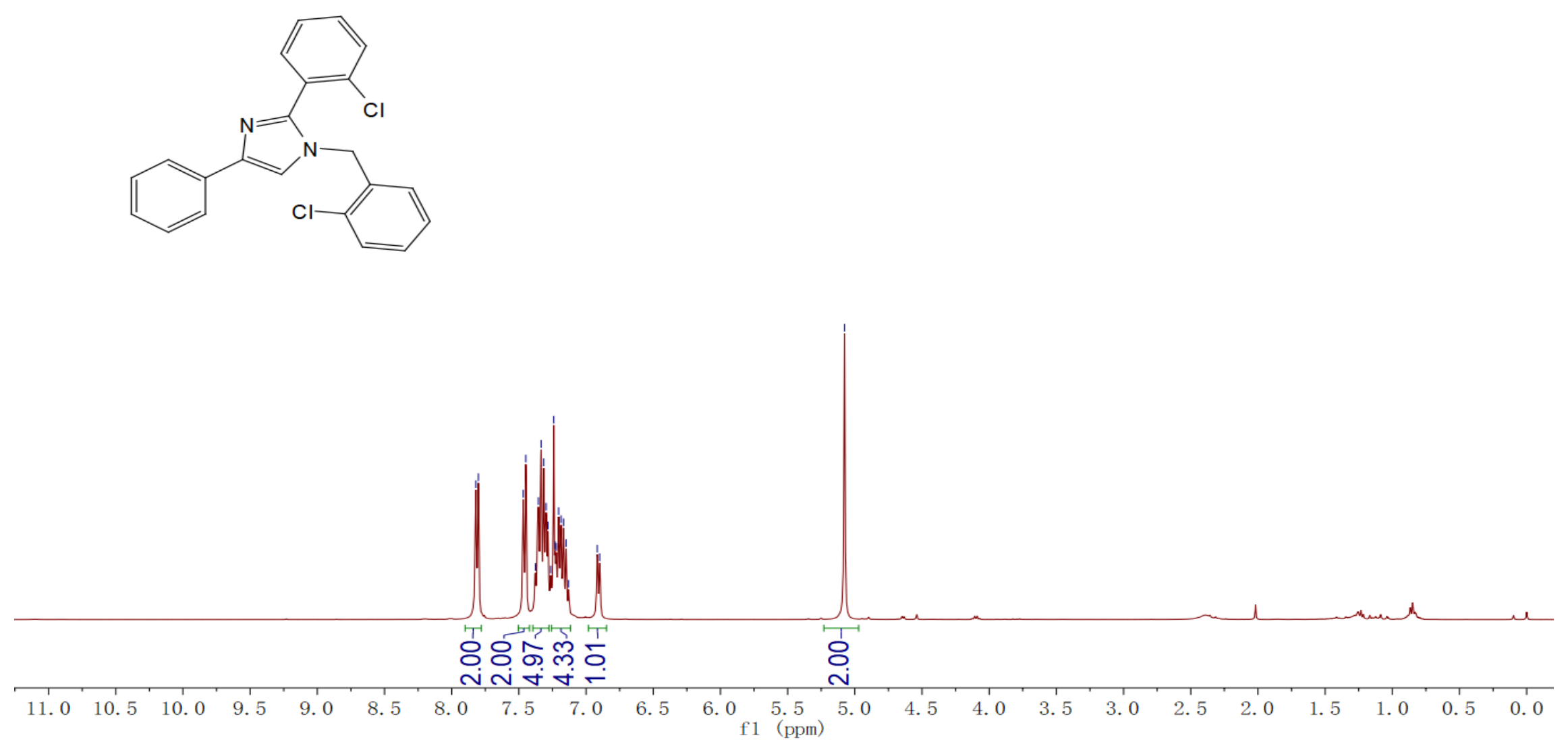

Figure $\mathrm{S} 61{ }^{1} \mathrm{H} \mathrm{NMR}\left(400 \mathrm{MHz}, \mathrm{CDCl}_{3}\right)$ spectra of 3ai 


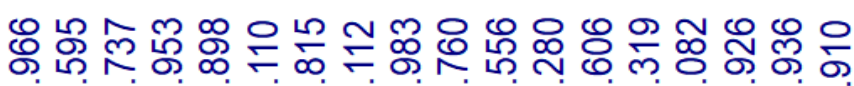

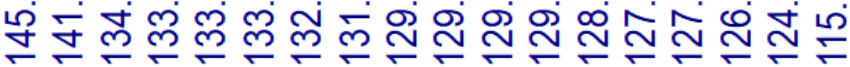

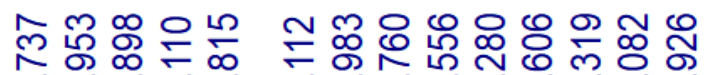

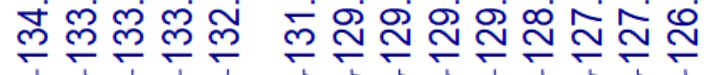

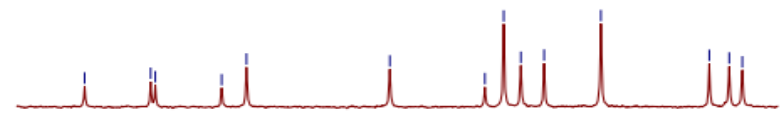

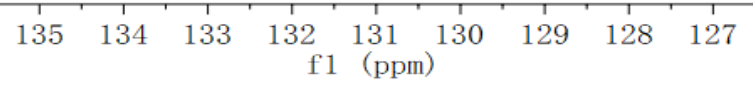
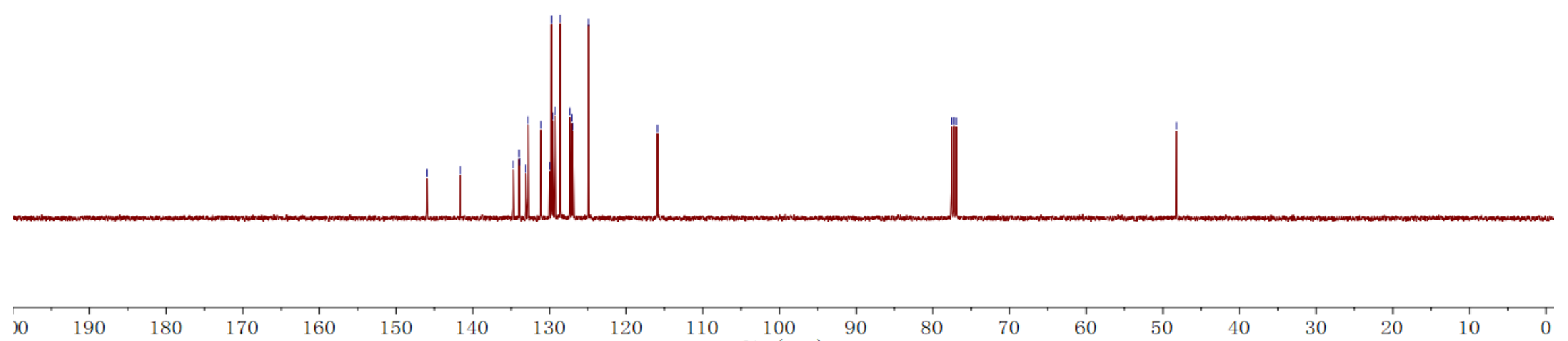

110

100

$90 \quad 80$

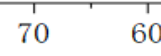

50

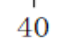

30

20

Figure $\mathrm{S} 62{ }^{13} \mathrm{C}$ NMR $\left(101 \mathrm{MHz}, \mathrm{CDCl}_{3}\right)$ spectra of 3ai 


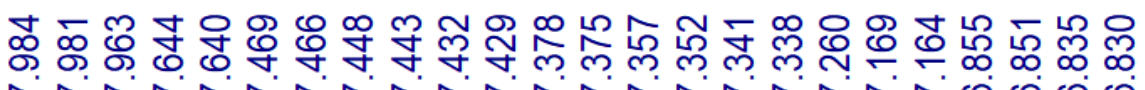

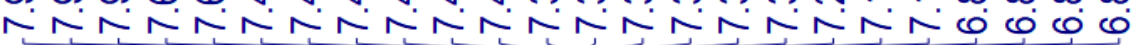
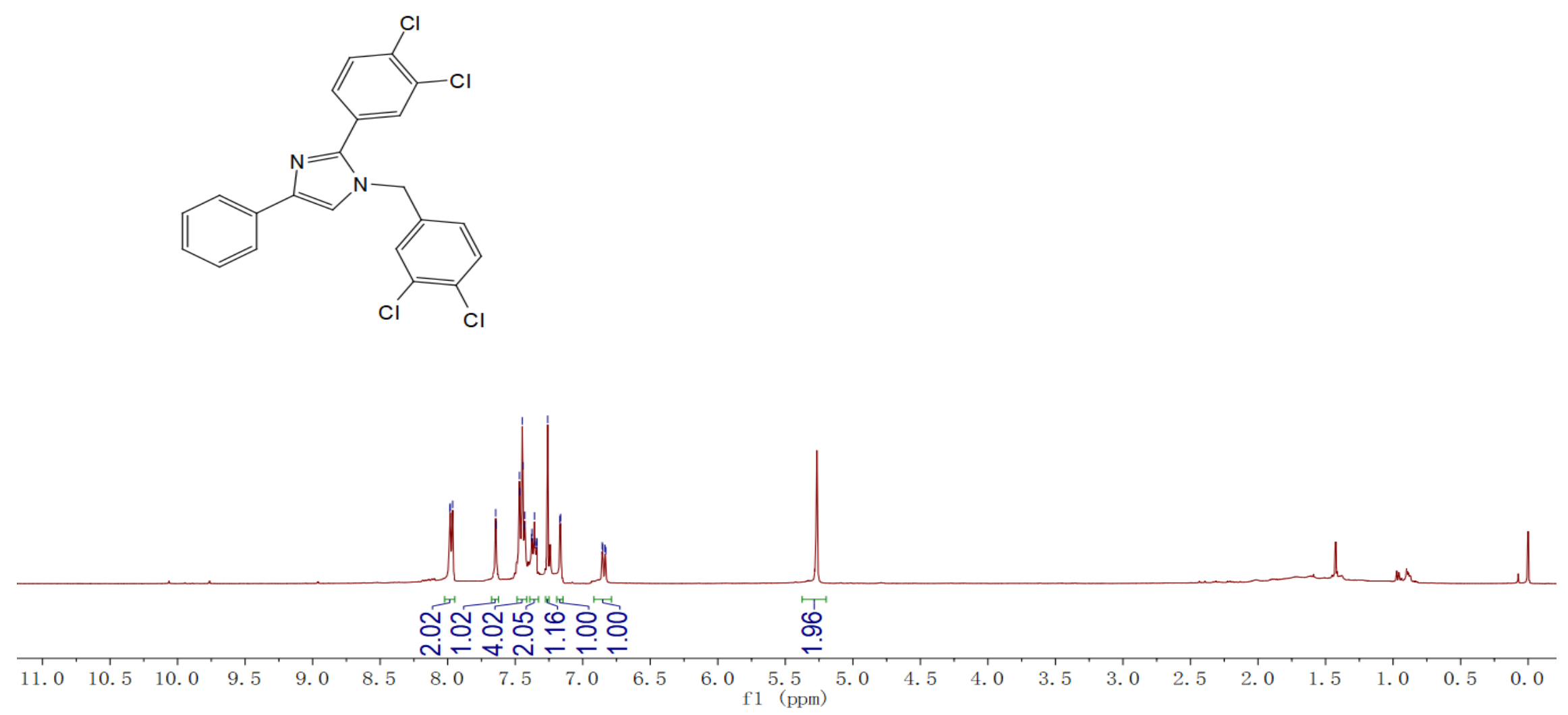

Figure $\mathrm{S} 63{ }^{1} \mathrm{H}$ NMR $\left(400 \mathrm{MHz}, \mathrm{CDCl}_{3}\right)$ spectra of 3aj 

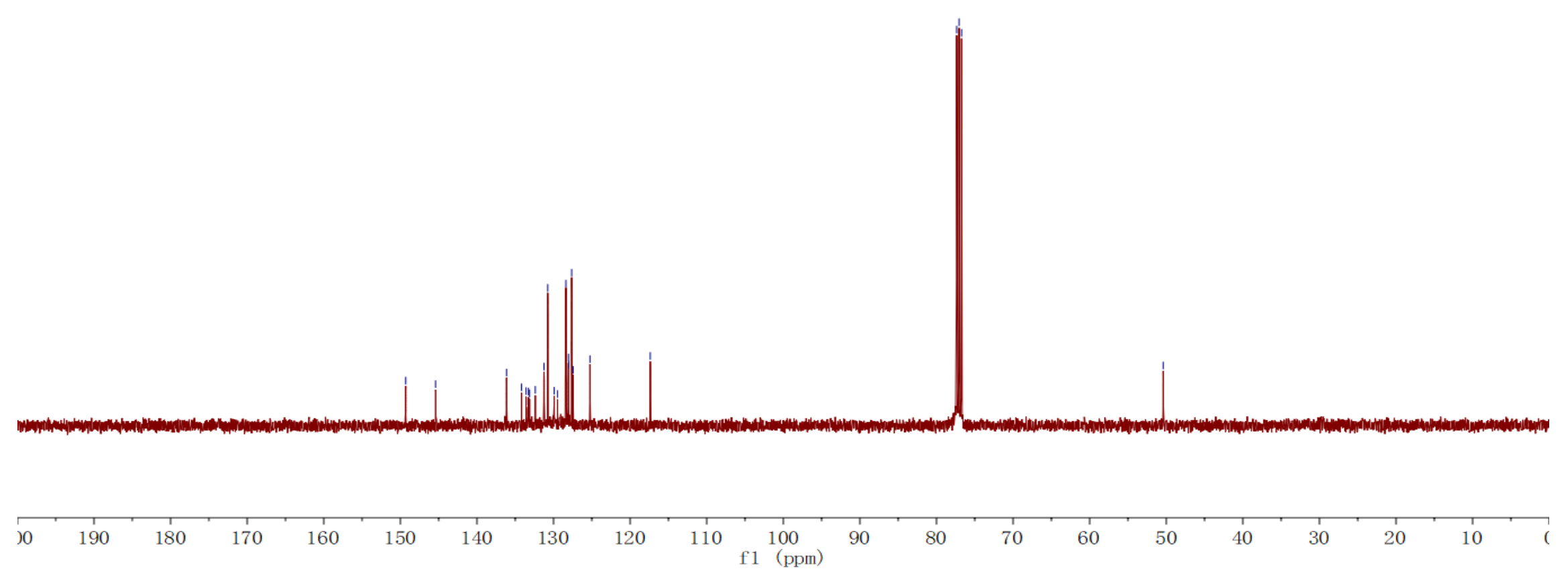

Figure $\mathrm{S} 64{ }^{13} \mathrm{C}$ NMR $\left(101 \mathrm{MHz}, \mathrm{CDCl}_{3}\right)$ spectra of 3aj 


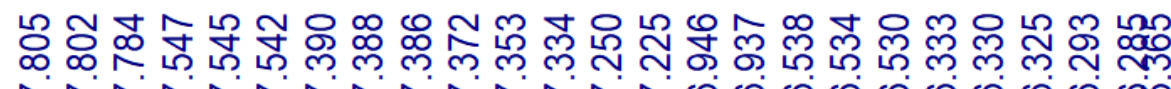

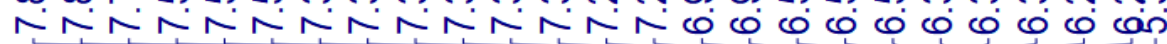
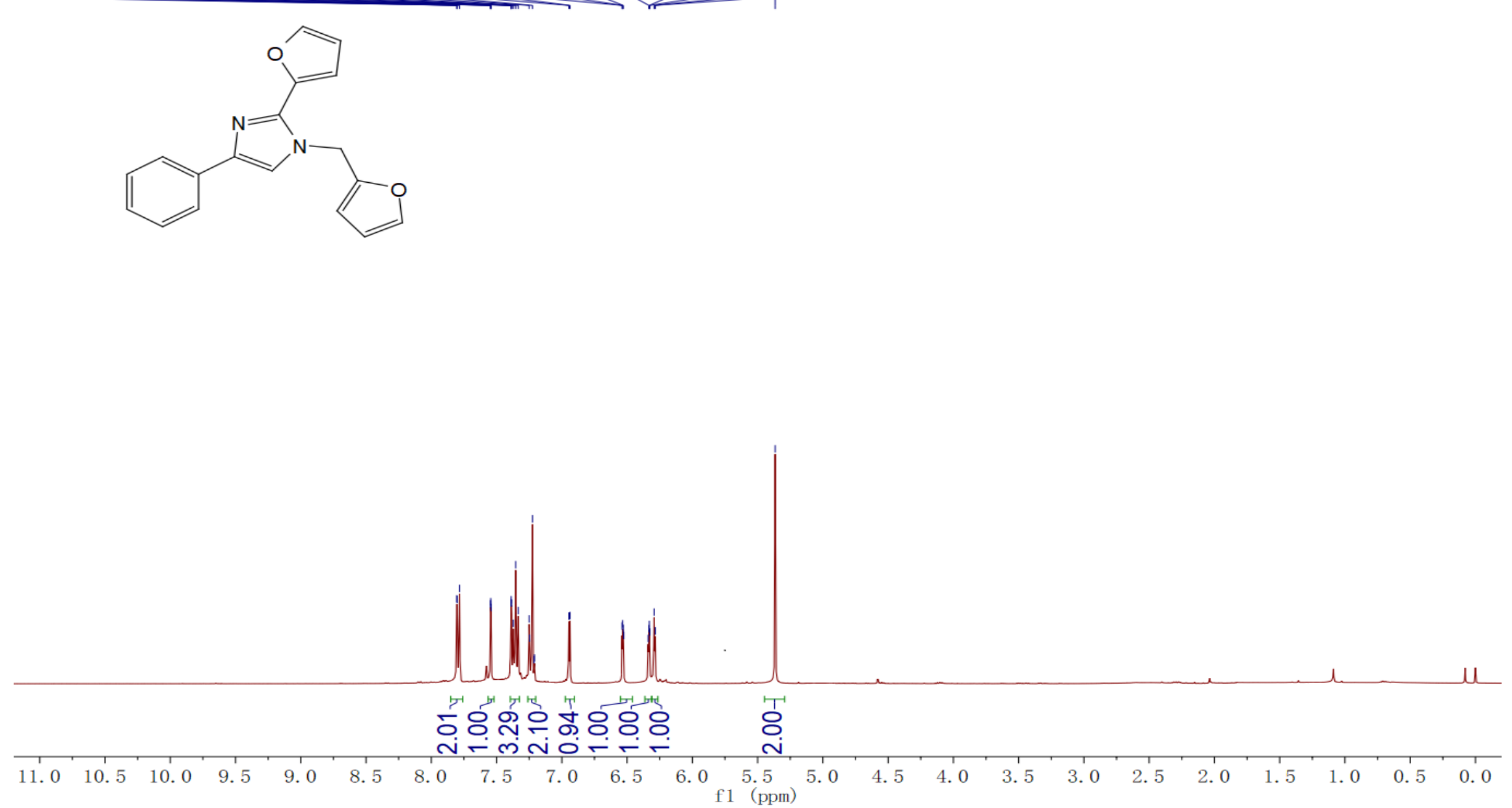

Figure $\mathrm{S} 65{ }^{1} \mathrm{H}$ NMR $\left(400 \mathrm{MHz}, \mathrm{CDCl}_{3}\right)$ spectra of 3ak 


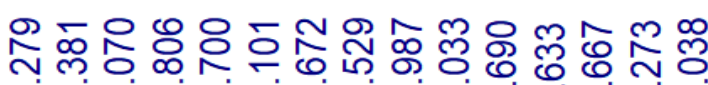

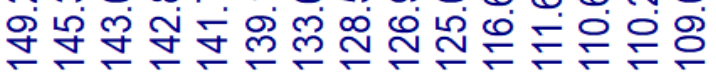

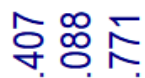

송ำ

$\stackrel{\leftrightarrow}{\circ}$

눈

ฯ

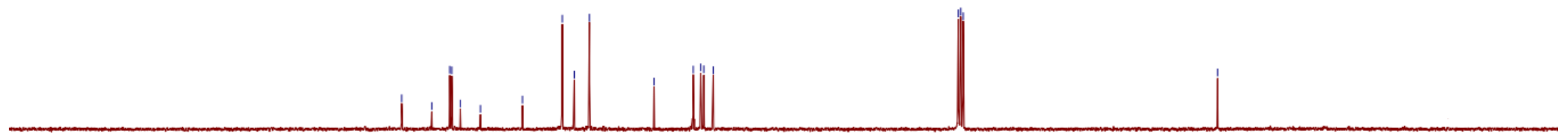

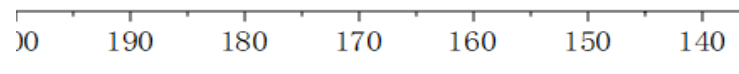

$130 \cdot 120$

110

100

$90 \quad 80$

70

60

50

40

30

Figure $\mathrm{S} 66{ }^{13} \mathrm{C}$ NMR (101 MHz, $\left.\mathrm{CDCl}_{3}\right)$ spectra of 3ak 